Portland State University

PDXScholar

Summer 8-5-2015

\title{
Investigating the Impact of Sibling Foster Care on Placement Stability
}

Jeffrey David Waid

Portland State University

Follow this and additional works at: https://pdxscholar.library.pdx.edu/open_access_etds

Part of the Social Work Commons

Let us know how access to this document benefits you.

\section{Recommended Citation}

Waid, Jeffrey David, "Investigating the Impact of Sibling Foster Care on Placement Stability" (2015). Dissertations and Theses. Paper 2483.

https://doi.org/10.15760/etd.2480

This Dissertation is brought to you for free and open access. It has been accepted for inclusion in Dissertations and Theses by an authorized administrator of PDXScholar. Please contact us if we can make this document more accessible: pdxscholar@pdx.edu. 
Investigating the Impact of Sibling Foster Care on Placement Stability

\author{
by \\ Jeffrey David Waid
}

A dissertation submitted in partial fulfillment of the requirements for the degree of

\title{
Doctor of Philosophy
}

in

Social Work and Social Research

\author{
Dissertation Committee: \\ Bowen McBeath, Chair \\ Katharine Cahn \\ Lew Bank \\ Neal Wallace
}

Portland State University 
(C) 2015 Jeffrey David Waid 


\begin{abstract}
Sibling relationships are an important, yet under investigated aspect of foster care research. Despite the fact that between $65-85 \%$ of children in care have brothers and sisters, only recently have child welfare researchers begun to explore the complex and dynamic nature of sibling relationships in substitute care settings. Although cross-sectional and longitudinal studies suggest differences in placement stability and permanency outcomes for siblings placed together versus those placed separately, the conditions under which sibling relationships influence placement stability, permanency, and well-being in foster care settings remain unknown.
\end{abstract}

This dissertation investigated how family dynamics and home setting characteristics influenced the likelihood of a foster care placement change for a sample of children who participated in a sibling relationship enhancement intervention (SIBS-FC) study. A conceptual model was proposed to help explain the circumstances which lead to foster care placement change, and the moderating effects of family living composition on the odds of placement change over an 18month period were examined.

Two multivariate statistical approaches were used in this investigation. The first approach involved examining the effects of a child's report of positive home integration, sibling relationship quality, caregiver's reported impact of child behavior, sibling living situation, kinship caregiver status, number of placements prior to study entry, and receipt of the SIBS-FC intervention on the odds of placement change. Results suggest that children in kinship care were $58 \%$ less 
likely to experience placement change than those who lived in non-relative care, and youth who lived apart from their siblings were $70 \%$ more likely to experience placement change than those who lived together.

In the second statistical approach, living composition categories were constructed to understand the moderating effects of different living situations on the odds of placement change. Living composition categories included youth who lived in kinship care with their siblings, youth who lived in kinship care without their siblings, and youth who lived in non-relative care with their siblings, with youth in non-relative care who lived apart from their siblings serving as the referent category. Findings support a moderation effect for different categories of living composition, as well as a trend level effect for sibling relationship quality and odds of placement change. Living with one's sibling in kinship care decreased the odds of placement change by $75 \%$, as compared to living apart from one's sibling in a non-relative foster home. A post-hoc analysis determined that all living composition categories were statistically different from one another in relative odds of a placement change.

This dissertation provides additional evidence concerning the protective nature of kinship care and sibling co-placement on reducing the odds of experiencing a foster care placement change, and provides support for practices and policies prioritizing kinship care and the co-placement of siblings when making substitute care placement decisions. Future studies of siblings in foster care should explore the experiences of youth across the different forms of foster care living composition, examine the relationship between placement stability and 
permanency outcomes, and examine the relationship between placement stability, permanency, and child well-being. 


\section{ACKNOWLEDGEMENTS}

I would like to acknowledge my family, who have been with me every step of the way and have provided and endless supply of love, emotional support, and encouragement to me throughout my life. I would also thank the many mentors who have guided my professional development with their wisdom, patience, and kindness. I would finally wish to acknowledge the children and families whom I have had the privilege to work with over the course of my career. It is these families who've shown me the true nature of resilience, bravery, and courage, and serve as my motivation to continue on this path. 


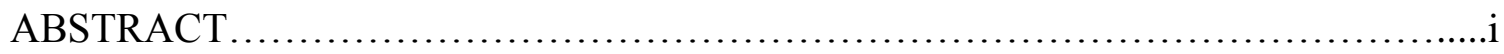

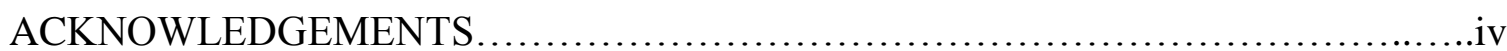

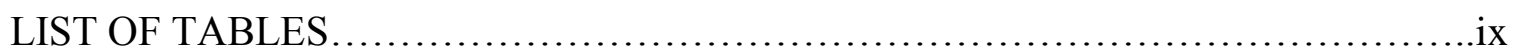

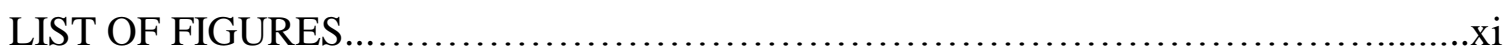

CHAPTER 1- REVIEW OF LITERATURE.....................................

Introduction

Permanency

Well-Being

Current Foster Care Statistics

Siblings in Foster Care

Prevalence of Siblings in Foster Care

Factors Associated with Co-Placement of Siblings

Siblings, Placement Stability, and Permanency

Siblings and Well-Being

Factors Associated with Foster Care Placement Disruption

Policy and Practice Interventions to Promote Permanency and Well-Being

Limitations of Current Research

Dissertation Research Questions

Relevance to Researchers, Practitioners, and Policymakers

CHAPTER 2- THEORY

Introduction

Bioecological Theory

Social Learning Theory

Coercion Theory

Summary of Dissertation Theory

Conceptual Model: Predicting Placement Change

Predictor Variables

Positive Home Integration

Sibling Relationship Quality

Impact of Child Behavior

Control Variables

Sibling Living Situation

Kinship Caregiver Status

Living Composition

Number of Prior Placements

Treatment Condition 
Dependent Variables

Placement Change

CHAPTER 3-METHODS.

Introduction

Introduction to the Parent Study

Parent Study Purpose and Research Questions

Parent Study Participant Eligibility and Recruitment Procedures

Parent Study Data Collection

The Current Study

Sample

Dependent Variables

Placement Change

Independent Variables

Positive Home Integration

Sibling Relationship Quality

Impact of Child Behavior

Control Variables

Sibling Living Situation

Kinship Status

Living Composition

Number of Placement Changes Prior to Study Entry

Treatment Condition

Analytical Assumptions

Preliminary Analysis of Model Variables

Bivariate Correlation Matrix for Model Variables

Chi-Square/Crosstab Analysis

Logistic Regression Model Predicting Placement Change

Sensitivity Analysis of the Logistic Regression Model

Examination of Kin, Apart Youth Characteristics

Analysis of Variance for Model Variables by Living Composition

Test of Moderation Effects According to Living Composition

Post-Hoc Analysis of Living Composition Categories

CHAPTER 4-RESULTS.

Introduction

Preliminary Analysis of Model Variables 
Treatment Condition

Sibling Living Situation and Kinship Caregiver Status

Positive Home Integration

Sibling Relationship Quality

Impact of Child Behavior

Number of Placements Prior to Study Entry

Number of Placement Changes

Bivariate Correlation Matrix for Model Variables

Chi-Square/Crosstab Analysis

Chi-Square Analysis of Kinship Care and Placement Change

Chi-Square Analysis of Sibling Living Situation and Placement

Change

Chi-Square Analysis of Youth Gender and Placement Change

Chi-Square Analysis of Youth Race and Placement Change

Cross Tab Analysis of Living Composition

Logistic Regression Model Predicting Placement Change

Sensitivity Analysis of Logistic Regression Model Predicting Placement

Change

Examination of Kin, Apart Youth Characteristics

Analysis of Variance for Model Variables by Living Composition

Analysis of Variance for Positive Home Integration by Living

Composition

Analysis of Variance for Sibling Relationship Quality by Living

Composition

Analysis of Variance for Impact of Child Behavior by Living

Composition

Analysis of Variance for Number of Placements Prior to Study Entry by

Living Composition

Analysis of Variance for Number of Placement Changes During

Study Enrollment (SIBS-FC) by Living Composition

Analysis of Variance and Cross-Tabulation for Youth Characteristics by Living Composition

Analysis of Variance for Youth Age by Living Composition

Chi-Square Analysis for Youth Gender by Living Composition

Chi-Square Analysis for Youth Race by Living Composition

Test of Moderation Effects according to Living Composition

CHAPTER 5-DISCUSSION

Introduction

Youth Characteristics

Control Variables 
Treatment Condition

Number of Placements Prior to Study Entry

Family Dynamics

Positive Home Integration

Sibling Relationship Quality

Impact of Child Behavior

Home Setting Characteristics

Sibling Living Situation

Kinship Caregiver Status

Living Composition

Study Limitations

Implications for Theory

Implications for Future Research

Implications for Policy

Implications for Practice

Conclusion

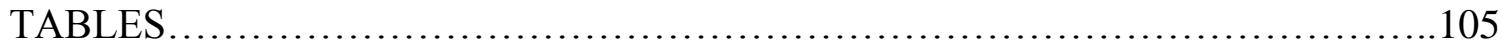

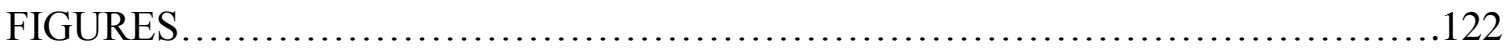

REFERENCES.......................................................... 134 


\section{LIST OF TABLES}

Table 1. Demographics of SIBS-FC Youth Participants...........................105

Table 2. Youth Treatment Condition........................................... 106

Table 3. Sibling Living Situation at Baseline..................................106

Table 4. Caregiver Relationship Status at Baseline................................ 106

Table 5. Positive Home Integration....................................... 107

Table 6. Sibling Relationship Quality..................................... 107

Table 7. Impact of Child Behavior.......................................... 108

Table 8. SIBS-FC Placement Changes...................................... 108

Table 9. ORKIDS Placement Changes...................................... 108

Table 10. SIBS-FC Binary Placement Changes.................................. 108

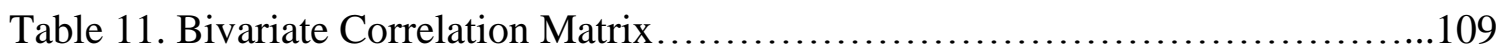

Table 12. Cross-Tabulation and Chi-Square Analysis of Kinship Care and Placement

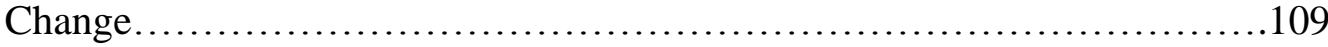

Table 13. Cross-Tabulation and Chi-Square Analysis of Sibling Living Situation and Placement Change...............................................110

Table 14. Cross-Tabulation of Living Composition.............................111

Table 15. Logistic Regression Model Predicting Placement Change (SIBS-FC)........111

Table 16. Characteristics of Youth Living Apart from their Siblings in Kinship Care..112

Table 17. Analysis of Variance for Sibling Relationship Quality by Living Composition.

Table 18. Analysis of Variance for Number of Placements Prior to Study Entry According to Living Composition.

Table 19. Analysis of Variance for Number of Placements Experienced During Study Enrollment According to Living Composition.......................... 115 
Table 20. Analysis of Variance for Age of Youth According to Living Composition..116

Table 21. Cross-Tabulation and Chi-Square Analysis for Gender by Living Composition......................................................... 117

Table 22. Cross-Tabulation and Chi-Square Analysis for Youth Race by Living Composition............................................................. 118

Table 23. Logistic Regression Moderation Model with Living Composition Predictor........................................................... 119

Table 24. Major Study Findings..................................................120 


\section{LIST OF FIGURES}

Figure 1. Conceptual model.............................................. 122

Figure 2. Moderation model.............................................. 122

Figure 3. Theoretical model................................................ 123

Figure 4. Measurement schedule......................................... 123

Figure 5. Histogram of placement changes prior to study entry $\ldots \ldots \ldots \ldots \ldots \ldots \ldots \ldots \ldots \ldots \ldots$

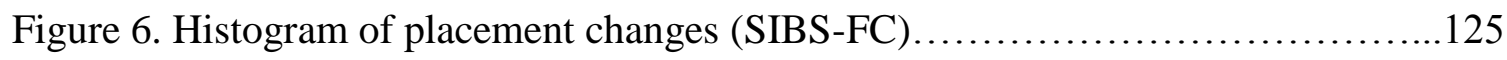

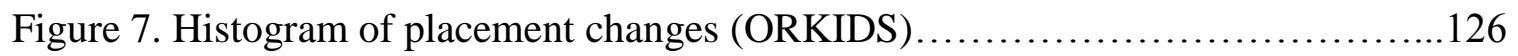

Figure 8 . Histogram of binary placement change variable $(0=0) \ldots \ldots \ldots \ldots \ldots \ldots \ldots \ldots \ldots \ldots$

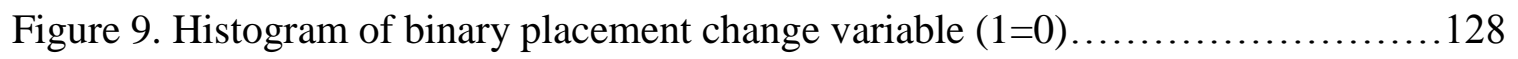

Figure 10. Mean differences in sibling relationship quality according to living

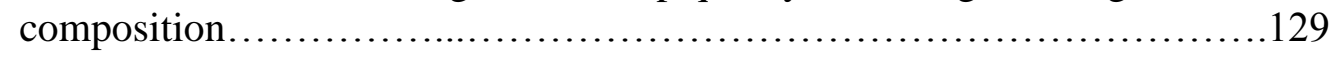

Figure 11. Mean differences in number of placements experienced prior to study entry....................................................... 130

Figure 12. Mean differences in number of placement changes during the course of study enrollment.................................................. 131

Figure 13. Mean differences in youth age according to living composition.............132

Figure 14. Causal mechanisms within the conceptual model......................133

Figure 15. Causal mechanisms within the moderation model......................133 


\section{CHAPTER 1-REVIEW OF LITERATURE \\ Introduction}

The primary purpose of the child welfare system is to promote the safety, permanency, and well-being of children who are at risk of, or who have experienced maltreatment. When a child experiences maltreatment and cannot be safely maintained in their home, the child welfare system may facilitate the temporary placement of the child, typically in a kinship or non-relative home setting, while organizing and delivering services to the children and their caregivers.

Foster care is designed to be a temporary intervention. Research has shown that long term stays in out-of-home care can be traumatic, impair child development, and disrupt attachment formation (Bruskas, 2008; Isquith, Merlender, Racusin, Sengupta, \& Straus, 2005). Children placed into unfamiliar living situations such as non-relative foster care at increased risk of developmental complications, behavior problems, and internalizing disorders (Lawrence, Carlson, \& Egeland, 2006) and protracted stays in the foster care system are associated with compromised economic, social, and emotional well-being (Buehler, Orme, Post, \& Patterson, 2000; Fallesen, 2013; Mersky \& Janczewski, 2013; Sullivan \& van Zyl, 2008; Zill \& Bramlett, 2014).

\section{Permanency}

All children who enter foster care deserve a permanent home, and this notion was codified in a series of federal laws starting with The Adoption Assistance and Child Welfare Act of 1980 (P.L. 96-272) and more recently with the Adoption and Safe Families Act of 1997 (P.L. 105-89) and the Fostering Connections to Success and 
Increasing Adoptions Act of 2008 (P.L. 110-351). The concept of permanency in child welfare is rooted in the appreciation for the importance of families, and an acknowledgement that children need continuity, attachment, and relational connection. Permanency is a child maintaining safe, stable, and secure parent-child relationship (Seneca Center, 2013) and in the context of the child welfare system is defined as a legally binding parent-child relationship (USDHHS, 2013). Children who are released from the child welfare system to a permanent, family-like living situation can be considered to have achieved permanency.

\section{Well-Being}

The concept of well-being has received renewed attention in the child welfare system, particularly around the dimensions of cognitive, physical, social, emotional, and behavioral health. Well-being has not been defined under a unified taxonomy, however Ben-Arieh \& Frones (2011) suggest that well-being is both process and outcome, with indicators of child well-being defined and measured according to social, economic, physical, emotional, and legal indicators. The US Department of Health and Human Services Administration for Children and Families has emphasized a focus specific to the well-being of children involved in the child welfare system. Specifically, the Children's Bureau emphasizes the role of trauma exposure in the compromise of well-being, and the impact of maltreatment on development, cognition, behavior, relational skills, mental health, and global functioning (Samuels, 2011). The Administration for Children and Families has made well-being a priority for children in the child welfare system and emphasizes the use of evidence based practices in addressing this important outcome. 
Studies of well-being for children in foster care settings have focused primarily on a few, limited indicators. Well-being has been conceptualized as academic achievement (Altshuler, 1998; Allen \& Vaca, 2010; Pecora, 2012; Pecora, et. al., 2006; Zorc, et. al, 2013), physical, mental health, and school functioning (Altschuler, 1998; Sullivan \& van Zyl, 2008), social and mental health (Conn, et. al., n.d.; McCue, et. al, 2012), teen pregnancy (Dworsky \& Courtney, 2010; Matta Oshima, Nrendorft, \& McMillen, 2013), labor, educational, and career outcomes (Fallesen, 2013; Stewart, Kum, Barth, \& Duncan, 2013), continuity of life activities (Fon, Schwabe, \& Armour, 2006), and youth connections (Semanchin Jones \& LaLiberte, 2013).

Like most research, operational definitions of well-being vary according to study design. Utilizing data from caseworker interviews, Altshuler (1998) compared kinship and non-relative foster homes on well-being outcomes as rated by school, medical, and psychological personnel, along with a 3-factor indicator of well-being. Altshuler found that younger children experience higher ratings of well-being, overall well-being for all children is higher when the mother is not experiencing housing barriers, and higher ratings of caregiver ability was associated with increased ratings of child well-being. With respect to academic indicators of well-being, Allen \& Vaca (2010) found that children in foster care who experience placement change are at increased risk of school absenteeism, discipline referrals, reduced grade performance, higher rates of grade retention, and lower scores on standardized tests.

The concept of resilience, often understood in child welfare research as the ability to withstand the negative effects of maltreatment and subsequent foster care placement, 
has been studied as an indicator of well-being. Investigating the multilevel correlates of resilience for children age 5-9 in Ontario, Bell, Romano, \& Flynn (2013) examined the relationship between child, family, worker, and agency level factors on caregiver rating of problem areas (conduct problems, social problems, pro-social behavior, peer relationships, and academic performance) and found that multiple levels of influence are likely to impact the presence of resiliency in children, with $64.7 \%$ of the variance attributable to child level characteristics and $29.4 \%$ of the variance was attributable to family level characteristics.

Taking a more novel approach to the notion of well-being, Fong, Schwab, and Armour (2006) examined the relationship between continuity of community attachments (i.e.: school, leisure, church, family, social, and therapeutic) and foster care placement stability. The authors conceptualized well-being as the ability of the child to fit into routines, get along with others, maintain sibling relationships, get good grades, the degree to which the caregiver worried about the future, concerns about safety, and the child's adjustment. The authors found school, leisure, and family continuity had the strongest relationship to well-being when the frequency of these activities did not change.

A few studies have specifically examined the role of positive home integration in foster care settings, which serve as an indicator of child well-being. These studies suggest this construct is important for understanding what is occurring within substitute care settings that promote placement stability and protect against the occurrence of unwanted placement change. In a study by Leathers (2006), integration into the foster home was hypothesized to mediate the relationship between behavior problems and placement 
change. Leathers utilized telephone interviews with 179 caseworkers and foster parents of middle adolescent children aged 12-13 years old. The author hypothesized that a foster parents report of behavior problems would predict placement change, but that this association would be mediated by the degree to which a child's feelings of belonging and integration. Leather's utilized questions of home integration created by Fanshel (1982), Poulin (1985), and Leathers (2002). The items Leather's used to measure home integration examined "feeling like a part of the family," "the child experiences foster parents as their own family," "participating in family activities," "the child wants this to be a permanent home," "encouraging child to participate in activities," and "conflict related to acceptance of foster parents." Leathers tracked these youth for five years and found that while half the sample experienced a placement change, integration into the foster home as reported by caseworkers and foster caregivers was highly predictive of placement stability. Similar findings were noted for a study utilizing this measure of positive home integration with children receiving a behavioral parenting intervention. In this study, Leathers (2012) examined the role of foster home integration for youth who were participating in a test of the Multidimensional Treatment Foster Care Model (Chamberlain, et. al., 2003) and found that behavior problems weakened a child's foster home integration, and foster home integration was found to be an independent predictor of adoption likelihood.

Two additional studies served as motivation to examine the role of a child's positive home integration and its impact on placement change. Brown \& Bednar (2006) identified reasons why foster parents may choose to end a foster care placement, and 
found that a child not adapting to the placement, i.e.; the child did not want help, did not respect family boundaries, the home could not meet the needs of the child, and the family experienced lack of success with getting the child to adapt to the home, served as reasons for a caregiver to end the placement. Brown \& Campbell (2007) also found that family connection was a key element of placement stability, such as the family liking the child, understanding the child's problems and situation, being accepted by extended family, meeting the child's emotional and physical needs, equal treatment of biological and other children, and trusting relationships between the child and caregivers.

These studies offer some insights both into the ways in which well-being is operationally defined, as well as provides some insight into the multiple levels of influence on well-being, and lend support for examining the role of placement stability as a component of well-being. Interestingly, sibling level findings remain largely absent from well-being research in child welfare.

\section{Current Foster Care Statistics}

There are currently two primary, nation-wide reporting structures that collect statistics related to reports of child maltreatment and foster care and adoption. The National Child Abuse and Neglect Data System (NCANDS) collects and analyzes case level data from 52 states and territories and provides annual reports on the nature of screened-in referrals, characteristics of children involved, type of maltreatment exposure, family risk factors, and case disposition. State level data are submitted to NCANDS on a voluntary basis (USDHHS, 2013). According to 2011 NCANDS data, over 3.7 million (duplicate count) children were investigated for allegations of child maltreatment, finding 
676,569 (unique count) victims of maltreatment, which amounts to 9.1 unique victims per 1,000 children in the population. The majority of these children suffered from neglect (78.5\%), followed by physical abuse (17.5\%), and sexual abuse (9.1\%). The majority of maltreatment victims were white (41.5\%), African-American (21.5\%), or Hispanic (22.1\%). Maltreatment victimization by gender was nearly equivalent. (USDHHS, 2013).

The Adoption and Foster Care Analysis and Reporting System (AFCARS) collects information from states, tribes, and other IV-E agencies on all children who are in foster care who have had an adoption facilitated through a IV-E funded agency. States are mandated to provide data to AFCARS on all children in foster care and adoptive placements both to determine the scope of foster care and adoptive placements over time, as well as monitor compliance with federal initiatives and allocate resources to states and agencies which facilitate foster care and adoptive placements (USDHHS, 2013).

According to most recent AFCARS reports, there were 400,540 children in foster care on September 30, 2011. In that reporting year 252,320 children entered and 245,260 exited the foster care system. There were 104,236 children awaiting adoption with an additional 61,361 children awaiting termination of parental rights so they may be freed for adoption. The mean age of children in the child welfare system in 2011 was 9.3 with a median of 8.8. The majority (52\%) of the children were male. The mean number of months a child had resided in a foster care placement was 23.9 with a median of 13.5 . The case goal for the majority of children was reunification with a family member (52\%), followed by adoption (25\%). The majority of children were living in non-relative foster care (47\%), followed by family/relative foster care (27\%), or living in an institutional setting (9\%). 
With respect to permanency outcomes, the AFCARS system data elements which record permanency events include the date of discharge from foster care, foster care discharge transaction date, and reason for discharge (USDHHS, 2013).

In addition to the NCANDS and AFCARS nationwide data systems, the National Survey of Child and Adolescent Well-Being (NSCAW) provides longitudinal data on a nationally representative sample of children and families involved in the child welfare system. Data are collected from children, caregivers, teachers, caseworkers, and administrative records, and examine child and family well-being outcomes (USDHHS, 2013). A substantial number of peer reviewed studies published in the child welfare literature utilize NSCAW data. The primary domains of well-being operationalized within the NSCAW data system include health and physical well-being, cognitive and school performance, behavior functioning, and social relationships (USDHHS, 2013). Specific areas of child well-being are operationalized as social competence and relationships, (relationships with parents and significant others, peers, and global social competence), health and cognitive status (development/cognition, communication skills, and health/disabilities), adaptive behavior and functional status (adaptive skills, academic achievement, special education status and receipt of related services, school socialization, engagement, and future expectation), behavior regulation, emotions, and mental health (temperament, behavior problems, mental health, delinquency, substance abuse and risky behaviors), and life experiences (child maltreatment, family/placement disruptions, loss, violence, and other stressors) (USDHHS, 2013). With respect to reunification and permanency outcomes, the NSCAW 2012 Permanency Report found that $36.5 \%$ of 
children in care experienced at least one reunification attempt and $47.7 \%$ achieved permanency (USDHHS, 2013).

Within the State of Oregon in 2011, there were an identified a total of 863,767 children under age 18, with 52,597 children subject to an investigation of maltreatment that year, resulting in an investigation rate of 60.9 per 1,000 children. There were 12,214 (duplicate count) victims of maltreatment, resulting in a rate of 14.1 per 1,000 children, 5 children per 1,000 higher than the national average. The majority of child victims were white $(73.3 \%)$ and under 1 year of age (12\%). The majority victim maltreatment type $(59.6 \%)$ was categorized as "other," (indicating more than one type of maltreatment), followed by neglect $(38.8 \%)$. A total of 9,239 children were residing in foster care in Oregon on September 30, 2011. There were a total of 4,344 new entries into foster care and 3,929 exits during this time. The median length of stay for a child in foster care was 15 months. The majority of children in care were white $(57.8 \%)$, followed by two or more races (14\%), and Hispanic (13.2\%). The age distribution of children in care was relatively even across children age $<1$ to 17 years (USDHHS, 2012).

\section{Siblings in Foster Care}

The preservation of sibling bonds is an important consideration for the safety, health, and well-being of maltreated children (Gass, Jenkins, \& Dunn, 2007; Shlonsky \& Berrick, 2001). Children who experience maltreatment are at risk of a host of negative developmental outcomes, including emotional, behavioral, and health related disorders (Fellitti, et. al., 1998), and for many of these children, maltreatment is compounded by exposures to other forms of violence (Finkelhor, Turner, Ormrod, Hamby, \& Kracke, 
2009). One long standing intervention for children who have suffered serious

maltreatment is removal from the unsafe environment and placement into a temporary, substitute care setting such as a kinship or non-relative foster home.

While placement into protective custody is an intervention designed to address immediate risks to a child's safety, children placed into foster care may experience the loss of their siblings (Lundstrom \& Sallnas, 2012), and this loss can lead to guilt, grief, worry, distress, loss of natural supports, and barriers to maintaining family relationships over time (Herrick \& Piccus, 2005).

When removal from a caregiver occurs, sibling based placements offer a form of relational continuity (McHale, Kim, \& Whiteman, 2006). Sibling relationships provide a basis for attachment, modeling and teaching, and endure over the life span (Dunn, 1983). Recognizing that removing a child from their family may disrupt the bonding and attachment process, policymakers and practitioners have emphasized the placement of siblings into the same foster home and with kin whenever possible. This practice was codified in the Fostering Connections to Success and Increasing Adoptions Act of 2008 (PL 110-351).

Despite an increase in the rate of sibling-based placements, the relationship between sibling co-placement, permanency, and well-being remains unclear. It is not enough to simply place siblings into the same home and expect successful permanency and well-being outcomes. Siblings placed together oftentimes share complex maltreatment histories, and in longitudinal studies with normative populations, unhealthy and coercive parenting practices have been shown to undermine sibling behavior (Bank, 
Burraston, \& Snyder, 2004). Negative sibling interactions may lead to adjustment difficulties, conduct problems, and antisocial behavior in later adolescence (Bank, Patterson, \& Reid, 1996).

\section{Prevalence of Siblings in Foster Care}

A review of international research estimates the proportion of children in foster care who have siblings at 65 to $85 \%$ (Hegar, 2005), however reliable estimates on the prevalence of siblings in foster care in the United States remain unknown. The federal government does not systematically collect sibling data (Herrick and Piccus, 2005) and the identification of sibling groups is complicated by the multiple ways in which sibling relationships can be defined. Sibling relationships may be defined in biological, legal, cultural, or relational terms, and states vary in their definition of siblings. No constitutional safeguards currently exist for the protection of the sibling relationship; however, the establishment of a relationship prior to system entry has previously been

protected in judicial proceedings (Shlonsky, Bellamy, Elkins, \& Ashare, 2005). Despite the lack of legal protections afforded to siblings in substitute care, the Child and Family Services Review measures the frequency in which states co-place siblings in substitute care. This federal review serves as the benchmark for states compliance with federal policies related to child welfare practices (USDHHS,2015).

At least one study has focused specifically on the reliable identification of sibling groups using child welfare administrative data. Using child referent, maternal method, paternal method, and removal address, $40 \%$ of siblings were identified across the four identification approaches (Lery, Shaw, \& Magruder, 2005). It is likely that the scope of 
sibling relationships is much larger than captured in child welfare administrative databases.

\section{Factors Associated with the Co-Placement of Siblings}

How siblings enter and move through the foster care system has been the focus of a number of peer reviewed studies. In an early descriptive study of siblings in foster care, Staff \& Fein (1992) examined the placement experiences of 262 children placed in a New England foster care agency between 1976-1990, and found that only $10 \%$ of the sample were only children. In this sample of siblings in care, gender match and size of sibling group appeared to impact placement together, and $25 \%$ of intact placements remained that way over the course of the study.

Utilizing New York City administrative data, Wulczyn and Zimmerman (2005) analyzed the placement experiences of sibling groups entering care for the first time, between 1985-2000. Sibling groups were defined as sharing the same birth mother and were tracked for a period of up to 4 years. The authors found that less than half of sibling groups enter on the same day, but when they do they are more likely to remain in intact placements over time. Intact placements were associated with sibling group size, the availability of kinship homes, and close age range of siblings.

Using the California Children's Services Archive, Shlonsky, Webster, and Needell (2003) conducted a cross-sectional analysis and found that entering care at the same time, placement into relative care, close age proximity, and matched sibling gender were predictive of intact sibling placements. Children in kinship care were three times as 
likely to be placed with siblings than children in non-relative care, and sibling groups with three or more children were half as likely to be placed together as sibling dyads.

In a review of international research published between 1998-2003, Hegar (2005) examined placement patters and outcomes across 17 studies. While siblings were defined differently in each study it was found that kinship foster care was a significant predictor of siblings being placed together into care, and siblings placed together appeared to have more stable placements than those who were placed apart.

To better understand the challenges and processes involved in maintaining sibling relationships in foster care settings, James, Monn, Palinkas, and Leslie (2008) conducted semi-structured interviews with 14 caregiver participants of a larger foster care study. Factors involved with the separation of siblings included complex family relationships, willingness and ability of caregivers to take in sibling groups, sibling age difference, sibling conflict, and adoption prior to the birth of siblings. Reasons for limited contact between separated siblings included sibling placement history, caregiver gate keeping, and a child's own thoughts and desires surrounding sibling contact.

\section{Siblings, Placement Stability, and Permanency}

A few studies have specifically focused on the relationship between sibling coplacement, placement stability, and permanency outcomes. Utilizing caseworker and foster parent reports on 197 adolescents in Illinois, Leathers (2005) found that consistent placement with one's siblings improved their sense of integration into the home and reduced the risk of placement disruption. Siblings who were living alone after a history of 
living together experienced weaker integration, and were less likely to be adopted or placed into guardianship over 5 years.

The effects of sibling separation suggest a co-occurring impact on placement stability and well-being. Using NSCAW data, Barth et. al (2007) examined placement stability of children with emotional and behavioral disorders, and found that children were more likely to disrupt from their placement when they evidenced depressive symptoms and were not living with their siblings.

To determine if sibling placement type predicted reunification status, Albert \& King (2008) examined Nevada state administrative data and found that siblings who were placed together over the course of their foster care stay reunified more quickly than those who were placed apart, including siblings who were living in kinship placements. Differences in the rates of reunification for siblings placed completely together versus completely apart grew more pronounced over time.

Using Midwestern administrative data, Akin (2011) identified siblings who entered foster care in 2006 and tracked permanency outcomes for 30 to 48 months. Siblings who were placed together fared better on reunification, guardianship, and adoption outcomes than siblings who were placed in only partially intact groups, children who were completed separated from their siblings, or children who had no siblings in care.

\section{Siblings and Well-Being}

The placement of siblings in the same foster home appears to be a promising intervention to promote stability and permanency for siblings who enter care. However, 
research on well-being paints a less compelling picture and raises some interesting questions. Studies of siblings in foster care have not specifically tested the relationship of placement type to well-being, and sibling relationship quality has been absent from a number of studies (Shlonsky, et. al., 2005).

Using NSCAW data from 1999-2000, Hegar \& Rosenthal (2009) investigated the relationship between kinship foster care, sibling placement, youth behavior, family and caregiver relationships, and school performance. Across placement types no differences were reported in caregiver or teacher reports of problem behavior, although siblings placed together did evidence fewer internalizing behaviors than those who were placed apart. Using the same data set, Hegar \& Rosenthal (2011) used child self-identification of sibling relationships to determine if placement type impacted youth behavior, academic performance, or satisfaction with their placement. Interestingly, sibling placement type did not influence a child's sense of belonging, satisfaction with placement, family relationships, or problem behaviors.

International research on siblings in foster care raises additional questions about the relationship of sibling foster care to well-being. Using highly structured interviews with 240 young people in out of home care in Sweden, Lundstrom and Sallnas (2012) found that the less frequently siblings are in contact, the more they crave contact. Siblings who were older, in care for longer periods of time, with a history of residential placement were less likely to have contact with their siblings. Despite a reported desire for more frequent contact with their siblings, the authors did not find a relationship between frequency of contact and a five-item indicator of child well-being. 
Using baseline data for 347 children in New South Wales, Tarren-Sweeney and Hazell (2005) examined the relationship between sibling placements, internalizing behaviors, externalizing behaviors, and a measure of socialization. Tarren-Sweeney and Hazell took a more comprehensive approach to their analysis by defining sibling placements according to history, present location of siblings, birth position in sibling group, size of sibling group, and if the relationship was full, maternal, or not established. The authors found that separation from siblings did not impact the mental health and socialization of boys, but girls who were separated from their siblings evidenced poorer mental health scores.

At least one study has examined the impact of sibling relationship quality on child well-being. Using data from 156 children in the New York City foster care system, Linares, Li, Shrout, Brody, and Pettit (2007) measured dimensions of sibling relationship quality in relationship to internalizing and externalizing behaviors, and found that over a 14 month period of time, evidence of sibling negativity at study baseline predicted an increase in both internalizing and externalizing problem behaviors 14 months later. Conversely, Linares et. al. (2007) found that positive sibling relationship quality at baseline predicted fewer internalizing and externalizing behaviors at follow up.

\section{Factors Associated with Foster Care Placement Disruption}

Research on how sibling relationships influence family processes and impact the likelihood of placement disruption is limited. In order to better understand the context of placement disruption in foster and kinship settings, examination of qualitative and intervention research is helpful. 
To understand caregiver perspectives on why placements break down, Brown and Bednar (2006) interviewed sixty-three foster parents from fifty families about why a caregiver may decide to end a placement, and discovered that placement breakdown is a process. Common themes caregivers reported for ending a placement included the child being a danger to the family, conduct problems, lack of adaptation, and children presenting with complex needs. Family and organizational factors were also identified, including changed circumstances in the family, caregiver health issues, lack of community resources, and problems with agencies and service providers. In asking foster parents what they think creates a stable placement, Brown and Cambell (2007) identified 6 themes. Specific dimensions of the foster experience that promote stability include family connections, good relationships, the child grows, positive family change, and seamless agency involvement.

The association between problem behaviors and placement disruption has been well studied. A review and meta-analysis of 26 studies of placement disruptions suggests that older age of the child, behavior problems, previous placements, and a history of residential care were associated with a placement breakdown (Oosterman, Schuengel, Slot, Bullens, \& Doreleijers, 2007).

At least two studies have identified a threshold effect for problem behaviors and placement disruption. Surveying foster and kinship caregivers for 246 elementary school aged children in California, Chamberlain et. al. (2006) asked about whether a foster child engaged in up to 30 different problem behaviors in the previous 24 hours. From this the researchers were able to determine caregivers would tolerate up to 6 problem behaviors 
from a child in a day, and as problem behaviors increased past 6 the likelihood of a disruption increased. Replicating this study using data from 117 pre-school aged children enrolled in a therapeutic foster care intervention, Fisher, Stoolmiller, Mannering, Takahashi, and Chamberlain (2011) found that caregiver reports of 5 or more problem behaviors in the first three months of placement predicted placement disruption within 12 months for families who did not receive the foster care intervention.

Behavior problems and placement change appear to exert a reciprocal influence on one another. Newton, Litrownik, and Landsverk (2000) investigated the relationship between problem behaviors and placement disruption with a sample of 415 youth in foster care, finding placement instability was associated with increased problem behaviors, and problem behaviors were associated with increased instability.

While the role of behavior problems is significant in predicting the likelihood of a placement disruption, other factors may also be present. Using Utah administrative data for 6,432 children in care between 2000-2002, Eggerstein (2008) found that children with major health problems were $60 \%$ more likely to experience a disruption, and mental health problems doubled the likelihood of experiencing three or more placements. Children with minor health problems were 4.5 times more likely to experience three or more placements. Placement for delinquency or dependency related to sexual abuse was associated with a disruption, and a bivariate correlation was found between the number of caseworkers and the number of placements a youth experienced.

Certain foster parent characteristics appear to increase the likelihood of a placement disruption. Crum (2010) surveyed 151 foster parents with at least two years of 
foster experience from 5 states in the Appalachian region, and found that parenting support and effective limit setting promoted stability while rigid parenting and firm rules promoted the occurrence of a placement disruption.

How a foster parent engages in caregiver training has been the focus of at least one study on placement disruption. Utilizing data from 337 foster parents nested within 50 foster parent training groups, DeGarmo, Chamberlain, Leve, and Price (2009) found that higher intervention engagement was associated with a decrease in the likelihood of placement disruption for children who had a higher number of prior placements at baseline measurement. In this sample, children were 13 times more likely to experience a placement change if caregivers displayed time varying negative mood. Controlling for other covariates in the model, the researchers also found that children in kinship care were $67 \%$ less likely to experience a disruption than those in non-relative care.

How many times a child moves may be the result of policy or organization related factors. Reviewing the records of 580 children in foster care five months or more in San Diego, James, Landsverk, and Slymen (2004) found that the majority of first and second placements were due to system or policy level factors, such as the use of short term and emergency shelter placements. The risk of placement was highest during the first 100 days of placement, however risk of placement change was lower when the child spent more of those days in kinship care.

A child's placement history appears to exert a strong influence on the likelihood of future disruptions. Using data from 700 kinship and non-relative families receiving a child for placement, Price, et. al. (2008) found that the number of prior placements 
increase the odds of a future disruption. Children in kinship care were less likely to experience a placement change of any kind, and receipt of a foster parent training intervention decreased the negative effects of prior placements on the probability of a future disruption.

Evidence of the protective effects of kinship care on placement disruption is available. Using NSCAW data from 1999-2004, Rubin (2008) compared kinship and non-relative homes on placement stability and found that children who entered kinship care early in their foster care stay were at lowest risk of disruption, and children who entered kinship care later in their stay still experienced greater stability than the general foster care population. With respect to the probability of experiencing behavior problems, risk was lowest in the early kinship group.

\section{Limitations of Current Research}

Research on siblings in foster care has identified the predisposing factors that predict co-placement, as well as the effects of co-placement on stability and well-being outcomes. While this information has been helpful in advancing the co-placement of siblings in child welfare practice, there are limitations to the research. Specifically, prior studies have not controlled for predisposing factors, such as the age of co-placed or separated siblings on placement stability, permanency, and well-being outcomes. It is possible that while siblings are more likely to experience beneficial stability and wellbeing outcomes when placed together, variance in outcomes within co-placed or separated groups may be present. Further investigation into how sibling group 
characteristics, co-placement, and stability, permanency, and well-being outcomes is indicated.

\section{Policy and Practice Interventions to Promote Permanency and Well-Being}

Federal legislation has been adopted to address the permanency needs of children in foster care through the Adoption Assistance and Child Welfare Act of 1980 (P.L. 96272), the Adoption and Safe Families Act of 1997 (P.L. 105-89), and the Fostering Connection to Success and Increasing Adoptions Act of 2008 (P.L. 110-51), which detail the specific policies, practice behaviors, and timelines required to ensure children who enter foster care return to their families or, if unable to be returned, placed into a permanent and stable family home. The Adoption Assistance and Child Welfare Act (P.L. 96-272) is a federal law that established adoption assistance for children who removed from their families and mandated states to make "reasonable efforts" to maintain children in their homes of origin, and if removal was required, to return the children to their families as quickly as is safe to do so. The Adoption and Safe Families Act of 1997 (P.L. 105-89) requires child welfare agencies to make reasonable efforts to reunify the child with their family within 15 months of initial placement into foster care, unless aggravated circumstances are present. If a child is unable to be reunified with their parent within 15 of 22 months of a foster care placement, the agency must implement a concurrent plan which provides the child with a permanent home outside of their primary caregivers. The Fostering Connections to Success and Increasing Adoptions Act of 2008 (P.L. 110-51) requires child welfare agencies to locate relatives of children who enter foster care, and to give preference to placement with kin when it is safe to do so. This act 
also requires child welfare agencies to preserve sibling bonds through co-placement in foster care settings whenever possible.

Evidence based practice refers to the integration of methodologically sound research, clinical expertise, and client values to inform decision making processes (Sacket, 1997). Multiple practices have been employed to address complications related to child maltreatment. However, few have focused on placement stability, permanency, and well-being outcomes specifically. Controlled studies which have focused on sibling relationships (Linares, Shrout, Brody, \& Petiti, 2007), caregiver training (Price, et. al., 2008) and specialized foster care settings (Price, et. al., 2008) are among the few empirical studies of interventions specific to children in foster care which have examined stability, permanency, and well-being outcomes in controlled clinical trials. These programs target child behavior, parenting skills, and quality of relationships amongst household members, and have found to decrease rates from foster care in these samples.

\section{Dissertation Research Questions}

The purpose of this dissertation was to examine how family dynamics and home setting characteristics in substitute care settings impact the likelihood of placement change for a sample of children in foster care. This dissertation also sought to investigate the moderating role of kinship care and sibling living situation on the likelihood of placement change for these children. This dissertation (1) Applied a conceptual model to a unique data set of siblings in foster care, and (2) Investigated the individual and combined effects of positive home integration, sibling relationship quality, foster caregiver reported impact of negative child behavior, sibling living situation, and kinship 
caregiver status, number of placement prior to study entry, and treatment condition on the likelihood of placement change, and (3) Investigated the moderating effects of living composition (kinship status, sibling living situation) on the likelihood of placement change. Figures 1 and 2 detail the conceptual models tested in this dissertation.

\section{Relevance to Researchers, Practitioners, and Policymakers}

This study may contribute to the field of child welfare in multiple ways. This study may improve our understanding of the role of family dynamics in foster care settings on the frequency of placement change, and illuminate those interactions most likely to benefit from intervention. For example, researchers understand the role of behavior problems on placement disruption, and practitioners and interventionists typically try to control and reduce negative problem behaviors among foster children as a primary family preservation or placement stabilizing intervention. While intervening to reduce specific behaviors among children is important, it may also make sense to intervene with the caregiver around their own stress response and cognitive appraisal of a child's behavior. If a child's behavior problems are embedded in ongoing interactions with other children and siblings in the home, it would also make sense to address relationship interactions among children. It may also make sense to address family routines and daily processes that alienate a foster child, and to create inclusive family routines and traditions that promote a child's sense of inclusion in their foster home.

This study critically examines the individual and combined effects of child, sibling, caregiver, and home setting characteristics on placement disruption using unique indicators, some of which not previously specified in published studies. By examining 
predictors not previously identified but similar to constructs investigated previously, this study may provide new perspectives on ways to measure interactive processes in home settings, and their relationship to key child welfare outcomes. 


\section{CHAPTER 2-THEORY}

\section{Introduction}

Identifying and utilizing a theoretical orientation to investigate questions of importance to the child welfare community is critical, yet underutilized in sibling focused child welfare research (Washington, 2007). In order to properly explain the logic of any research question, researchers must be able to ground their model using a theoretical orientation that explains why a conceptual model contains specific variables and explains the hypothesized relationships contained within.

This chapter identifies three theoretical approaches to understanding the experiences of children in substitute care. This chapter also details a conceptual model proposed for investigating the relationship between family dynamics, home setting characteristics, and placement change. Then, this chapter utilizes theory to explain how the relationships among variables in the conceptual model may impact placement change outcomes.

The three theoretical orientations reviewed in this chapter contribute a unique lens from which to investigate relational dynamics occurring within family systems. One theoretical orientation, Bioecological Theory (Bronfenbrenner, 1979; Bronfebrenner, 1986), allows for investigating foster home processes and child welfare outcomes using a broad, overarching framework. The second, Social Learning Theory (Bandura, 1977), focuses on the dyadic interactions that occur within foster homes and how these dyadic interactions may create and reinforce behaviors that may increase or decrease the likelihood of a substitute care placement change. The third, Coercion Theory (Bank, 
Burraston, \& Snyder, 2004; Bank, Patterson, \& Reid, 1996) speak to the potential mediating effects of caregivers and siblings on child functioning and subsequent placement change.

Research on placement instability and impermanence for children who are transitioning from care as young adults suggest they are at increased risk of a host of negative outcomes (Bruskas, 2008; Isquith, Merlender, Racusin, Sengupta, \& Straus, 2005). As a result of increased understanding of the experiences of transition age foster youth, many programs have emerged to address their needs. However, the issues facing early adolescents in foster care are less understood, particularly with respect to the relationship of home setting characteristics, family dynamics, and permanency and wellbeing outcomes. For these middle-adolescent aged children, who may eventually become transition age youth, the child welfare field must work to identify areas of intervention within home settings, in casework practice, and in placement related policy formation that are most likely to yield positive permanency and well-being outcomes for these children. The child welfare field must work to understand and address the experiences of these early adolescent age foster youth.

Theory can be quite useful in helping Social Workers understand the relationship between the experiences of siblings in substitute care settings and child welfare outcomes, yet there is a paucity of theory in sibling-focused foster care research (Washington, 2007). Multiple theoretical perspectives have been proposed to help explain the experiences of siblings and sibling relationship development in normative populations 
(Whiteman, McHale, \& Soli, 2011), however their application to child welfare research has not been well established.

Research on siblings in foster care suggest that the co-placement of siblings is in many instances beneficial to the placement stability and permanency of children in foster care (Akin, 2011; Albert \& King, 2008) while findings regarding the relationship between co-placement and well-being is less clear (Hegar \& Rosenthal, 2009; Hegar \& Rosenthal, 2011; Lundstrom \& Sallnas, 2012). Outcomes for children in foster care are part of a dynamic set of processes occurring both within the home (Brown \& Bednar, 2006; Brown \& Campbell, 2007) as well as subject to the influence of external forces such as system and policy level factors (James, Landsverk, \& Slymen, 2004).

\section{Bioecological Theory}

Bioecological theory (Bronfenbrenner, 1979) is particularly suitable to helping researchers and practitioners map out and measure the multiple levels of influence occurring within foster home settings, as well as between foster homes and larger child welfare related systems. Bioecological theory views the social environment as a series of nested structures, and the focus of inquiry is on the inter-relationships between structures. Dyads are considered important for individual development, and serve as building blocks for larger inter-personal relationships (Bronfenbrenner, 1986). Where a child spends the majority of his or her daily life, and the interactions and experiences occurring within these settings are considered the microsystem. A foster home, classroom, or therapist's office may be considered a microsystem. Interactions between microsystems, such as interactions between a school counselor, therapist, and foster parent, is considered a 
mesosystem. Both microsystems and mesosystems directly involve the child in the shaping of their experience. Children are also impacted by the influences of indirect processes, such as caregiver-caseworker interactions, or caseworker-supervisor interactions, which inform case planning and decision making. These indirect interactions and processes are called exosystems. Finally, child development is also subject to broader, more abstract processes such as social attitudes, belief systems, culture, and community norms and values, which are referred to as macrosystems (Bronfenbrenner, 1979).

\section{Social Learning Theory}

Social Learning theory (Bandura, 1977) helps orient practitioners and researchers to the interactive processes occurring between individuals that may promote a particular outcome. Social learning theory views behavior as a result of both internal processes and external forces, and is a function of the reciprocal nature of person-in-environment. Learning is influenced by an individual's biology, cognitive functioning, regulatory systems, and reinforcements in the environment.

Social learning theory is useful in helping explain the interactive processes occurring between children, their siblings, and caregivers in foster care settings, and can be applied to the management of problematic child behavior, sibling conflict, and antisocial behaviors. Social Learning theory can help inform intervention approaches as applied to dyadic interactions between siblings, caregivers, caseworkers, and others involved in case planning processes. For example, every child in a foster home setting can be understood in terms of individual biology, temperament, cognition, psychological 
and emotional health, and behaviors. While some characteristics of individual children are less malleable than others, many, if not all, may be subject to the influence of the external environment. For a child in a foster home setting, the placement environment and the individuals within may assert an influence on this child. Furthermore, this child may assert a reciprocal influence on others living within the home setting.

\section{Coercion Theory}

Coercion theory suggests that child and adolescent deviant behavior (e.g. behavior problems in foster care settings) may be a function of sibling conflict and influence, caregiving practices, discipline, monitoring, and reinforcement strategies (Bank, Burraston, \& Snyder, 2004; Crosswhite \& Kerpelman, 2008). Applied to this dissertation, Coercion theory may help explain some of the processes occurring in home settings that lead to placement change. Specifically, that caregiver and sibling level influences may be reciprocal in their influence on whether a youth experiences a placement change. This study utilizes child, sibling, caregiver, and home setting levels to help explain the occurrence of placement change. With Coercion theory, a caregiver who provides high ratings of impact of child behavior may lead to a placement change for the child, irrespective of the actual level of child's behavior problems. If a caregiver lacks the capacity to modulate their emotions and respond calmly to the child, this caregiver level factor may influence a placement change. Similarly, if conflict between siblings living in the same home is high, this may impact a child's sense of positive home integration and level of sibling conflict a caregiver must then address. Sibling level conflict could lead to decreased satisfaction with the placement, and possibly increased behavioral difficulties. 
Coercion theories focus on reciprocal influences, and applied to this studies conceptual model may provide some insight into the ways family dynamics occur within a home settings and how these dynamics influence the odds of placement change over an 18 month period of time.

\section{Summary of Theory}

A number of lessons can be learned from Bioecological, Social Learning, and Coercion theory for building a conceptual model that seeks to explain the relationship between family dynamics and home setting characteristics influence on placement stability over time. First, we must understand that the systems in which children are embedded are complex and multilevel in nature. Second, each level within a complex system is comprised of its own characteristics and processes, which may vary over time. Third, each level will interact to varying degrees with the other levels within the complex

system. Fourth, relational processes between levels may be characterized by interactions. Fifth, interactions between levels may be understood as behaviors, responses, modifications, and reinforcement. Sixth, these interactions may be reciprocal in nature. Seventh, these interactions may be amenable to intervention. Eighth, targeted intervention within the conceptual model may promote beneficial outcomes at multiple levels.

\section{Conceptual Model: Predicting Placement Change}

This dissertation proposed a multi-level conceptual model to help explain the varying levels of influence on the frequency of placement change for siblings in foster care. This model identified child, sibling, caregiver, and foster home levels of influence 
on placement disruption. Variables identified at each level of the conceptual model are grounded in prior research and salient to foster home processes as understood in the Biological, Social Learning, and Coercion Theory frameworks. Figure 3 details the dissertation's theoretical model.

\section{Predictor Variables}

\section{Positive Home Integration}

Research suggests that the degree to which a child feels integrated into family processes is associated with the stability of their foster care placement (Leathers, 2005). Children who feel as though they have a voice in the family, are included in decisionmaking, and participate actively in family activities may fare better than children who do not feel integrated into the family placement. The child level predictor of placement disruption in this conceptual model is a measure of the child's report of positive home integration. Specifically, positive home integration relates to a child sense of inclusion and belonging in the foster home setting and family related processes, the extent to which a child feels like they are treated with kindness and respect, are involved in decision making, how well they feel their caregiver listens to and responds to the child, how available a caregiver is when the child has a problem, how well a caregiver responds to a child's needs, and how frequently they communicate. In this dissertation it was theorized that a child's increased sense of positive home integration, such as being included in conversations, having a say, being informed, and included in family activities will create a sense of connection and relationship with others in the home. The benefits of feeling integrated in a family may promote communication and strengthen relationships, thereby 
reducing the occurrence of conflict in the home and presence of disruptive behaviors. It was hypothesized a child with a high sense of positive home integration will be less likely to experience a placement disruption.

\section{Sibling Relationship Quality}

The co-placement of siblings appears to be protective against the occurrence of placement disruption (Akin, 2011; Albert \& King, 2008), while the relationship between co-placement and well-being is less clear (Hegar, 2005; Hegar \& Rosenthal, 2011). Moving beyond simple administrative indicators of sibling co-placement and towards the examination of indicators of sibling relationship quality is an important step towards understanding how sibling dynamics and relational quality may influence stability and well-being outcomes when children are placed together or apart. The sibling level predictor in this conceptual model is sibling relationship quality (Furman \& Buhrmester, 1985). Sibling relationship quality is the degree to which a child feels connected to and supported by their sibling, whom they can share emotions, communicate effectively, take and give advice, and relate to. Sibling relationships may be protective against the traumas associated with maltreatment exposure and substitute care placement. A positive sibling relationship may also be an indicator of child well-being. In this dissertation it was expected that sibling relationship quality will vary, particularly if children reside together or separately. It was hypothesized that a positive sibling relationship will be associated with a decrease in the likelihood of a placement disruption.

\section{Impact of Child Behavior}


Behavior problems are consistent predictors of placement disruption for children in foster care (Oosterman, et. al, 2007) and placement disruption asserts a reciprocal influence on problem behaviors (Newton, Lintrownik, \& Landsverk, 2000). Researchers have traditionally examined frequency of behavior when measuring its influence on placement stability, however this focus on the child may not necessarily yield the outcomes child welfare professionals seek when attempting to stabilize placements and achieve well-being and permanency outcomes for children. How a foster parent appraises a child's behavior and its perceived impact on family functioning may be more amenable to successful intervention, or at least a complimentary form of measurement and pathway to intervention with a traumatized child who is displaying disruptive behaviors.

While behavior is a potent predictor of placement disruption, this dissertation examined how a caregiver feels a child's behavior impacts family processes. Specifically, caregiver predictors examined the degree to which a child's behavior impacts a caregiver's ability to take the child into public, cause the caregiver anxiety, creates conflict with a spouse, prevent others from visiting the home, and if others express concern for the child's behavior. Caregiver appraisal of problematic behavior is an important yet under examined target of measurement and intervention in foster care settings. While addressing child behavior directly may be indicated, there may be benefits to working with caregivers to strengthen their ability to appraise problematic behavior therapeutically. In this dissertation it was hypothesized that caregiver reports of negative impacts of a child's behavior on family processes will be associated with an increased likelihood of placement disruption. 


\section{Control Variables}

\section{Sibling Living Situation}

Siblings who live together fare better on placement stability (Leathers, 2005) and permanency outcomes (Akin, 2011); however co-placement and well-being results are mixed (Hegar \& Rosenthal, 2011). Sibling co-placement may influence the degree to which children may support each other in traumatic and unfamiliar circumstances and may influence and child's comfort and familiarity in unfamiliar living situations. It was hypothesized that youth who live apart will be at greater risk of placement change than siblings who are placed together.

\section{Kinship Care}

Whether a child is related to their caregiver may influence family processes and targeted outcomes. Kinship care is associated with placement stability and child wellbeing (Rubin, 2008). Kinship caregivers may have a better understanding of the child's needs, their trauma history, and they may feel a stronger obligation to care for the child than a non-relative caregiver, and kinship caregivers are also more likely to accept sibling groups than non-relative caregivers. In this dissertation it was hypothesized that youth who live in kinship care would be less likely to experience placement change than youth who live in non-relative care.

\section{Living Composition}

Siblings may reside together in kinship care, together in non-relative care, apart in kinship care, or apart in non-relative care. It was hypothesized that the experience of 
placement change will differ, depending on the living composition category the youth resides in at the time of study enrollment.

\section{Number of Prior Placements}

Youth with multiple placements prior to study entry may differ from children who experienced stability in their substitute care placements. Youth who have experienced multiple placements may be at greater risk of future placement changes than children who experienced prior stability. It was hypothesized that youth with prior placement experiences would be more likely to experience a placement change during study enrollment than youth who did not experience placement changes prior to study enrollment.

\section{Treatment Condition}

Children who participated in the SIBS-FC intervention may develop increased relationship building skills and advocate better for their needs than children who were randomized to receive treatment as usual. It was hypothesized that youth in the treatment condition would be less likely to experience a placement change during the course of the study than youth who received services as usual.

\section{Dependent Variables}

\section{Placement Change}

Children in foster care often experience short term transitions, however those transitions in which a child's life is disrupted may negatively impact their well-being over time. This study conceptualizes placement stability as the absence of movement from one home to another. Placement change is conceptually defined as a change in 
physical residence which is perceived to be permanent, not a placement considered to be for visitation or respite care purposes. 


\section{CHAPTER 3- METHODS}

\section{Introduction}

This dissertation sought to understand how family dynamics and home setting characteristics impacted the likelihood of foster care placement disruption over an 18month period of time. To investigate these questions, this study (1) Applied the conceptual model detailed in section 1.5 to a unique sibling data set, (2) Investigated the individual and combined effects of positive home integration, sibling relationship quality, impact of negative child behavior, sibling living situation, kinship caregiver status, number of prior placements, and treatment condition on the likelihood of foster care placement disruption over the course of study enrollment, and (3) Explored the potential moderating effects of sibling living situation and kinship care on the likelihood of placement change. This was done by examining different combinations of living composition at study enrollment and comparing the odds of a placement change over the duration of study participation for each living composition category.

This chapter first provides an introduction to the parent study and the data from which this secondary analysis was conducted. Then, the dissertation purpose and specific research questions are explained. Finally, this chapter will provide an overview of the statistical methodology that was employed, and the justification for its use.

\section{Introduction to the Parent Study}

This dissertation was built from a larger five-year NIMH funded study that was designed to promote positive connections for siblings, reduce youth internalizing and externalizing symptoms, and improve quality of life in a community sample of siblings in 
foster care. The SIBS-FC study was a randomized controlled clinical investigation of an intervention targeting sibling family sub-systems of children who reside in substitute care in the Portland, Oregon metropolitan region. The Supporting Siblings in Foster Care intervention was designed to improve the quality of sibling-sibling interaction through strengthening problem solving skills and increasing supportive behaviors, while reducing trauma associated with maltreatment and removal. The parent study tested the Supporting Siblings in Foster Care curriculum, a 12-session relationship enhancement intervention. Sibling dyads who enrolled were randomized to treatment or control conditions and yoked according to their living situation, to test for differences in intervention effects.

The SIBS-FC intervention focused on pre and early adolescent youth (older sibling) and an identified younger sibling who was no more than four years younger in age. The intervention was designed to promote a positive sibling relationship through a progressive curriculum that addresses social and self-regulatory skills such as communication, cooperation, problem solving, and conflict abatement. Skills were delivered to the youth and reinforced through experiential activities by a coach under the supervision of a Licensed Master of Social Work (MSW). Specific intervention objectives were modeled by the coach, and the siblings then practiced and reinforced new skills through fun and engaging activities in the community and in the home.

The intervention contained eight sessions and four community activities. Session one focused on relationship building between the clinician and siblings, and served as an introduction to the intervention. Session two focused on skills associated with cooperation, and in session three the siblings began to apply cooperation skills through 
planning the community activities they would engage in during the course of study enrollment.

Following session three, the siblings and coach engaged in their first community activity. In session four the siblings were taught emotion regulation skills, and in session five learned about problem solving. Following session five, siblings engaged in their second community based activity. The second community based activity focused on practicing sibling support and incorporating supportive adults into the activities.

In session six, the siblings were taught techniques to obtain adult support. At the contact following this session, the siblings practiced building adult alliances for their third community based activity. In session seven, the siblings learned about how to ask for support from individuals within the foster care system. In the final community activity, the siblings practiced advocating for themselves and their sibling with their DHS caseworker. In the eighth and final session, the siblings discuss staying connected.

This intervention format, which blends skill development and activity-based sessions, was designed to improve self-regulation, engaging adults and building supports, and to promote collaborative problem solving and pro-social development within the sibling relationship (Kothari et. al., 2014).

\section{Parent Study Purpose and Research Questions}

The SIBS-FC study tested the efficacy of a cognitive-behavioral sibling intervention with siblings who resided in substitute care settings. This study utilized randomized controlled trial design, with sibling dyads assigned to receive either the SIBS-FC intervention or services as usual. In the control condition youth received typical 
child welfare case management and behavioral health services. The SIBS-FC study tested a theoretical model for sibling youth outcomes in which mental health, academic success, quality of life, and sibling relationship quality could potentially be improved through the delivery of a sibling-focused intervention. In this theoretical model gender, age, disability status, race/ethnicity, and sibling living situation were hypothesized to moderate the sibling interventions treatment effect. After randomization to treatment or control conditions, study participants were observed for an 18 month period of time.

The SIBS-FC study is important to understanding the potential protective effects of siblings, particularly for children whom have experienced maltreatment and discontinuity in caregiving. This study builds upon decades of research on parent management training (Kazdin, 1997; Kazdin, Esveldt-Dawson, French, \& Unis, 1987; Kjobil, Hukkelberg, \& Ogden, 2013; Kling, Forster, Sundell, \& Melin, 2010; Kuncel, Ones, \& Sackett 2010; Lee, Niew, Yang, Chen \& Lin, 2012), cognitive behavioral therapy (Beck, 1995; Cohen, Mannarino, \& Deblinger, 2006; Dorsey, Berliner, Koschmann, McKay, \& Deblinger, 2014), sibling research (Bank, Burraston, \& Snyder, 2004; Bank, Patterson, \& Reid, 1996; Feinberg, Sakuma, Hostetler, \& McHale, 2013; McBeath, et. al., 2014), as well as delinquency prevention in family systems (Barkan, et. al, 2014; Mulvey, Arthur, \& Reppucci, 1993; Postlethwait, Barth, \& Guo, 2010; Ryan \& Testa, 2005); Sander, Patall, Amoscato, Fisher, \& Funk, 2012; Tolan \& Guerra, 1994; Van Horn, Fagan, Hawkins, \& Oesterle, 2014), and provides the child welfare field with important information related the role of siblings on well-being related outcomes. 
The scope of the parent study and nature of its design permit the opportunity to test an intervention with the potential for export to the broader child welfare community, providing information related to the role of siblings in child and family well-being.

\section{Parent Study Participant Eligibility Criteria and Recruitment Procedures}

A total of 328 youth were enrolled in 5 cohorts. Study participants were enrolled from the Portland, Oregon metropolitan region and siblings must have been no younger than 7 and no older than 11 at time of enrollment. The Oregon Department of Human Services provided legal consent for participation in the study. Siblings in foster care from three Oregon counties (Multnomah, Clackamas, Washington) were enrolled. Complete data across four waves of measurement (baseline, term, follow-along 1, follow-along 2) have been collected and available for secondary analysis.

\section{Parent Study Data Collection}

The parent study utilized a multiple method, multiple indicator data collection and measurement strategy (Chamberlain \& Bank, 1989). Data were collected from the youth, their sibling, primary caregiver, caseworker, and teacher. Youth, caregiver, caseworker, and teacher data were collected using survey methodology. When a sibling dyad enrolled in the project, baseline data was collected from the youth and their sibling in person, in the form of a youth survey packet. If the youth required assistance in reading the survey questions the data collector would provide assistance according to predefined protocols. The caregiver survey packet was provided to the primary caregiver at the same time as the youth, and caregivers were asked to complete and return this information to the coach the same day. Concurrently, the youth's teacher and caseworker were identified and 
outreach to these individuals was conducted. If the youth's teacher and caseworker agreed to participate, they were provided teacher and caseworker surveys electronically.

These multiple sources of data (youth, sibling, caregiver, teacher, caseworker) were collected on four occasions, each separated by 6 months in time. Once baseline data were collected, a 6 month term, 12 month follow along 1, and 18 month follow-along 2 measurement timeline was established and implemented. Figure 4 details the parent study measurement schedule.

In addition to major measurement waves, administrative data was collected from the Oregon Department of Human Services ORKIDS database utilizing a standardized data collection template. Administrative data included the date of initial placement, total number of placements, and dates of placement change. Administrative data was collected for each youth at the end of their participation in the study.

The breadth and scope of information collected allows for multiple lines of empirical inquiry, and provides the opportunity for secondary investigation of research questions related to placement stability and the occurrence of substitute care placement change.

\section{The Current Study}

\section{Sample}

Study participants were in the legal custody of the Oregon Department of Human Services and residing in the Portland Metropolitan Region at the time of enrollment. At study enrollment, the mean age of the older sibling was 13.1 years and the younger sibling was 10.7 years, with an average age difference of 2.4 years. Full siblings account 
for $62 \%$ of the sample, with half siblings accounting for the second largest sibling group type at $37 \%$. The majority $(73 \%)$ of the sample lived together at study enrollment, with $57 \%$ of older siblings and $55 \%$ of younger siblings living in a non-relative foster care placement. Siblings were in foster care for an average of 2 years. The gender distribution of siblings was nearly even, with females accounting for $51 \%$ of older siblings and $49 \%$ of younger siblings respectively. With respect to race of older/younger sibling groups, $40 \%$ of older and younger siblings identified as Caucasian, $29 \%$ of older and $28 \%$ of younger siblings identified as multiracial, $13 \%$ of older and $12 \%$ of younger siblings identified as African-American, 5\% of older and younger siblings identified as Native American, $1 \%$ of older and younger siblings identified as Asian/Pacific Islander, and $12 \%$ of older and $14 \%$ of younger siblings identified as "other." With respect to ethnicity, $26 \%$ of older and younger siblings identified as Hispanic. Table1 provides a summary of the demographic characteristics of study participants and sibling dyads.

\section{Dependent Variables}

\section{Placement Change}

In this study, placement moves for reasons other than visitation, respite care, or achieving an established permanency goal and subsequent exit from care was considered a placement change. This approach is consistent with prior research on placement moves (Akin, 2011; Albert \& king, 2008; Barth, et al., 2007; Chamberlain, et al., 2006; Degarmo, Chamberlain, Leve, \& Price, 2009; Fisher, Stoolmiller, Mannering, \& Takahashi, 2011; Linares, Li, Shrout, Brody, \& Pettit, 2007). Placement change was represented as a binary variable. 


\section{Independent Variables}

\section{Positive Home Integration}

Positive home integration was measured using an 11 item indicator $(\mathrm{n}=312, \propto=$ .87), extracted from the Essential Youth Experiences instrument. Each item is rated on a 10-point scale, with a rating of 1 representing never/not at all, a rating of 5 representing sometimes, and a rating of 10 representing always/a lot. Four of the 11 items ask the child to rate the family overall, while 7 items are specific to their primary caregiver. The particular items are:

To what extent do you feel included in your (foster) family?

To what extent do you feel you are treated with kindness in your (foster) home?

To what extent do you feel you are treated with respect in your (foster) home?

To what extent do you feel that you are involved in decision making in your (foster) home?

How often do you see your (foster) parent?

How often do you talk to your (foster) parent?

On a scale of 1-10, how good is your relationship with your (foster) parent?

How well do you get along with your (foster) parent?

On a scale of 1-10, how well does your (foster) parent listen to you?

How well does your (foster) parent respond to your needs?

When you have a problem, how well does your (foster) parent respond to you?

\section{Sibling Relationship Quality}


Sibling relationship quality was measured using the Sibling Relationship Questionnaire (Furman \& Burmhester, 1985). This standardized scale is a 72 item instrument $(\mathrm{n}=327, \propto=.97)$ which asks the child to rate multiple dimensions of the sibling relationship, on a 5 point Likert scale, with a rating of 1 representing strong disagreement with an item statement and a rating of 5 representing a strong agreement with an item statement. Items in this scale ask the child about communication, emotional expression, and perceptions of the sibling's view of the respondent child. Total scores for the Sibling Relationship Questionnaire were used in this analysis.

\section{Impact of Child Behavior}

The Impact of Child Behavior (ICB) is a six item scale $(\mathrm{n}=312, \propto=.85)$ derived from the Parent-Child Health Questionnaire. This scale asks the primary caregiver of the target child to rate the degree to which a child's behavior has impacted their lives. Each item asks the caregiver to rate the frequency of a specific impact, from $1=$ never, $2=$ sometimes, $3=$ often, to $4=$ always. The specific items in the construct are: How frequently has this child's behavior made it difficult for you, or prevented you from taking him/her out in public or going shopping or visiting?

How frequently have you quarreled with you partner, ex-partner, or the child's other parent about this child's behavior?

How frequently has this child's behavior caused you to be anxious or worried about his/her chance for doing well in the future?

How frequently has this child's behavior prevented you from having friends, relatives, or neighbors to your home? 
How frequently has this child's behavior prevented his/her brothers or sisters from having friends, relatives, or neighbors to your home?

How frequently have neighbors, relatives, or friends expressed concern to you about this child's behavior?

\section{Control Variables}

\section{Sibling Living Situation}

A measure of sibling living situation was established at baseline. Sibling living situation was recorded as a binary measure, with 0 identifying the siblings as living together and 1 identifying the siblings as living apart.

\section{Kinship Status}

A measure of the child's relationship to the caregiver was established at baseline. After examining and reporting the multiple forms of child-caregiver relationship, caregiver kinship status was coded with 0 representing a non-relative caregiver and 1 representing a kinship caregiver.

\section{Living Composition}

A living composition variable was constructed to examine the various combinations of potential sibling and kinship care placement types. For this dissertation youth who resided separately from their siblings was coded as the referrent category. Siblings who lived together in non-relative homes was coded as 2. Youth who lived apart from their siblings in a kinship placement was coded as 3, and siblings who resided together in kinship care was coded as 4.

\section{Number of Placements Prior to Study Entry}


The number of placements a youth experienced between their initial foster care stay and prior to study enrollment was recorded in the ORKIDS database and recorded as a count variable.

\section{Treatment Condition}

Siblings enrolled in this study were yoked and randomly assigned to either the sibling intervention or control condition. The treatment condition was represented as a binary variable, with 0 representing the control condition and 1 representing the treatment condition.

\section{Analytical Assumptions}

To investigate how family dynamics and home setting characteristics predict placement disruption over time, a modeling strategy was developed that attended to a number of statistical assumptions. First, the nature of relational data is non-independent, meaning that any measure of a behavior or attitude in a home setting is in part a function of other household members. Second, the occurrence of placement disruptions has been shown in the literature to follow a non-normal distribution, with a small sub-sample of the study populations to account for the majority of placement disruption occurrences (James, Landsverk, \& Slyman, 2004). Third, the collection of longitudinal data is hampered by study attrition and missing data. This dissertation addressed these methodological concerns in the analytical work plan by utilizing the cluster command in Stata to calculate robust standard errors in the logistic regression modeling procedures. Robust standard errors account for issues of conditional dependence within the model (Zorn, 2006). Standard errors were calculated by clustering the data according to sibling 
living situation in the conceptual model and clustered according to living composition in the moderation model.

\section{Preliminary Analysis of Model Variables}

Prior to investigating the conceptual model, a preliminary analysis of the data was conducted. Each variable within the conceptual model was examined in its original form. Mean, standard deviation, and range was computed for placement change, positive home integration, sibling relationship quality, impact of child behavior, and number of placements prior to study entry. Frequency distributions for treatment condition, living situation, and caregiver relationship status were also calculated. Following preliminary examination of study variables, caregiver relationship status was collapsed into a binary non-relative/kinship variable. Mean scores were computed for the positive home integration and impact of child behavior constructs. Frequencies for the binary caregiver status, binary placement change, and living composition variables were also examined.

With respect to placement disruption, the total number of changes a youth experienced during their enrollment in the study was examined using two data sources. These data sources include the SIBS-FC study, as well as placement changes recorded in the ORKIDS database. Four total forms of the binary placement change variable were constructed for reasons of sensitivity analysis. The SIBS-FC placement change variable was collapsed so that no placement change $=0$ as well as one placement change $=0$. The ORKIDS placement was also collapsed so that no placement change $=0$ and one placement change $=0$.

\section{Bivariate Correlation Matrix for Model Variables}


Following preliminary analysis, a bivariate correlation matrix was constructed. This illuminated the strength and direction of relationships amongst the model variables and determined the amount of missing data present for each variable in the data set.

\section{Chi-Square/Crosstab Analysis}

A chi-square analysis was used to examine the differences amongst observed frequencies of discrete variables (Tabachnick \& Fidell, pp. 58-59). Using the binary form of the placement disruption variable, a chi-square analysis was conducted to determine if siblings who live together differ from those who live apart on the occurrence of placement change. This test was also employed to examine if youth who reside in nonrelative foster care differ from those who live in kinship care on the occurrence of placement change. In addition, cross-tabulations were computed to determine the characteristics and number of youth who reside in the four living composition categories, and a chi-square analysis was conducted to determine if youth gender (male, female) and youth race (white, non-white) differ in the occurrence of placement change.

\section{Logistic Regression Model Predicting Placement Change}

To investigate the individual and combined effects of the conceptual model on the likelihood of placement change, a logistic regression model was tested using the cluster command in Stata and clustering according to sibling living situation. In this model the positive home integration, sibling relationship quality, impact of child behavior, sibling living situation, kinship caregiver status, number of placements prior to study entry, and treatment condition were used to predict the occurrence of placement change using the SIBS-FC dependent variable. 


\section{Sensitivity Analysis of the Logistic Regression Model}

Not all placement changes are suggestive of placement disruption. At times, youth in care may move from a less stable environment, such as an emergency placement or illfitting non-relative home, and into a more stable placement such as a pre-adoptive or kinship home. Youth in these situations may experience one change, but then experience no further movements through the duration of the study. In such situations, these youth may be inappropriately categorized as experiencing a disruption when they are in fact experiencing increased stability.

To address this, a sensitivity analysis was conducted using two forms of the dependent variable. The first form of the dependent variable represented any placement change experienced by a youth as a placement move. Youth who move homes at any time during the course of study enrollment $(x>0)$ were categorized as experiencing a placement change. In the second form of the dependent variable, youth who experienced more than one placement change $(x>1)$ were categorized as experiencing a move. These two forms of the logistic regression model were compared to determine if the conceptual model better predicts placement change for youth who experience two or more changes versus those who experience any placement change during the course of study enrollment.

In addition to utilizing two binary count variables, the conceptual model was tested using both SIBS and ORKIDS placement change data. The SIBS data set captures all placement changes known to the study investigators, whereas the ORKIDS database captures all changes known to the Department of Human Services. While it was expected 
that all placement changes represented in ORKIDS are also known to the parent study, a comparative analysis of the conceptual model using both forms of the dependent variable was conducted to help inform the results found in the model that was tested in this dissertation.

\section{Examination of Kin, Apart Youth Characteristics}

Due to the low sample size for the Kin, Apart living composition category $(n=15)$, an exploration of sibling dyad characteristics was conducted to help understand the potential conditions under which these siblings were separated from one another while at least one member of the dyad was in a kinship home. To conduct this exploration each youth in the Kin, Apart dyad was identified and a review of case notes written by the study assessors was conducted.

\section{Analysis of Variance for Model Variables by Living Composition}

To examine differences for positive home integration, sibling relationship quality, impact of child behavior, number of placements prior to study entry, and total number of placement changes occurring during study enrollment across the four categories of living composition, a one-way analysis of variance was conducted for each variable in the conceptual model. For living composition, youth were grouped according to four possible categories: living apart in non-relative care, living together in non-relative care, living apart in kinship care, and living together in kinship care. Analysis of variance was tested for living composition and positive home integration, sibling relationship quality, impact of child behavior, number of placements experienced prior to study entry, and number of placements experienced during study enrollment. To test for differences in youth 
characteristics according to living composition, an analysis of variance was also conducted for living composition and youth age, and a chi-square analysis was conducted for living composition and youth gender (male, female) and youth race (white, nonwhite).

\section{Test of Moderation Effects according to Living Composition}

The second set of logistic regression analysis was conducted by examining the moderating effects of living composition on the likelihood of placement change. Using the categorical living composition predictor, living composition was entered into a logistic regression model which included all independent predictors and control variables specified in the original conceptual model.

\section{Post-Hoc Analysis of Living Composition Categories}

To examine differences in odds of placement change for the living composition categories tested in the logistic regression moderation model, a post-estimation computation of the coefficients tested for differences in odds of placement change according to the different living composition categories. 


\section{CHAPTER 4-RESULTS}

\section{Introduction}

This chapter reports findings from the analytical plan detailed in chapter three. The specific research questions this study sought to answer were (1) What are the individual and combined effects of positive home integration, sibling relationship quality, impact of child behavior, sibling living situation, kinship caregiver status, number of prior placements, and treatment condition on the likelihood of placement change over the 18-month course of study enrollment?, and (2) What are the moderating effects of living composition, i.e.; four possible combinations of sibling living situation and kinship caregiver status, on the likelihood of placement change?

This chapter begins by providing a summary of the individual items and subscales embedded within the conceptual model. This preliminary analysis details the frequencies for treatment condition, sibling living situation, and kinship caregiver status. Then, descriptive statistics are provided for the positive home integration, sibling relationship quality, and impact of child behavior individual items and subsequent subscales developed from these items. Descriptive statistics are also provided for the number of placement changes experienced by the youth prior to study entry.

After summarizing the variables within the conceptual model, a bivariate correlation matrix was constructed to determine the strength and direction of model variables. Following this, a chi-square analysis was calculated for the binary measure of kinship care and placement change, as well as sibling living situation and placement change. Then, a cross-tabulation was constructed from the binary forms of kinship care 
and sibling living situation, to identify the frequencies for each potential living composition arrangement experienced by the youth.

Upon completion of the above mentioned analysis, a logistic regression model was tested utilizing all variables detailed in the conceptual model. This logistic regression analysis utilized robust standard errors clustered according to sibling living situation, to account for heteroscedasticity of residuals in the conceptual model. Following the test of the conceptual model, a sensitivity analysis was conducted. This sensitivity analysis involved testing three additional forms of the model in which (1) the binary measure of SIBS-FC placement change dependent variable was recoded to allow 1 placement change to equal no change, (2) utilization of the ORKIDS version of the dependent variable to replace the SIBS-FC measure of placement change, and (3) the binary measure of the ORKIDS placement change dependent variable was recoded to allow 1 placement change to equal no change.

Following the test of the conceptual model and subsequent sensitivity analysis, an in depth review of the characteristics of youth who lived in kinship care and apart from their siblings was conducted by examining study records, to determine the reasons why some siblings may reside in kinship care but not with their brother or sister. A table was created to identify the relationship of the older and younger sibling to their identified caregiver, the relationship status of the siblings (i.e.; full, half, step), along with any case notes from the study record which may explain why these siblings did not live together.

After completion of the case review and analysis of the living composition table, an analysis of variance was conducted for each living composition category. In each 
ANOVA, living composition was tested against positive home integration, sibling relationship quality, impact of child behavior, number of placements experienced prior to study entry, and number of placements experienced during study enrollment. In addition to an analysis of variance for living composition and model variables, an ANOVA was also calculated for living composition and youth age. A chi-square analysis/crosstabulation was also calculated for living composition and youth gender (male, female) and youth race (white, non-white).

After completing a comprehensive analysis of the living composition variable, a logistic regression moderation model was constructed using the SIBS-FC dependent variable and the categorical living composition supplanting the kinship caregiver and sibling living situation variables. All family dynamic conceptual model predictors were included in this analysis along with youth age. In this test of moderation, robust standard errors were calculated to account for heteroscedasticity of residuals in the conceptual model by clustering according to living composition.

\section{Preliminary Analysis of Model Variables}

\section{Treatment Condition}

A total of 328 youth nested in 164 dyads were represented in the SIBS-FC data set. Within this data set, $48.8 \%(\mathrm{n}=160)$ of the sample were randomly assigned to the treatment condition with the remaining $51.2 \%(\mathrm{n}=168)$ assigned to the control condition. Table 2 details the distribution of treatment condition for study participants.

\section{Sibling Living Situation and Kinship Caregiver Status}


The majority of study youth $(72 \%, \mathrm{n}=236)$ lived with their sibling at the time of baseline assessment. With respect to placement with kin or non-kin, youth reported living with a non-relative foster parent $(57 \%, \mathrm{n}=187)$, with their biological aunt, $(12.5 \%$, $\mathrm{n}=41)$, grandmother $(11 \%, \mathrm{n}=36)$, mother $(10.4 \%, \mathrm{n}=34)$, uncle $(2.4 \%, \mathrm{n}=8)$, father $(.9 \%$, $\mathrm{n}=3)$, sister $(.6 \%, \mathrm{n}=2)$, other biological caregiver $(1.2 \%, \mathrm{n}=4)$, or other non-relative caregiver $(3.7 \%, \mathrm{n}=12)$. When caregiver relationship status was collapsed into binary categories, youth resided in non-relative care $(60.7 \%, \mathrm{n}=199)$ and in kinship care $(39.3 \%$, $\mathrm{n}=129$ ). Table 3 details the living situation for siblings and table 4 details the relative caregiver status for study youth at the time of baseline measurement.

\section{Positive Home Integration}

Youth reported positive ratings for individual items contained in the Positive Home Integration construct $(\mathrm{n}=312, \propto=.87, \bar{x}=8.74, s d=1.23)$. Scores were negatively skewed with respondents reporting high levels of integration for the 11 item scale $(\bar{x}=8.74, s d=1.23)$. Highly rated items included frequency of discussions with the primary foster parent $(\bar{x}=9.81, s d=.74)$, and responses to questions regarding the frequency of contact with the primary foster parent $(\bar{x}=9.35, s d=1.93)$. Respondents provided the lowest rating for their involvement in decision making $(\bar{x}=6.96, s d=$ 2.89). Table 5 provides a summary of ratings for the positive home integration construct.

\section{Sibling Relationship Quality}

Youth reported positive ratings for the nine subscales embedded within the Sibling Relationship Questionnaire $(\mathrm{n}=327, \propto=.97, \bar{x}=3.65, s d=.70)$. Scores were slightly negatively skewed with respondents reporting moderate to strong agreement on 
all subscales and total sibling relationship quality $(\bar{x}=3.65, s d=.70)$. Respondents provided highest ratings for the responsive to sibling subscale $(\bar{x}=3.84, s d=.84)$, receiving positive affect subscale $(\bar{x}=3.82, s d=.94)$, expressing positive affect subscale $(\bar{x}=3.79, s d=.81)$. Lowest ratings of agreement were noted for expressing negative affect $(\bar{x}=3.27, s d=.71)$ and receiving negative affect $(\bar{x}=3.43, s d=.72)$ subscales. Table 6 provides a summary of ratings for subscales and total scores within the Sibling Relationship Quality questionnaire.

\section{Impact of Child Behavior}

Caregivers reported low overall ratings for individual items within the Impact of Child Behavior Subscale $(\mathrm{n}=312, \propto=.85, \bar{x}=1.87, s d=.73)$ Scores ranged from 1.31 to 2.09 and were positively skewed. Caregivers reported higher frequencies for impact on a caregivers anxiety and concern for the child's ability to do well in the future ( $\bar{x}=2.09, s d=1.04$ ) and lower frequencies for impact on the ability of the caregiver to have friends, relatives, or neighbors over to the home $(\bar{x}=1.31, s d=.64)$. For the six item scale average, caregivers reported low overall impact of child behavior on the caregiver and family functioning $(\bar{x}=1.87, s d=.73)$. Table 7 provides a summary of ratings for the impact of child behavior construct.

\section{Number of Prior Placements}

Data related to total number of placements prior to study entry was collected from the ORKIDS database. Youth varied in the number of placements experienced prior to enrollment in the SIBS-FC study $(\mathrm{n}=217, \bar{x}=4.08, s d=3.19$, range $=0-21)$. Figure 5 
provides a histogram detailing the distribution of placements experienced by youth prior to study enrollment.

\section{Number of Placement Changes}

Placement change information collected from the SIBS-FC staff found that youth experienced few placements between baseline and term assessment $(\bar{x}=.30, s d=.54$, range $=0-2$ ). Some youth experienced placement changes between baseline and followalong $1(\bar{x}=.50, s d=0.82$, range $=0-4)$ and between baseline and follow-along $2(\bar{x}=$ $.70, s d=1.12$, range $=0-7)$. Between baseline and follow-along 2 assessment, placement change data were available for 239 youth. For those youth for whom data was available, the distribution of placement change we zero $(59.2 \%, \mathrm{n}=142)$, one change $(23.8 \%, \mathrm{n}=57)$, two changes $(10.8 \%, \mathrm{n}=26)$, three changes $(3.8 \%, \mathrm{n}=9)$, four changes $(.4 \%, \mathrm{n}=1)$, five changes, $(1.3 \%, \mathrm{n}=3)$, six changes $(.4 \%, \mathrm{n}=1)$ and seven changes $(.4 \%, \mathrm{n}=1)$. Figure 5 and table 8 detail the number of placement changes experienced by the youth prior to their enrollment in the study.

Information collected from the ORKIDS database suggest a broader range of placements experienced by the youth over the course of study enrollment. Prior to study orientation youth experienced about 4 placements on average $(\bar{x}=4.08, s d=3.19$, range $=0-21)$. Placements remained stable for these youth between study orientation and baseline assessment $(\bar{x}=.04, s d=.30$, range $=0-4)$. Between baseline and term assessments the occurrence placement change remained low for the overall sample ( $\bar{x}=$ $.39, s d=.81$, range $=0-7)$ and continued for baseline to follow-along $1(\bar{x}=.57, s d=$ .93 , range $=0-5)$ and baseline to follow-along $2(\bar{x}=.90, s d=1.59$, range $=0-11)$.Figures 
6 and 7 and table 9 detail the number of placement changes experienced by the youth during the course of study enrollment.

For the test of the dissertation's conceptual model, placement data from the SIBSFC study was collapsed into a binary outcome variable. Using the standard $0=0$ coding format, a minority of youth $(43.3 \%, \mathrm{n}=142)$ experienced no placement changes during the course of study participation. When utilizing a modified $1=0$ coding format, a majority of youth $(60.7 \%, n=199)$ of the sample experienced no placement changes. Figure 8 provides a histogram of placement changes when coded as $0=0$, and figure 9 provides a histogram of placement changes coded as $1=0$. Table 10 summarizes the recoded binary placement change variable.

\section{Bivariate Correlation Matrix for Model Variables}

Prior to running multivariate models, a bivariate correlation matrix was constructed to examine relationships among study variables. A number of statistically significant relationships were noted and detailed in table 11 . With respect to the positive home integration measure, relationships were noted for sibling relationship quality $(\mathrm{r}=$ $.18, \mathrm{p}<.01)$, living with a kinship caregiver $(\mathrm{r}=.11, \mathrm{p}<.05)$, and number of placements prior to study entry $(\mathrm{r}=-.16, \mathrm{p}<.05)$. Higher levels of sibling relationship quality was associated with living apart from one's sibling $(\mathrm{r}=.20, \mathrm{p}<.01)$. Caregiver-reported impact of child behavior was associated with living apart from one's sibling $(r=.11$, $\mathrm{p}=.05$ ) and the number of placements occurring during the course of study participation (SIBS-FC $\mathrm{r}=.16, \mathrm{p}<.05$, ORKIDS $\mathrm{r}=.19, \mathrm{p}<.01)$. Kinship care was negatively associated with living apart from one's sibling $(r=-.29, \mathrm{p}<.01)$, number of placement 
changes occurring during the course of study participation (SIBS-FC $r=-.25, p<.01$, ORKIDS $\mathrm{r}=-.19, \mathrm{p}<.01)$, and number of placement changes prior to study entry $(\mathrm{r}=-$ $.23, \mathrm{p}<.01)$. Living apart from ones sibling was associated with number of placement changes occurring during study participation (SIBS-FC $r=.24, \mathrm{p}<.01$, ORKIDS $\mathrm{r}=.24$, $\mathrm{p}<.01)$ and number of placement changes occurring prior to study entry $(\mathrm{r}=.41, \mathrm{p}<.01)$. Treatment condition was not associated with any variables in the correlation matrix.

\section{Chi-Square/Cross Tab Analysis}

To investigate differences in the odds of placement change for study youth, a series of chi-square tests were performed.

\section{Chi-Square Analysis of Kinship Care and Placement Change}

To investigate if children in kinship care differed from children in non-relative care on the occurrence of placement change during the course of study participation (SIBS-FC), a chi-square test of independence was performed. Children in non-relative $(66.8 \%, \mathrm{n}=133)$ care were more likely to experience a placement change than were children in kinship care $(41.1 \%, \mathrm{n}=53)$. Differences in the odds of placement change according to kinship caregiver status were statistically significant $\left(X^{2}=21.136, d f=1\right.$, $\mathrm{p}<.01)$. Table 12 provides a summary of the findings from this chi-square analysis.

\section{Chi-Square Analysis of Sibling Living Situation and Placement Change}

To investigate if children living with their siblings differed from children who lived apart from their siblings on the odds of placement change during the course of study participation (SIBS-FC), a chi-square test of independence was performed. Children living together with their sibling $(50.8 \%, \mathrm{n}=120)$ were less likely to experience a 
placement disruption than children who lived apart from their sibling $(71.7 \%, \mathrm{n}=66)$.

These differences in the occurence of placement change according to sibling living situation were statistically significant $\left(X^{2}=11.77, d f=1, p=.01\right)$. Findings from this analysis are detailed in table 13.

\section{Chi-Square Analysis of Youth Gender and Placement Change}

To investigate if males differed from females in the occurrence of placement change during study participation, a chi-square test of independence was performed. For those youth who experienced a placement change, males $(53.7 \%, \mathrm{n}=88)$ did not differ from females $(59.8 \%, \mathrm{n}=98)$ on the occurrence of placement change $\left(\mathrm{X}^{2}=1.24, \mathrm{df}=1\right.$, $\mathrm{p}=.27$ ) during study enrollment.

\section{Chi-Square Analysis of Youth Race and Placement Change}

To investigate if youth differed on the occurrence of placement change according to youth rare, a chi-square test of independence was performance. For youth who experienced a placement change, non-white youth $(45.2 \%, \mathrm{n}=84)$ did not differ substantially from white youth $(54.8 \%, \mathrm{n}=102)$ on the occurrence of placement change. However, a trend level effect for youth race in the chi-square analysis $\left(X^{2}=3.07, \mathrm{df}=1\right.$, $\mathrm{p}=.08$ ) suggest white youth may experience marginally higher rates of placement change overall.

\section{Cross Tab Analysis of Living Composition}

A cross-tab analysis of living composition was conducted to determine the number of children living in kinship care with their siblings versus those who lived apart, as well as to determine the number of children in non-relative care who lived with their 
sibling versus those who lived apart. Children in non-relative care lived with their sibling at higher rates $(61.3 \%, \mathrm{n}=122)$ than those who lived apart from their sibling $(38.7 \%$, $\mathrm{n}=77$ ). Children who lived in kinship care also lived with their sibling at higher rates $(88.4 \%, \mathrm{n}=115)$ than those who lived apart from their sibling $(11.6 \%, \mathrm{n}=15)$. Table 14 provides a summary of the distribution of youth kinship and sibling living situation according to the living composition variable.

\section{Logistic Regression Model Predicting Placement Change}

A logistic regression model was constructed to identify the influence of positive home integration, sibling relationship quality, impact of child behavior, kinship caregiver status, sibling living situation, number of placements prior to study entry, and treatment condition on the odds of experiencing a placement change over the 18-month period of study enrollment. The dependent variable in this model was the presence of a placement change using the SIBS-FC data set. The logistic regression model was run in Stata 12.1 and utilized cluster command to estimate robust standard errors to account for potential heteroscedasticity of error variance. The standard errors were clustered according to sibling living situation.

A total of 246 youth were represented in the logistic regression analysis, designed to assess the impact of family dynamics (positive home integration, sibling relationship quality, impact of child behavior), home setting characteristics (kinship caregiver status, sibling living situation) placement history (number of prior placements), and treatment condition on the odds of placement change over the course of study enrollment. In this analysis, living in a kinship home $(\operatorname{Exp}(\mathrm{B})=.42, \mathrm{RSE}=.13, \mathrm{p}<.01, \mathrm{CI}=.23-.78)$, was 
significant, suggesting youth in a kinship home were $72.4 \%$ less likely to experience a placement change that youth in a non-relative home. Sibling living situation was also significant $(\operatorname{Exp}(\mathrm{B})=1.71, \mathrm{RSE}=.21, \mathrm{p}<.01, \mathrm{CI}=1.34-2.16)$, suggesting youth who live apart are $71 \%$ more likely to experience a placement change than youth who lived with their sibling. Table 15 details findings from the logistic regression analysis.

\section{Sensitivity Analysis of Logistic Regression Model Predicting Placement Change}

A post-hoc sensitivity analysis was conducted to determine if the logistic regression model best predicted odds of placement change for this sample of youth in care. The sensitivity analysis was conducted using two approaches. First, placement change using the SIBS-FC data was recoded so that no placement changes were represented $(0=0)$ and in the second form, one placement change was coded as no change $(1=0)$. This approach was taken to account for the possibility that youth who were enrolled in the study may have experienced one change that was positive, such as a move from non-relative care to kinship care, or from out-of-home care to reunification.

Findings from the sensitivity analysis using the recoded SIBS-FC placement change variable found that kinship care was no longer a statistically significant predictor of change, thus rendering the entire model statistically insignificant. Using the SIBS-FC data, the $0=0$ form of the dependent variable best fit the data.

In addition to examination of the recoded SIBS-FC, a logistic regression model was tested using the placement change data recorded in the ORKIDS database. Kinship care was associated with a decreased likelihood of placement change $(\mathrm{B}=-.82$, $\operatorname{Exp}(B)=.44, \mathrm{p}<.01, \mathrm{CI}=.25-.77)$. No additional model predictors approached significance 
when substituting the SIBS-FC placement change variable for the ORKIDS variable. Similar to the recoding approach used to conduct a sensitivity analysis with the SIBS-FC data, recoding the ORKIDS placement change variable to allow for one move before registering a change did not improve the model and kinship care was no longer statistically significant.

Results of the sensitivity analysis suggested that utilizing the SIBS-FC data and representing placement change as any occurrence of move $(0=0)$ during study enrollment is the most appropriate form of the model. Differences between ORKIDS and SIBS-FC models were insignificant. With respect to statistically significant predictors, both SIBSFC and ORKIDS found kinship care to impact the odds of a placement change, with the strength of odds being higher for Kinship care in the SIBS-FC data set $(\operatorname{Exp}(B)=.42$, $\mathrm{p}<.01, \mathrm{CI}=-1.31-1.42)$.

\section{Examination of Kin, Apart Youth Characteristics}

Data were available for 14 of the 15 youth dyads represented in the Kin, Apart living composition category. Half siblings represented the majority dyads in this category $(57.1 \%, \mathrm{n}=8)$, with full $(37.5 \%, \mathrm{n}=5)$ and step $(7.1 \%, \mathrm{n}=1)$ representing the remaining relational compositions of these sibling youth dyads. With respect to the different variations of dyadic living arrangements available, 4 youth (28.6\%) lived apart from their sibling but both resided in a kinship foster home, for 3 youth (21.4\%) the older sibling was in kinship care and the younger sibling was in non-relative care, for 5 youth (35.7\%) the older sibling was in non-relative care and the younger sibling was in kinship care, and for 2 youth (14.3\%) the older sibling was in kinship care and the younger sibling was in a 
residential treatment facility or group home living arrangement. Little information beyond the dyadic relationship and type of placement was available for these youth, however in one instance full siblings were separated because a younger sibling had special needs, in another instance full siblings were separated because a mother was experiencing housing instability that required the younger sibling to enter into care. With respect to half siblings, a younger sibling experienced multiple psychiatric emergencies requiring residential treatment and in two instances a younger sibling did not enter into child welfare custody. In the situations in which two youth resided separately in kinship care, paternal or maternal relationship status was unable to be determined. Table 16 summarizes the examination of kin, apart youth characteristics.

\section{Analysis of Variance for Model Variables by Living Composition}

To examine differences for positive home integration, sibling relationship quality, impact of child behavior, number of placements prior to study entry, and total number of placement changes occurring during study enrollment across the four categories of living composition, a one-way analysis of variance was conducted for each variable in the conceptual model. For living composition, youth were grouped according to four possible categories: living apart in non-relative care, living together in non-relative care, living apart in kinship care, and living together in kinship care.

\section{Analysis of Variance for Positive Home Integration by Living Composition}

A one-way analysis of variance was conducted to investigate how youth levels of positive home integration varied across the four categories of living composition. A test of homogeneity of variance for positive home integration across the four forms of living 
composition found this assumption was not violated $(\mathrm{W}=3.367, \mathrm{dfl}=3, \mathrm{df} 2=308, \mathrm{p}=.019)$. Using Tukey's method, a post-hoc comparison of positive home integration across the four forms of living composition found no statistically significant differences for these groups, however the ANOVA $[\mathrm{F}(3,308)=2.19, \mathrm{p}=.09]$ trended toward significance.

\section{Analysis of Variance for Sibling Relationship Quality by Living Composition}

To examine differences in youth reported sibling relationship quality according to living composition, a one-way analysis of variance was conducted. A test of homogeneity of variance for sibling relationship quality across the four forms of living composition found this assumption was not violated $(\mathrm{W}=.275, \mathrm{dfl}=3, \mathrm{df} 2=323, \mathrm{p}=.844)$. Using Tukey's method, a post-hoc comparison of sibling relationship quality by living composition found mean differences for non-relative/apart and kin/together categories $(\mathrm{qs}=.27)$, non-relative/together and kin/apart $(\mathrm{qs}=.55)$, The ANOVA $[\mathrm{F}(3,323)=5.27$, $\mathrm{p}<.01$ ) found statistically significant differences between these groups. A summary of findings from this analysis of variance can be found in table 17 and figure 10 .

To calculate an effect size for sibling relationship quality according to living composition, the sum of squares between groups was divided by the total sum of squares. A small to moderate effect size $\left(\mathrm{n}^{2}=.05\right)$ for sibling relationship quality according to living composition was noted.

\section{Analysis of Variance for Impact of Child Behavior by Living Composition}

To examine differences in caregiver reported impact of child behavior according to living composition, a one-way analysis of variance was conducted. A test of homogeneity of variance for impact of child behavior according to living composition 
found this assumption was not violated $(\mathrm{W}=1.975, \mathrm{dfl}=3, \mathrm{df} 2=308, \mathrm{p}=.118)$. The ANOVA $[F(3,308)=1.61, p=.186]$ found no statistically differences between these groups.

\section{Analysis of Variance for Number of Placements Prior to Study Entry by Living Composition}

A one-way analysis of variance was conducted to examine differences in the number of placements a youth experienced prior to study entry, according to the various forms of living composition. A test of homogeneity of variance suggested that this assumption was violated $(\mathrm{W}=6.675, \mathrm{dfl}=3, \mathrm{df} 2=267, \mathrm{p}=.00)$. The $\operatorname{ANOVA}[\mathrm{F}(3,267)=$ $18.44, \mathrm{p}<.01]$ finding statistically significant differences between these groups. Using Tukey's method, a post-hoc analysis of mean differences for number of placements prior to study entry found differences for non-relative/apart, non-relative/together (qs=2.79), as well as kin/together and non-relative/apart ( $\mathrm{qs}=3.36)$. A summary of findings from this analysis of variance can be found in table 18 and figure 11.

To calculate an effect size for number of placements prior to study entry according to living composition, the sum of squares between groups was divided by the total sum of squares. A large effect size $\left(n^{2}=.17\right)$ for was noted for number of placements prior to study entry according to living composition.

\section{Analysis of Variance for Number of Placement Changes During Study Enrollment (SIBS-FC) by Living Composition}

To examine differences in the number of placement changes experienced by a youth during study enrollment, a one-way analysis of variance was conducted. A test of 
homogeneity of variance for number of placement changes experienced during study enrollment according to living composition found this assumption was violated $(\mathrm{W}=5.496, \mathrm{df} 1=3, \mathrm{df} 2=235, \mathrm{p}=.001)$. The ANOVA $[\mathrm{F}(3,236)=8.02, \mathrm{p}<.01)$ finding statistically significant differences between these groups. Using Tukey's method, a posthoc analysis of mean differences for placement changes experienced during study enrollment found statistically significant differences between non-relative/apart and non-

relative/together (qs=.54) and non-relative/apart and kin/together (qs=.88). A summary of findings from this analysis of variance can be found in table 19 and figure 12 .

To calculate an effect size for number of placements experienced during study enrollment according to living composition, the sum of squares between groups was divided by the total sum of squares. A medium to high effect size $\left(n^{2}=.09\right)$ was noted.

\section{Analysis of Variance and Cross-Tabulation for Youth Characteristics by Living Composition}

To examine differences in youth characteristics according to living composition, a one-way analysis of variance was also constructed for living composition and the age. A cross-tabulation was also constructed to examine youth differences in living composition by youth race and gender

\section{Analysis of Variance for Youth Age by Living Composition}

To examine differences in youth age according to living composition, a one-way analysis of variance was conducted. A test of homogeneity of variance for age of youth found this assumption was violated $(\mathrm{W}=5.496, \mathrm{df} 1=3, \mathrm{df} 2=235, \mathrm{p}=.001$ ). The ANOVA $[F(3,324)=3.13, p<.05)$ finding statistically significant differences between these 
groups. Using Tukey's method, a post-hoc analysis of mean differences for placement changes experienced during study enrollment found differences in age for youth in nonrelative care/apart and non-relative care/together ( $\mathrm{qs}=.76)$, and non-relative care/apart and kin/together (qs=.83). To calculate an effect size for youth age according to living composition, the sum of squares between groups was divided by the total sum of squares. A small effect size $\left(\mathrm{n}^{2}=.03\right)$ was noted. A summary of the analysis of variance for youth age according to living composition can be found in table 20 and figure 13 .

\section{Chi-Square Analysis for Youth Gender by Living Composition}

To examine group differences in youth gender by living composition, a chi-square test of independence was calculated. Findings suggest that the odds of being female [nonrelative/apart $(22 \%, \mathrm{n}=36)$, non-relative-together $(37.8 \%, \mathrm{n}=62)$, kin/apart $(4.3 \%, \mathrm{n}=7)$, kin/together $(36 \%, n=59)$ ] vs. male [non-relative/apart $(25 \%, n=41)$, non-relative/together (36.6\%, $\mathrm{n}=60)$, kin/apart $(4.9 \%, \mathrm{n}=8)$, kin/together $(33.5 \%, \mathrm{n}=55)]$ did not differ

significantly across the four living composition categories $\left(X^{2}=.564, \mathrm{df}=3, \mathrm{p}=.905\right)$. These findings are detailed in table 21 .

\section{Chi-Square Analysis for Youth Race by Living Composition}

To examine group differences in youth race by living composition, a chi-square test of independence was calculated. Findings suggest the odds of white youth [nonrelative/apart $(23.5 \%, \mathrm{n}=39)$, non-relative-together $(41 \%, \mathrm{n}=68)$, kin/apart $(4.8 \%, \mathrm{n}=8)$, kin/together $(30.7 \%, \mathrm{n}=51)$ ] do not differ from non-white youth [non-relative/apart $(23.5 \%, \mathrm{n}=38)$, non-relative/together $(33.3 \%, \mathrm{n}=54)$, kin/apart $(4.3 \%, \mathrm{n}=7)$, kin/together 
$(38.9 \%, \mathrm{n}=63)]$ on rates of placement across the four living composition categories $\left(X^{2}=2.901, d f=3, p=.407\right)$. Results of this analysis are detailed in table 22 .

\section{Test of Moderation Effects according to Living Composition}

To test whether the odds of placement disruption different by living composition, a logistic regression moderation model was tested. In this model, the four category living composition variable was substituted for the sibling living situation and kinship caregiver status variables. Because the age youth varied according to living composition, this variable was added to the analysis along with the family dynamic predictors. For living composition, the non-relative, apart living composition category was specified as the referent category. A total of 246 youth were represented in this analysis. This model accounted for approximately $5 \%$ of the variance in placement change (log pseudolikelihood=-1.59.98, Pseudo $\mathrm{R}^{2}=.05$ ). In this model living together with ones sibling in kinship care was most protective against placement change $(\operatorname{Exp}(B)=-.25$, $\mathrm{RSE}=.08, \mathrm{p}<.01, \mathrm{CI}=-.12=-.49$ ). Living together in non-relative care trended toward significant $(\operatorname{Exp}(B)=-.66, \mathrm{RSE}=.15, \mathrm{p}<.06, \mathrm{CI}=-.43-1.02)$. Living apart in kinship care was not protective against the occurrence of placement change.

While living composition did impact the likelihood of placement change for youth living together in kinship care, youth age, positive home integration, and impact of child behavior did not influence the odds of placement change. However, sibling relationship quality trended toward significant $(\operatorname{Exp}(\mathrm{B})=1.04, \mathrm{RSE}=.02, \mathrm{p}=.08, \mathrm{CI}=.1 .00-1.07)$. Table 23 details the findings from the logistic regression moderation model. To test for differences among the living composition categories, a post-hoc analysis was conducted 
using the LINCOMM command in Stata. In this analysis, comparison of the living composition categories were statistically significant for comparison of non-relative, together and kinship care, apart ( $\mathrm{p}<.01)$, non-relative, together and kinship care, together $(\mathrm{p}<.01)$, and kinship care, together and kinship care, apart $(\mathrm{p}<.01)$. 


\section{CHAPTER 5-DISCUSSION}

\section{Introduction}

This study sought to test a conceptual model that would help practitioners and policymakers better understand the role of family dynamics and home setting characteristics in predicting the occurrence of placement change. The hope for this inquiry was to identify practice and policy considerations the child welfare field could utilize to make more informed decisions about substitute care placement and casework practice with families, towards the goal of reducing the occurrence of placement change when children need to be placed into substitute care. The specific research questions this study sought to answer were (1) What are the individual and combined effects of positive home integration, sibling relationship quality, impact of child behavior, sibling living situation, kinship caregiver status, number of prior placements, and treatment condition on the likelihood of placement change over the 18-month course of study enrollment?, and (2) What are the moderating effects of living composition, i.e.; four possible combinations of sibling living situation and kinship caregiver status, on the likelihood of placement change?

This chapter discusses the study findings by first detailing findings from the covariates in the conceptual model. Second, results related to family dynamics, which are the conditions and processes occurring in families that are most amenable to in-home intervention, are described and contextualized in light of current research. Third, findings related to home setting characteristics, which are primarily the domain of early case planning decision making and agency, state, and federal policy are contextualized in light 
of current knowledge. After discussing the major study findings, this chapter discusses study limitations and possibilities for future research, practice, and policy. A summary of major study findings can be found in table 24 . The causal mechanisms within the conceptual model are detailed in figure 14, and the causal mechanisms within the moderation model are detailed in figure 15.

\section{Youth Characteristics}

This study examined youth age, race, and gender in relationship to placement change and family living composition. In this investigation, youth age was found to differ according to family living composition, with older children residing in non-relative care and apart from their siblings. No differences in youth age were present among the three remaining living composition categories, and in preliminary model development age was not independently predictive of placement change so it was excluded from the final conceptual model. Youth who lived apart from their sibling's non-relative care served as the referent category in the living composition moderation model, and this living composition group contained primarily older youth.

Youth race was tested in pre-dissertation models to determine if an independent effect was present for race and odds of placement change. No statistically significant findings were noted in these preliminary models and therefore this variable was not included in the final conceptual model. In chi-square analysis of placement change according to youth race, trend level findings suggest white youth are more likely to experience a placement change than non-white youth, however this effect is marginal. It is unclear why white youth may experience more changes than non-white youth, but 
perhaps this is due in part to differences in rates of placement into kinship care. This study did find that kinship care was predictive of placement stability, however a comparative analysis of characteristics of youth and caregivers in kin and non-relative homes may be indicated in future investigations, to determine if white and non-white children differ in rates of placement into kinship care situations.

Youth gender was tested in pre-dissertation models to determine if this variable independently predicted placement change. No statistically significant findings were noted in early model development, so gender was removed from the final conceptual model. Youth gender was tested in a chi-square analysis of placement change, and no differences were found amongst male and females on the occurrence of placement change during study enrollment. This non-finding may suggest that males and females are more similar than different in their emotional and behavioral presentation in foster care settings. Caregiver's experiences with females and males may be more similar than dissimilar. An additional consideration related to non-findings for gender may relate to common practices of separating pre-teen and teenage boys and girls when making placement decisions, as well as caregiver specialization with youth of one gender or another. Agencies may be more inclined to maintain non-relative foster homes as placement settings for females or males, with the exception of kinship homes who by their nature are not designed to accommodate children outside the family unit.

\section{Control Variables}

\section{Treatment Condition}


This dissertation was drawn from a randomized controlled trial in which sibling dyads were randomized to receive the SIBS-FC intervention or services as usual. The parent study hypothesized that receipt of a sibling relationship enhancement intervention would improve the quality of the sibling relationship for these children (Kothari, et. al, under review). In this secondary analysis, receipt of the SIBS-FC intervention was hypothesized to influence the occurrence of placement change.

Interestingly, in bivariate correlation analysis and subsequent multivariate models, no significant effects were noted for treatment condition. Receipt of the sibling intervention was not associated with any other variables in the conceptual model, and did not specifically impact the likelihood of placement change for youth in this sample.

Non-findings related to treatment condition and placement stability is likely due to the fact that the SIBS-FC intervention was not specifically designed to impact this outcome but rather focused on sibling relationship quality and other indicators of wellbeing (McBeath, et. al., 2014; Kothari, et. al., 2014; Kothari, under review). Over half the sample analyzed for this dissertation did not experience any placement change, and 88 youth were missing from the data set due to missing data. Analyzing only those youth who experienced placement change and excluding those who experienced stable placements could potentially lead to different findings with respect to receipt of the SIBS-FC intervention. An additional consideration for treatment non-findings could relate to treatment fidelity and dosage. The SIBS-FC intervention requires sibling dyads to be together when engaging in skill building and practice activities. If youth were 
experiencing placement changes during the study, it is possible that fidelity to the intervention protocol was compromised.

\section{Placements Prior to Study Entry}

The role of placement history and the number of prior placements a youth has before entering a foster home setting has been the focus of a number of empirical investigations. Prior studies have found that previous foster care placements influence the occurrence of placement change (Oosterman, et. al., 2006) and the length of time a youth spent in the current home was reflective of prior placement experiences - with a higher number of prior placements associated with a shorter length of stay in the current placement (Leathers, 2006). Volatile placement histories were also associated with the presence of behavior problems in the current home setting, leading to an increased the likelihood of placement change in the future (Newton, et al., 2000). This finding suggests a reciprocal relationship between placement change and behavioral disturbance for youth in substitute care.

The majority of youth in this sample experienced few placements prior to study entry. Bivariate correlation analysis suggested a modest negative association between prior placement experiences and living in kinship care, and a modest positive association between number of prior placement and living apart from one's sibling. A modest positive association was also noted for number of prior placements and number of placements experienced during the study. These findings suggests that children who experience placement changes prior to the study may be more likely to live in family living situations that promote placement change, i.e.; living in non-relative care and 
separated from their siblings. While this study does not allow us to investigate the particular characteristics of children who experience multiple placements such as maltreatment history, mental health diagnosis, or disability status, the associations between previous placement experiences, sibling separation, and non-relative placement could potentially be reflective of a child's cognitive, emotional or behavioral needs, thus making them less than ideal candidates for co-placement with their siblings or placement into kinship care. If children who have experienced prior placements were fundamentally different in their maltreatment histories or emotional and behavioral functioning than children who did not experience prior placements, they may require increased monitoring in their interactions with other children, or in need of more professional caregiving services than typically provided in kinship care settings.

Experiencing multiple placements prior to study enrollment was associated with increased number of placements experienced during the course of study enrollment. This is consistent with prior research related to placement history influencing odds of future disruption (Newton, et. al., 2000). In multivariate models, however, number of prior placements was not predictive of placement change.

The associations related to prior placements that were found in this study suggest that history is an important aspect of what is currently going on in a child's life, and has implications for how well they do moving forward. Children carried their prior experiences of placement instability into their study participation, and while this was not predictive of placement change, associations with future moves suggest practitioners 
should give consideration to a child's placement history when developing interventions to promote stability for youth in care.

\section{Family Dynamics}

This study utilized three unique measures to better understand the processes occurring within foster homes, in the hopes of identifying potential levers of change caseworkers and service providers could use when developing intervention strategies with families. The family dynamic measures chosen for this investigation included a child's rating of positive home integration, a child's rating of sibling relationship quality, and a caregiver's report of impact of child behavior.

In this investigation, multiple statistically significant bivariate correlations were noted for family dynamic predictors with home setting characteristics and placement change variables. The findings from these associations are detailed and contextualized here. In multivariate analysis, family dynamic predictors were not independently predictive of placement change; however, trend-level improvements were noted for sibling relationship quality in subsequent moderation models. The implications for these findings for policy, practice, and future research are discussed below.

\section{Positive Home Integration}

The positive home integration measure examines youth perspective on how they feel treated, how they are responded to, how often they are included, and how frequently they see and speak to their caregivers. Descriptive analysis suggest that youth in this sample tended to provide high ratings for the positive home integration scale at baseline, 
suggesting a general satisfaction with their perceived level of integration into the families with whom they resided when they entered the parent study.

In bivariate correlation analysis, modest positive associations were noted for positive home integration and living in kinship care. This positive association suggest that youth may feel more integrated into processes within the home when they live with relatives than in non-relative care. This is important in that it provides information into potential differences between kinship and non-relative homes, particularly with respect to how children view their experience in the home, the quality and frequency of contact with their caregivers, and how they feel they are responded to when they express their needs.

Also in the bivariate analysis, modest positive associations were noted for positive home integration and sibling relationship quality. This finding suggests that children who feel positively integrated into their home may also feel better about the quality of their sibling relationship, independent of whether they live in the same home as their sibling or not. The positive home integration scale measures a child's perception of caregiver and family level processes, not sibling level processes. This may suggest a general contentment with their siblings, caregiver, and family. Deeper examination of the sibling relationship construct may provide more information into this positive modest association.

In multivariate analysis, positive home integration was not independently predictive of placement change. This suggests that even if a child feels listened and responded to, included in family routines, or interacts with their caregivers frequently; 
this does not specifically influence the odds of placement change. That positive home integration was not predictive in multivariate models may suggest that processes responsible for placement change are not directly related to a youth's sense of inclusion in routines, but may be a more a function of caregiver or home setting characteristics.

The Leathers $(2006 ; 2012)$ studies served as a starting point for this study's effort to measure a child's adaptation to a substitute care placement. Specifically, this study sought to follow up on her work by examining the youth's perspective of integration into the home setting. This study diverges from the Leathers investigation by utilizing the child as the reporting source for measures of adaptation into a foster home, and the home integration measure used in this investigation focused primarily around frequency of inclusion of family activities and frequency of contact with caregivers. As mentioned previously, little variance was noted among the youth who completed the positive home integration subscale at study baseline. It is possible that caregiver and caseworker report of home integration is a more sensitive predictor of placement quality and subsequent occurrence of placement change.

Despite the non-findings for positive home integration in this study, this construct appears to be an important aspect of the foster care experience and remains a place for investigation and possible intervention. This study utilized an eleven item measure of home integration, from the youth's perspective. To better understand the true nature of foster home adaptation and home integration, future studies would benefit from the creation of a multiple method-multiple indicator construct (Chamberlain \& Bank, 1989) 
of home integration that utilizes not only youth perspective, but incorporates caregiver, caseworker, sibling, and other family member perspectives as well.

\section{Sibling Relationship Quality}

Intervening to improve sibling relationship quality was the basis from which the parent study was developed (Kothari, et. al., 2014). Prior studies of siblings have found the sibling relationship plays a significant role in development and well-being (Kim, McHale, Crouter, \& Osgood, 2007) and quality sibling relationships have been show to mediate the negative experiences of maltreatment exposure and internalizing symptoms for children in substitute care (Stevenson-Wojciak, McWey, \& Helfrich, 2013). Sibling relationship quality has been found to predict the occurrence of placement change (Linares, Shrout, Bordy, \& Pettit, 2007).

The associations between sibling relationship quality and other predictors in the conceptual model paint an interest picture. In descriptive analysis of the sibling relationship quality subscales, youth tended to report moderately positive relationship quality, suggesting overall that children reported good relationships with their siblings. In analysis of variance according to living composition, however, children who lived apart from their sibling rated the quality of the sibling relationship higher than those who lived together. This finding was present for youth in both kin and non-relative homes. That siblings who live apart rate the quality of their relationship higher than those who live together is quite interesting, and may reflect a number of potential explanations. As mentioned by Kothari, et. al (under review), the sibling relationship may be particularly important for youth who live in separate homes. Lundstrom \& Sallnass (2012) found that 
siblings who were separated crave contact and desire more time together, and this desire increases the longer siblings go without contact with one another. Siblings who live apart also may be more likely to idealize the sibling relationship more than those who spend their daily lives in the company of their sibling.

In bivariate correlation analysis, a weak positive association was noted for sibling relationship quality and living in kinship care. This weak but statistically significant relationship may suggest that emphases around the value and quality of family relationships may be comparatively more present in kinship homes than in non-relative care. For example, children in kinship homes may be more likely to experience opportunities to discuss family history, circumstances surrounding removal, and hear messaging from caregivers regarding the value of kinship and family relationships than do children who reside in non-relative care.

In multivariate analysis, sibling relationship quality was not predictive of placement change in the conceptual model; however, a trend-level effect was found for sibling relationship quality and odds of placement change in the moderation model. This moderation analysis finding suggests that odds of placement change increase slightly when children rate their relationship quality higher. This finding was not present when sibling living situation was entered as an independent predictor in the conceptual model.

While this study found a marginal effect of sibling relationship quality on placement change using the sibling relationship questionnaire (Fuhrman \& Burmhester, 1985), it may make sense to utilize more robust measures in future studies. This standardized measure was also used in the Linares, et. al (2007) investigation, whereas 
the Stevenson-Wojciak, et. al (2013) investigation utilized three items from the University of California at Berkeley Foster Care Study Questions. In a separate test of the efficacy of the SIBS-FC intervention on sibling relationship quality, Kothari, et. al (under review) utilized a multi-method, multi-indicator construct (MAC-SRQ) comprised of seven items gathered from four respondents. The MAC-SRQ contained two items of sibling relationship quality reported by the youth, one foster parent item, and four project staff items. In this test of the efficacy of the SIBS-FC intervention, the youth in the treatment group improved on the MAC-SRQ at greater rates that youth in the control group.

Similar to recommendations for constructed measures of positive home integration, future studies of sibling relationship quality should utilize youth, foster parent, caseworker, and other reporting sources to gather a more complete picture of the role of sibling relationship on placement change.

\section{Impact of Child Behavior}

The impact of child behavior subscale asks the caregiver to rate the degree to which a youth's behavior problems impacts the caregiver, family processes, and family routines. Caregivers were asked to rate the degree to which child behavior caused the caregiver anxiety, impacted the ability of the caregiver to take the child into public, caused concern amongst the caregiver's friends, caused conflict with the reporting caregiver's spouse, or impacted the caregiver's ability to have friends and family in the home. Caregivers tended to provide low ratings for the items embedded in this subscale, suggesting that when a youth displayed behavior problems this did not impact the 
caregiver's own sense of personal well-being, and did not disrupt the caregiver's ability to manage family activities.

In bivariate correlation analysis, a modest positive association was noted between the impact of child behavior and living apart from ones sibling, suggesting that caregivers were more likely to rate the problem behaviors displayed by the youth to be impactful on family processes when siblings were living in separate homes. This may suggest that when siblings are present in the home, children are less likely to behave in ways that negatively impact the caregiver and family routines, or perhaps children are provided with opportunities to observe, learn, and cope with difficulties and behavior problems in the company of their sibling, thereby buffering the potential negative impacts of behavior on the caregiver.

The second modest positive association noted in the bivariate correlation analysis was for impact of child behavior and placement changes experienced during study enrollment. When caregivers rated the impact of child behavior more highly, children were also likely to experience more placement episodes. This is consistent with prior research that found behavior problems as predictive of placement disruption (Brown \& Bednar, 2006; James, 2004).

In this sample, an ANOVA found no differences in mean scores concerning the impact of child behavior by living composition, suggesting caregivers were not any more or less likely to rate the impact of child behavior higher or lower if the child was in a kinship or non-relative home or with or without one's sibling. 
In multivariate analysis, impact of child behavior was not independently predictive of placement change in the conceptual or moderation model. This finding diverges from prior research, which has found a strong association between child behavior problems and placement change (Brown \& Bednar, 2006; Chamberlain, et. al, 2006; Fisher, et. al, 2011; James, 2004; Newton, et. al., 2000; Rubin, et. al., 2007). Prior studies of behavior problems and placement change have used established measures such as the Child Behavior Checklist (Newton, et. al., 2000; Rubin, et. al., 2007), Child Symptom Inventory (Leathers, 2006), Parent Report Daily Checklist (Chamberlain, et. al, 2006; Fisher, et. al., 2011). While those investigations utilize measures that specifically examine child behaviors, this study utilized a unique 6 item measure of caregiver perceived impact of child behavior. It was our hope that utilizing a 6 item measure may supplant the lengthy and exhaustive measures used in the aforementioned studies, however it is possible that if more established measures of child behavior were utilized for this particular investigation, different results may have been produced.

Child behavior remains a very important aspect of the foster care experience and is the target of many substitute care interventions. Despite this investigation's nonfinding related to child behavior, child behavior should continue to be considered when intervening to promote placement stability in foster care settings. Future investigations may benefit from utilizing measures of child behavior that have been established in prior research. However, the refinement of more concise measures (such as the impact of child behavior contruct employed in this study) may be useful.

\section{Home Setting Characteristics}




\section{Sibling Living Situation}

Living with one's sibling appears to be significant in a number of ways. The majority of youth in this sample lived with their sibling at the time of study enrollment, either in kinship $(n=114)$ or non-relative care $(n=122)$. Chi-square analysis of sibling living situation found no differences in rates of co-placement according to youth race (white/non-white) or youth gender (male/female), and siblings who were co-placed were less likely to experience a placement change than were siblings who were separated at the time of study enrollment.

In the bivariate correlation analysis, a number of moderate associations were noted. As mentioned in the reported findings for sibling relationship quality, a modest positive association was noted for living apart and increased ratings of sibling relationship quality. This finding may be explained by prior research suggesting separation from siblings often leads to a desire for increased contact (Lundstrom \& Sallnas, 2012) and highlights the importance of the relationship for the separated siblings (Kothari, et al., under review).

Living apart from one's sibling was also positively associated with increased rating of impact of child behavior. As explained previously, co-placed siblings may have opportunities for building solutions to problems between one another in the home setting that separated siblings are not afforded. Modest positive associations were also noted for living apart and the number of placement changes experienced during the course of study enrollment. This is consistent with prior research (Akin, 2011; Albert \& King, 2008) that suggest separate placements reduces timing to permanency exit (Akin, 2011;Albert \& 
King, 2008) and leads to increased mental health problems and the occurrence of placement change (Barth, et. al., 2007).

In multivariate analysis, siblings who were living apart were $70 \%$ more likely to experience a placement change over an 18 month period than those who lived together. This finding is consistent with multiple prior studies that have found sibling separation is associated with an increase in placement change (Leathers, 2005; Linares, Shrout, Brody, \& Pettit, 2007; Wulczyn \& Zimmerman, 2005).

It is possible that living apart from one's sibling increases a youth's level of stress, reduces the opportunities to provide and receive support, thus leading a series of emotional and behavioral processes that reduce a child's emotional well-being (Stevenson-Wojciak, McWey, \& Helfrich, 2013) thereby leading to placement change (Linares, Shrout, Brody, \& Pettit, 2007). Conversely, co-placement may provide an opportunity for emotional support and connection, provide opportunities to learn new coping strategies, and provides a sense of relational continuity (Gamble, Jeong, \& Keuhn, 2011; Herrick \& Piccus, 2005). While the reasons why siblings were separated at the time of study enrollment are unknown for the full sample, in the case review of youth who were living in kinship care but separated from their sibling $(\mathrm{n}=15)$, a number of potential explanations were noted. Youth in this sub-sample were separated due to relationship status (half or step siblings), availability of kinship providers that could accommodate the sibling dyad, and emotional and behavioral problems of one member of the dyad that required a more restrictive placement setting, such as residential or psychiatric care. 
Findings from the analysis of sibling living situation suggest separation is a potent predictor of placement change. While this finding is important, more research is needed to understand the contextual factors that underscore this finding. If sibling co-placement is protective against placement change, what are the reasons for this, and why is sibling separation damaging? Examining indicators of well-being may provide some insights. In a study of 357 youth in New South Wales, Tarren-Sweeney \& Hazell (2005) examined the mental health of youth in foster care and found that sibling separation impacted the mental health of females, but not males. Hegar \& Rosenthal (2011) utilized NSCAW data and found that co-placement did not impact internalizing or externalizing behaviors, placement satisfaction, or quality of family relationships. What is clear is that coplacement is associated with decreased odds of placement change, however co-placement is also associated with lower levels of sibling relationship quality and higher levels of caregiver reports of behavioral impacts in the home setting.. Additional research that investigates the role of well-being and co-placement may help to explain the reasons why co-placement is protective against the occurrence of placement change.

\section{Kinship Care}

At the time of baseline assessment, 39\% of the sample lived in kinship care. In bivariate correlation analysis, kinship care was associated with higher levels of positive home integration and negatively associated with placements during the course of study enrollment. In multivariate analysis, children living in kinship care were 58\% less likely to experience a placement change than children living in non-relative care. 
While some studies have demonstrated a protective kinship effect on placement stability (Cuddeback, 2004; Wells \& Guo, 1999) others have not found this same association (Holtan, Handegard, Thornblad, \& Vis, 2013; Oosterman, Scheungel, Slot, Bullens, \& Doreleijers, 2007). Kinship care appears to be associated with child wellbeing (Rubin, 2008; Winokur, Holtan, \& Batchelder, 2014).

While there is some degree of disagreement in the literature with respect to the benefits of kinship care on placement stability and permanency outcomes, the protective effects of kinship care in this sample are quite notable. Youth in these homes reported higher levels of integration than those in non-relative care. What this study does not tell us, however, is if these children are doing better in areas of well-being, and if maintaining a stable placement leads to permanency. It is possible that children in kinship care are experiencing more stability, but their well-being could still be compromised. Future studies should examine indicators of well-being for kinship and non-relative youth over time, as well as examine if children in kinship care achieve reunification, guardianship, or adoption at rates that differ from children in non-relative care.

\section{Living Composition}

The majority of the sample lived together in non relative care (37\%), followed by together in kinship care (35\%), apart in non-relative care (23\%), and together in nonrelative care (5\%). This distribution is reflective of the Oregon Department of Human Services efforts to place siblings together, a direct mandate of the Fostering Connections to Success and Increasing Adoptions Act (PL 110-351). 
The composition of the family a youth resides with at the beginning of study enrollment appears to have an impact on a number of study variables. With respect to sibling relationship quality, youth who were co-placed in non-relative care and co-placed in kinship care both reported lower overall scores than youth who lived separately in nonrelative care or kinship care. Children who were co-placed in kinship care and co-placed in non-relative care also experienced fewer placements prior to study entry than youth who were separated and living in kinship or non-relative care. Differences were also noted for living composition and the occurrence of placement change, with youth in nonrelative care experiencing a greater mean number of changes than youth who lived together in non-relative care, apart in kinship care, or together in kinship care. Youth who were living apart in non-relative care experienced the greatest mean number of placement changes during the course of study enrollment. Age differences were also noted for youth according to their living composition. The mean age of youth in non-relative care was 12.5, whereas the mean age range for children in the other three living composition categories varied between 11.6 and 11.7 years of age.

Differences were not present according to living composition for the youth report of positive home integration or a caregivers reported impact of child behavior. This may be a result of the measurement strategy employed, as detailed in the family dynamic section of this chapter.

The composition of the home a youth resided in at study enrollment appears to moderate the occurrence of placement change. Youth who lived in kinship care with their siblings were $75 \%$ less likely to experience placement change than children who lived 
apart in non-relative care. A trend level effect was also noted for non-relative coplacement, suggesting children in this living composition category were $43 \%$ less likely to experience placement change. Living in kinship care apart from one's sibling was not protective or predictive of placement change, this perhaps being a function of the small sample size $(\mathrm{n}=15)$.

The living composition findings suggest varying levels of protection depending on living situation, with living with one's sibling in kinship care exerting the strongest protective effects and the most ideal placement situation for children who require removal from their families for maltreatment related concerns. In terms of placement stability, there appears to be a strong beneficial effect for placing siblings together, even when unable to co-place siblings into a kinship care home. Children appear to experience greater stability when placed with their siblings, regardless of their biological relationship to their caregiver.

Few studies have gone beyond examination of kinship and sibling co-placement to examine the moderating effects of different combinations of placement and its impact on placement change outcomes. To this author's knowledge only one study has examined the interaction effects of sibling co-placement and kinship care, and not in relationship to placement stability. Hegar \& Rosenthal (2009) utilized NCSAW data for 1415 children, to investigate the role of sibling co-placement and kinship care on internalizing and externalizing behaviors, school performance, and closeness to caregiver, finding the interaction of sibling co-placement and kinship care to have no effect on youth, teacher, and caregiver reported outcomes. 
The findings from the analysis of living composition may be the most important finding from this investigation and most innovative contribution of this dissertation to the child welfare literature. Differences are noted depending on sibling co-placement and kinship caregiver status, and protective effects are noted for co-placement regardless of caregiver kinship status. This finding supports the continued investigation of sibling level processes and development of preventive interventions (McBeath, et. al, 2014; Kothari, et. al, under review) for siblings in substitute care.

\section{Study Limitations}

A number of limitations are present in this study that should be noted. First, the reasons for placement changes for youth in this sample could not be determined. Children experienced placement moves for a variety of reasons, and simply counting the number of moves a youth experiences does not explain if the move was in support of a case permanency plan or a placement disruption. While this study attempted to determine if a placement change was towards a permanency goal, the nature of the data did not allow a more nuanced examination of placement changes and if the effect of the change was stabilization or disruption.

This study utilized a binary measure to account for placement change in this sample of youth. While utilizing a binary measure is useful for predicting odds of disruption, it is not sensitive to differences between youth who experienced one placement change during the course of the study and those who experienced two or more placement changes. While the sensitivity analysis conducted in this study did recode the binary measure to account for potential differences in placement change for youth who 
experienced two placements during study enrollment, this additional analytical step did not account for youth who experienced three or more changes, and youth who experienced three or more changes in the 18 month widow of time may have very different family dynamic profiles than those who did not. An additional limitation in this study is the omission of 88 youth from the logistic regression and moderation analysis. These youth were not included in the final conceptual model because placement change data was not available for these youth across the full 18 month period of study enrollment. Because these youth were not included in the multivariate analysis, the findings are not representative of the full SIBS-FC sample.

This study utilized three distinct measures of family dynamics to predict the likelihood of placement change. Despite utilizing measures to address child, sibling, and caregiver influences on placement disruption, omitted variable bias may be present. Important variables that were not included in the conceptual model may have led to errors in the estimation of placement change. For example, this study was unable to identify the type, severity, and frequency of maltreatment experienced by youth, specific youth and caregiver needs, frequency of visitation with the removal home, or the occurrence and frequency of caseworker turnover. This study also did not utilize multiple method, multiple indicator constructs in its design, which may also lead to measurement error.

In addition to omitted variable bias, youth placed into the various forms of living composition may be different based on unobserved factors related to the placement change. This form of selection bias may be a result of some behavioral symptom related to prior maltreatment, caseworker or supervisor decision making, availability of a viable 
caregiver at the time of placement, or length of time in the foster care system when they siblings were enrolled in the SIBS-FC study.

Finally, this secondary analysis is non-experimental; in nature. While the parent study utilized randomization procedures to investigate the impact of a sibling relationship enhancement intervention on sibling relationship quality and youth well-being, this study utilized available data to consider the role of family dynamics and home setting characteristics on the likelihood of disruption. Due to this secondary design, findings from this study cannot be considered causally related and must be interpreted simply as associations.

\section{Implications for Theory}

This study utilized bioecological, social learning, and coercion theory frameworks to understand how family dynamics and home setting characteristics influence the likelihood of placement change for a sample of youth who participated in a sibling focused intervention. The major findings from this study support the role of kinship care and sibling co-placement in reducing the odds of placement change. In the bioecological framework, placement change is suppressed when children reside with members of their family, a beneficial interaction of the child (micro) and family (meso) systems. Placement stability is noted for youth when they reside with family.

With respect to social learning and coercion theories, less can be explained by these particular theories. In the social learning and coercion theory frameworks, children learn from observation, practice, and reinforcement. The family dynamic predictors in this model provide weak support for the use of these theories to explain the occurrence of 
placement change. In this study, sibling separation was associated with higher levels of sibling relationship quality, and higher sibling relationship quality was modestly associated with placement change. The learning, observing, and reinforcement mechanisms that ground social learning and coercion theory do not explain these findings.

This study may best be supported by the bioecological model of human development. Children, nested in sibling and family systems, appear to be the operating mechanisms behind placement change and stability. Non-findings related to family dynamics require further investigation and additional exploration of how social learning and coercion may occur in homes where children live apart from siblings or reside in non-relative care.

\section{Implications for Future Research}

This study examined the role of family dynamics and home setting characteristics on the occurrence of placement change, with empirical support found for the role of home setting characteristics on the odds of placement change over time. Current measures of family dynamics did not independently predict placement change, but do provide evidence that suggest that the experiences of foster care, particularly around a youth's sense of integration, rating of sibling relationship, and caregiver impact of child behavior, vary depending on if the youth live with their sibling, in kinship care, or in one of the four forms of living composition. What this study does not tell us is how family dynamics and home setting characteristics influence permanency outcomes or child wellbeing. 
With respect to culturally centered child welfare practice, findings from this study do not suggest a unique contribution to the occurrence of placement change according to youth race and gender. Cautious interpretation of this non-finding is indicated, as the primary purpose of this dissertation was to investigate the role of family dynamics and home setting characteristics on the occurrence of placement change. Culture is a complex construct and in research requires careful consideration of structural and system level variables not available in the SIBS-FC data set. However, because this study found strong findings for kinship care and co-placement, future research should investigate the characteristics of these homes more fully. For example, investigations should examine the racial demographics of kinship and non-relative caregivers, and determine the frequencies of racial matching for children in non-relative homes. It is possible that children who are placed into non-relative care may not share the same racial and ethnic similarities as their caregivers, and this could potentially impact the stability of such a foster care placement.

Future research should examine how family dynamics and home setting characteristics influence permanency outcomes, as a stable placement does not necessarily suggest movement towards permanency. This could be accomplished by following this sample of youth for an additional period of time, to determine if the predictor variables in this model promote reunification, adoption, or guardianship.

A youth's experience with placement stability does not necessarily suggest the youth in these homes have improved well-being. While this study suggest that kinship care and sibling living situation promote placement stability, it does not tell us if these 
children are actually doing better than children who experience moves during their stay in substitute care. Future research should identify and measure indicators of well-being to determine if sibling living situation, kinship care, and living composition influence a child's physical, emotional, and behavioral health. Following these children beyond the 18-month window of study enrollment could also potentially shed light on how home setting characteristics influence educational, employment, and economic outcomes over time.

A number of new questions have been raised as a result of this investigation. Why were separated siblings likely to experience more placements than children who were coplaced? Why did kinship care differ from non-relative care with respect to placement stability? Why was sibling co-placement in kinship care more protective than other forms of living composition? What is the relationship between placement stability and permanency? What is the relationship between placement stability and child well-being?

Investigation into these additional research questions would likely require a number of investigative approaches. First, this study could be replicated with more robust measurement strategies and the inclusion of additional predictors and outcome variables not specified in the conceptual model. This study could be extended by comparing youth with stable placements to those who experienced placement changes on permanency exits and indicators of well-being.

Utilizing nationally representative data sets such as NSCAW could be useful for investigating the relationship between placement stability, permanency, and well-being. Investigators could compare children classified according to their living composition, 
take measurements of well-being, and conduct follow up analysis after a period of time to examine later measures of well-being and exits to permanency.

To understand what is occurring in family systems that promote placement stability could be undertaken using qualitative methods. Interviews with children and caregivers in different living compositions may help unpack the processes occurring within families that promote placement stability or the occurrence of placement change over time.

\section{Implications for Policy}

Federal child welfare policy supports the placement of youth into kinship care and with siblings whenever possible. This study provides additional evidence that supports the application of these policies in practice.

Specifically, this study demonstrates the variability present within homes where children are co-placed, or with kin. As mentioned previously, simply placing children into the same home or with a kinship provider does not immediately assure children will do well in these homes. Child welfare policy directed towards the placement of children needs to account for the contextual factors present in a child's life at the time of placement. Given that children entering substitute care have experienced maltreatment, comprehensive screening should be conducted to ensure that the well-being needs of the children will be met when they are co-placed and/or sent to relative care. Policies that emphasize placement type alone do not account for placement context and the experiences of children in these homes. This study demonstrates that even in light of coplacement, youth in this sample rated the quality of their sibling relationship lower than 
did siblings who were placed apart. Further, while this study demonstrates a stabilizing effect for co-placement and kinship care, we as a field know little about how well the children in this home are actually doing developmentally, and if their personal trajectories for well-being and permanency are similar or different to children who are not co-placed and/or live in non-relative care.

Policy around kin and siblings in foster care could be strengthened by providing resources to states to develop and implement a series of structured assessment protocols that examine how children are doing once they are placed in kinship and non-relative care. These assessment protocols could be applied universally to children in all types of living arrangement compositions. Acknowledging that differences exist for children depending upon the composition of their living arrangements, and adapting casework practice and service planning by strengthening the availability of structured assessment and decision making protocols is a step states can take to refine their service to children and families, and begin to address the link between family living composition, placement stability, well-being, and permanency. In order to do this, federal funders would need to allocate more resources to the development and piloting of structured assessment protocols, and states would need to develop policies to ensure uniform training and implementation of these assessments into routine casework practice.

\section{Implications for Practice}

This study supports current child welfare practice related to the co-placement of siblings whenever possible. Co-placement is shown to protect against the occurrence of placement change, and is associated with a child's sense of home integration, sibling 
relationship quality, and impact of child behavior. Practitioners - notably child welfare caseworkers, but also community-based case managers and clinicians - should understand that the presence or absence of a sibling in the home setting may have significant impact on the relationships the child has to others in the home setting, the perceived quality of the substitute care setting, and impacts the odds of a placement change over time.

When practitioners make substitute care placement decisions, either at the onset of placement or in the course of case planning and service delivery, they should try to keep children together so long as it is safe to do so. Practitioners should understand that sibling relationships are a valuable source of support to a child who has been removed from their family. When siblings are placed together, they can support one another through the difficult adjustments that come with removal. Siblings provide the opportunity for continued learning and growth in the substitute care placement. When siblings are separated, practitioners need to work actively to support the sibling relationship. This can be achieved through visitation, phone calls, experiential activities, and targeted interventions. This is equally as important if siblings are separated but plan to be reunified, or if permanency plans differ from one sibling to the next.

In all placement decisions for siblings, practitioners should not simply assume that co-placement alone equals success. As seen in this study, the quality of sibling relationships varies significantly if children are placed together or separately. Practitioners need to make time to adequately assess the quality of the sibling relationship in relationship to whether siblings live together or apart. 
This study also supports current child welfare practice related to the prioritization of kinship placements when placing children into substitute care. In this study, kinship care was shown to protect against the occurrence of placement change. Researchers and practitioners alike should spend time identifying what the experiences of youth are within kinship homes that promotes this stabilizing effect. Practitioners should understand that the experiences of youth and stability related outcomes are in part related to the relatedness of the caregiver to the child. But more than simple relatedness is at play. Nonrelative foster parents differ from kinship providers in a number of ways, and practitioners should seek to understand and be sensitive to these differences and adjust assessment practices, case planning, and service delivery accordingly.

Practitioners should also know that just because a youth may experience more stability in kinship care than non-relative care, their emotional and behavioral well-being may still be at risk. For example, non-relative providers may feel more comfortable contacting caseworkers and service providers for supports whereas kin providers may feel a hesitation to reach out and ask for support for fear of the child being removed from their home. While child welfare caseworkers may believe no news is good news, they can address continued risks by building meaningful relationships with kinship foster care providers, checking in with them regularly, and taking time to comprehensively assess the well-being of children in their home.

This study also found that children tended to feel more integrated in kinship homes than they do in non-relative homes. If children feel a stronger sense of integration when living with relative caregivers, practitioners should consider providing additional or 
different supports and resources to children and caregivers in non-relative homes. For example, while many agencies conduct a screening and matching process at initial placement into care, these screening and matching processes may not specifically target the ways in which caregivers interact with children, or how children find themselves to be positively integrated when they enter a new home. Caseworkers could spend time during the initial placement search process to assess the ways in which the caregivers work with a child who is new to the home, to find out how they operate the day to day functioning of their family. Do caregivers simply bring a child in, show them to their room, and continue on with their lives, or do caregivers purposefully take time to orient the child to how the family operates, showing the child how the family goes about its day-to-day lives by including the child in experiential activities? Practitioners should talk with the child about the things that make them feel comfortable and supported. For example, did the child typically eat dinner with their family, or is this a new experience? How does a child know when they feel listened to, respected, and supported? Figuring out how children feel a sense of integration will provide information to caseworkers who want to facilitate a successful and stable placement. In assessing caregiver and family practices and understanding how children feel a sense of integration, a caseworker could work with the family unit to develop activity based interventions that build a sense of positive home integration for the child.

Results of this study suggest that children vary in their ratings of sibling relationship quality, and this rating varies according to whether the child lives with their sibling or not. Children who live apart rated the quality of their relationship higher than 
children who lived together. Practitioners should attend to the quality of sibling relationships in their assessment and intervention planning. Checking in with a child about their relationship to their sibling, asking them about the quality of the relationship, and their desires related to the sibling relationship should be a part of routine discussions with the child. If siblings are separated, practitioners should inquire about the desire for more contact, and help facilitate this contact whenever safe and feasible to do so. This study provides evidence that sibling relationships are a key aspect of the substitute care experience. This study provides support for more in-depth assessment of sibling relationships and use of evidence based interventions to promote sibling bonds in substitute care settings.

Findings from this study also suggest caregivers experience more difficulties managing a youth's behavior when siblings live apart. Caregivers for separated children may need more support managing child behaviors than do caregivers who are caring for sibling in intact placements. While the exact mechanisms underlying the protective effects of co-placement are unknown, these impacts appear to not only influence the youth and siblings but the caregivers as well. Talking with caregivers about the experiences of working with co-placed and separated youth may provide insights into the processes occurring sibling groups that make the foster care experience more or less manageable for caregivers.

\section{Conclusion}

This study utilized secondary data from a sibling focused intervention study, to examine the impact of family dynamics and home setting characteristics on the likelihood 
of foster care placement disruption. Findings suggest living with one's sibling and in kinship care was most protective against the occurrence of placement disruption, and protective effects were also noted for siblings who live together in non-relative care. Independently, living apart and living in non-relative care were predictive of placement change. This study provides additional empirical evidence in support of current federal policy and best practices related to the co-placement of siblings and placement into kinship care whenever safe and feasible to do so.

This dissertation extends prior research by examining the moderating effects of different possible combinations of kinship care and sibling living situation, finding differences in the odds of a youth experiencing a placement change depending on the type of living composition the youth finds themselves in.

Implications for this study include continued support of current practice and federal policy related to the prioritization of kin when making substitute care placement decisions, and giving strong consideration to placing siblings together whenever safe to do so. Future studies of siblings in foster care should examine the relationship between placement stability and permanency outcomes, as well as examine the relationship between placement stability, permanency, and child well-being. 


\begin{tabular}{|c|c|c|c|c|c|c|}
\hline \multicolumn{7}{|c|}{$\begin{array}{l}\text { Table } 1 \\
\text { Demographics of SIBS-FC Youth Participants }\end{array}$} \\
\hline & \multicolumn{2}{|c|}{ Treatment } & \multicolumn{2}{|c|}{ Control } & \multicolumn{2}{|c|}{ Total } \\
\hline & $\begin{array}{c}\text { Older } \\
\text { Sibling } \\
\text { (OS) }\end{array}$ & $\begin{array}{c}\text { Younger } \\
\text { Sibling } \\
\text { (YS) }\end{array}$ & $\begin{array}{c}\text { Older } \\
\text { Sibling } \\
\text { (OS) }\end{array}$ & $\begin{array}{l}\text { Younger } \\
\text { Sibling } \\
\text { (YS) }\end{array}$ & $\begin{array}{c}\text { Older } \\
\text { Sibling } \\
\text { (OS) }\end{array}$ & $\begin{array}{c}\text { Younger } \\
\text { Sibling } \\
\text { (YS) }\end{array}$ \\
\hline & $(n=84)$ & $(n=84)$ & $(\mathbf{n}=\mathbf{8 0})$ & $(\mathbf{n}=\mathbf{8 0})$ & $(n=164)$ & $(n=164)$ \\
\hline \multirow{2}{*}{ Age (SD) } & 13.1 & 10.7 & 13.1 & 10.6 & 13.1 & 10.7 \\
\hline & -1.4 & -1.7 & -1.5 & -1.8 & -1.4 & -1.7 \\
\hline \multirow{2}{*}{ Age Difference (SD) } & \multicolumn{2}{|c|}{2.4} & \multicolumn{2}{|c|}{2.4} & \multicolumn{2}{|c|}{2.4} \\
\hline & \multicolumn{2}{|c|}{-1} & \multicolumn{2}{|c|}{-1.1} & \multicolumn{2}{|c|}{-1.1} \\
\hline \multicolumn{7}{|l|}{ Sibling Type (n) } \\
\hline Full & \multicolumn{2}{|c|}{$61 \%(102)$} & \multicolumn{2}{|c|}{$63 \%(100)$} & \multicolumn{2}{|c|}{$62 \%(202)$} \\
\hline Half & \multicolumn{2}{|c|}{$37 \%(62)$} & \multicolumn{2}{|c|}{$38 \%(60)$} & \multicolumn{2}{|c|}{$37 \%(122)$} \\
\hline Step & \multicolumn{2}{|c|}{$1 \%(2)$} & \multicolumn{2}{|c|}{$0 \%(0)$} & \multicolumn{2}{|c|}{$1 \%(2)$} \\
\hline Other & \multicolumn{2}{|c|}{$1 \%(2)$} & \multicolumn{2}{|c|}{$0 \%(0)$} & \multicolumn{2}{|c|}{$1 \%(2)$} \\
\hline \multicolumn{7}{|l|}{$\begin{array}{l}\text { Living Situation at } \\
\text { Orientation }(\mathrm{n})\end{array}$} \\
\hline Together & \multicolumn{2}{|c|}{$71 \%(120)$} & \multicolumn{2}{|c|}{$74 \%(118)$} & $73 \%$ & $(238)$ \\
\hline Apart & $29 \%$ & $(48)$ & $26 \%$ & $(42)$ & $27 \%$ & $(90)$ \\
\hline Gender (n) & & & & & & \\
\hline Female & $50 \%(42)$ & $46 \%(39)$ & $53 \%(42)$ & $51 \%(51)$ & $51 \%(84)$ & $49 \%(80)$ \\
\hline Male & $50 \%(42)$ & $54 \%(45)$ & $48 \%(38)$ & $49 \%(39)$ & $49 \%(80)$ & $51 \%(84)$ \\
\hline Gender Composition (n) & & & & & & \\
\hline OS male, YS male & $31 \%$ & (52) & $29 \%$ & (46) & $30 \%$ & (98) \\
\hline OS male, YS female & $19 \%$ & $(32)$ & $19 \%$ & $(30)$ & $19 \%$ & $(62)$ \\
\hline OS female, YS female & $27 \%$ & (46) & $33 \%$ & $(52)$ & $30 \%$ & $(98)$ \\
\hline OS female, YS male & $23 \%$ & $(38)$ & $20 \%$ & (32) & $21 \%$ & $(70)$ \\
\hline Years siblings were in & 2 & 2 & 2.4 & 2.3 & 2.2 & 2.1 \\
\hline (SD) & -3.7 & -3.1 & -3.5 & -3.2 & -3.6 & -3.2 \\
\hline $\begin{array}{l}\text { Placement type at TX start } \\
\text { (n) }\end{array}$ & & & & & & \\
\hline $\begin{array}{r}\text { Non-Relative Foster } \\
\text { Parent }\end{array}$ & $51 \%(43)$ & $55 \%(46)$ & $63 \%(50)$ & $55 \%(44)$ & $57 \%(93)$ & $55 \%(90)$ \\
\hline Kinship Care & $31 \%(26)$ & $31 \%(26)$ & $25 \%(20)$ & $25 \%(20)$ & $28 \%(46)$ & $28 \%(46)$ \\
\hline Biological Parent(s) & $13 \%(11)$ & $10 \%(8)$ & $9 \%(7)$ & $14 \%(11)$ & $11 \%(18)$ & $12 \%(19)$ \\
\hline Other Caregiver(s) & $5 \%(4)$ & $5 \%(4)$ & $4 \%(3)$ & $6 \%(5)$ & $4 \%(7)$ & $6 \%(9)$ \\
\hline Race (n) & & & & & & \\
\hline $\begin{array}{r}\text { American Indian or } \\
\text { Alaskan Native }\end{array}$ & $6 \%(5)$ & $6 \%(5)$ & $4 \%(3)$ & $4 \%(3)$ & $5 \%(8)$ & $5 \%(8)$ \\
\hline Asian or Pacific Islander & $3 \%(2)$ & $2 \%(2)$ & $0 \%(0)$ & $0 \%(0)$ & $1 \%(2)$ & $1 \%(2)$ \\
\hline $\begin{array}{r}\text { Black or African } \\
\text { American }\end{array}$ & $13 \%(10)$ & $11 \%(9)$ & $14 \%(11)$ & $13 \%(10)$ & $13 \%(21)$ & $12 \%(19)$ \\
\hline White & $45 \%(36)$ & $41 \%(34)$ & $35 \%(27)$ & $39 \%(30)$ & $40 \%(63)$ & $40 \%(64)$ \\
\hline
\end{tabular}




\begin{tabular}{|r|c|c|c|c|c|c|} 
Multi-racial & $23 \%(18)$ & $25 \%(21)$ & $35 \%(27)$ & $31 \%(24)$ & $29 \%(45)$ & $28 \%(45)$ \\
\hline Other & $11 \%(9)$ & $15 \%(12)$ & $13 \%(10)$ & $14 \%(11)$ & $12 \%(19)$ & $14 \%(23)$ \\
\hline Ethnicity (n) & & & & & & \\
\hline Hispanic & $21 \%(15)$ & $23 \%(17)$ & $31 \%(21)$ & $29 \%(20)$ & $26 \%(36)$ & $26 \%(37)$ \\
\hline Non Hispanic & $80 \%(58)$ & $77 \%(56)$ & $69 \%(46)$ & $71 \%(50)$ & $\begin{array}{c}74 \% \\
(104)\end{array}$ & $\begin{array}{c}74 \% \\
(106)\end{array}$ \\
\hline
\end{tabular}

\begin{tabular}{|llll|}
\hline Table 2 & & \\
Youth Treatment Condition & $\underline{\mathrm{N}}$ & $\underline{\%}$ \\
\hline Treatment Condition & 160 & 48.8 \\
\hline Treatment & 168 & 51.2 \\
Control & & 168 \\
\hline
\end{tabular}

\begin{tabular}{|llll|}
\hline Table 3 & & \\
Sibling Living Situation at Baseline & $\underline{\mathrm{N}}$ & $\underline{\%}$ \\
\hline Sibling Living Situation & 236 & 72.0 \\
Together & 92 & 28.0 \\
Apart & & 92 \\
\hline
\end{tabular}

\begin{tabular}{|lll|}
\hline Table 4 & & \\
Caregiver Relationship Status at Baseline & $\mathrm{N}$ & $\%$ \\
\hline Caregiver Type & 187 & 57.0 \\
Non-relative Foster Parent & 34 & 10.4 \\
Biological Mom & 3 & .9 \\
Biological Dad & 41 & 12.5 \\
Biological Aunt & 8 & 2.4 \\
Biological Uncle & 36 & 11.0 \\
Biological Grandma & 2 & .6 \\
Biological Sister & 4 & 1.2 \\
Other Biological Caregiver & 12 & 3.7 \\
Other Caregiver & 1 & .3 \\
Missing & 129 & 39.3 \\
\hline Kinship Caregiver & 199 & 60.7 \\
Non-Relative Caregiver & & \\
\hline
\end{tabular}




\begin{tabular}{|c|c|c|c|}
\hline$\underline{\text { Variable }}$ & $\underline{\mathrm{N}}$ & Mean & $\underline{\mathrm{SD}}$ \\
\hline How often do you see your (foster) parent? & 320 & 9.81 & 0.74 \\
\hline How often do you talk to your (foster) parent? & 319 & 9.35 & 1.54 \\
\hline When you have a problem, how well does your (foster) parent respond to you? & 316 & 8.98 & 1.68 \\
\hline How well does your (foster) parent respond to your needs? & 318 & 8.95 & 1.62 \\
\hline $\begin{array}{l}\text { On a scale of } 1-10 \text {, how well does your (foster) parent listen to you? } \\
\text { To what extent do you feel you are treated with kindness in your (foster) }\end{array}$ & 319 & 8.76 & 1.8 \\
\hline home? & 321 & 8.72 & 1.89 \\
\hline On a scale of $1-10$, how good is your relationship with your (foster) parent? & 319 & 8.69 & 1.93 \\
\hline To what extent do you feel included in your (foster) family? & 321 & 8.63 & 2.08 \\
\hline To what extent do you feel you are treated with respect in your (foster) home? & 321 & 8.56 & 1.99 \\
\hline How well do you get along with your (foster) parent? & 319 & 8.55 & 1.94 \\
\hline $\begin{array}{l}\text { To what extent do you feel that you are involved in decision making in your } \\
\text { (foster) home? }\end{array}$ & 319 & 6.96 & 2.89 \\
\hline Total Scale (11 Items) & 312 & 8.74 & 1.23 \\
\hline
\end{tabular}

\begin{tabular}{|lllll|}
\hline Table 6 & & & & \\
Sibling Relationship Quality & $\underline{\mathrm{N}}$ & $\underline{\mathrm{Mean}}$ & $\underline{\mathrm{SD}}$ \\
\hline Variable & 327 & 3.84 & 0.82 \\
Responsive to Sibling & 327 & 3.82 & 0.94 \\
Receives Positive Affect & 327 & 3.79 & 0.81 \\
Expresses Positive Affect & 327 & 3.73 & 0.82 \\
Influenced by Sibling & 327 & 3.68 & 0.87 \\
Influences Sibling & 327 & 3.64 & 0.91 \\
Shared Fantasy with Sibling & 327 & 3.58 & 0.84 \\
Responded to by Sibling & 327 & 3.43 & 0.72 \\
Receives Negative Affect & 327 & 3.27 & 0.71 \\
Express Negative Affect & 327 & 3.65 & 0.70 \\
\hline SRQ Total at Baseline & & & \\
\hline
\end{tabular}




\begin{tabular}{|lllll|}
\hline $\begin{array}{l}\text { Table } 7 \\
\text { Impact of Child Behavior }\end{array}$ & $\underline{\text { Nean }}$ & $\underline{\text { SD }}$ \\
\hline $\begin{array}{l}\text { Item } \\
\begin{array}{l}\text { How frequently has this child's behavior caused you to be anxious or worried } \\
\text { about his/her chance for doing well in the future? }\end{array}\end{array}$ & 314 & 2.09 & 1.04 \\
$\begin{array}{l}\text { How frequently has this child's behavior made it difficult for you, or } \\
\text { prevented you from taking him/her out in public or going shopping or } \\
\text { visiting? }\end{array}$ & 315 & 1.54 & 0.73 \\
$\begin{array}{l}\text { How frequently have neighbors, relatives, or friends expressed concern to } \\
\text { you about this child's behavior? }\end{array}$ & 316 & 1.54 & 0.79 \\
$\begin{array}{l}\text { How frequently have you quarreled with you partner, ex-partner, or the } \\
\text { child's other parent about this child's behavior? }\end{array}$ & 315 & 1.48 & 0.76 \\
$\begin{array}{l}\text { How frequently has this child's behavior prevented you from having friends, } \\
\text { relatives, or neighbors to your home? }\end{array}$ & 314 & 1.33 & 0.69 \\
$\begin{array}{l}\text { How frequently has this child's behavior prevented his/her brothers or sisters } \\
\text { from having friends, relatives, or neighbors to your home? }\end{array}$ & 315 & 1.31 & 0.64 \\
\hline Total Scale (6 Items) & 312 & 1.87 & 0.73 \\
\hline
\end{tabular}

\section{Table 8}

SIBS-FC Placement Changes

$\begin{array}{lllll}\underline{\text { Item }} & \underline{\mathrm{N}} & \underline{\underline{M e a n}} & \underline{\underline{S D}} & \underline{\text { Range }} \\ \text { Placements between Baseline and Term Assessment } & 263 & .30 & .54 & 2 \\ \text { Placements between Baseline and FA1 Assessment } & 239 & .50 & .82 & 4 \\ \text { Placements between Baseline and FA2 } & 240 & .70 & 1.12 & 7\end{array}$

\begin{tabular}{|llllll|}
\hline Table 9 & & & & \\
ORKIDS Placement Changes & $\underline{N}$ & $\underline{M e a n}$ & $\underline{\text { SD }}$ & $\underline{\text { Range }}$ \\
\hline Item & 271 & 4.08 & 3.19 & 21 \\
Placements before Orientation & 271 & .04 & .30 & 4 \\
Placements between Orientation and Baseline Assessment & 223 & .39 & .81 & 7 \\
Placements between Baseline and Term Assessment & 206 & .57 & .93 & 5 \\
Placements between Baseline and FA1 Assessment & 205 & .90 & 1.59 & 11 \\
Placements between Baseline and FA2 & & & & \\
\hline
\end{tabular}

\begin{tabular}{|llllll|}
\hline Table 10 & & & & & \\
SIBS-FC Binary Placement Changes & $\underline{\mathrm{N}}$ & $\underline{\text { Mean }}$ & $\underline{\mathrm{SD}}$ & $\frac{\%=}{43.3}$ \\
\hline$\underline{\text { Item }}$ & 328 & .57 & .50 & 43 \\
Sibs Binary Disruption $(0=0)$ & 328 & .39 & .49 & 60.7 \\
Sibs Binary Disruption $(1=0)$ & & & &
\end{tabular}




\begin{tabular}{|c|c|c|c|c|c|c|c|c|}
\hline \multicolumn{9}{|c|}{$\begin{array}{l}\text { Table } 11 \\
\text { Bivariate Correlation Matrix }\end{array}$} \\
\hline Variable & PHI & SRQ & ICB & $\frac{\text { Kinship }}{\text { Home }}$ & $\frac{\text { Living }}{\text { Apart }}$ & $\frac{\text { Treatment }}{\text { Condition }}$ & $\begin{array}{l}\text { Prior } \\
\text { Placements }\end{array}$ & $\begin{array}{l}\text { Changes } \\
\text { During } \\
\text { Study }\end{array}$ \\
\hline PHI & 1 & & & & & & & \\
\hline SRQ & $0.18^{* *}$ & 1 & & & & & & \\
\hline $\begin{array}{l}\text { ICB } \\
\text { Kinship }\end{array}$ & -0.07 & -0.41 & 1 & & & & & \\
\hline Home & $0.11^{*}$ & -0.04 & -0.07 & 1 & & & & \\
\hline $\begin{array}{l}\text { Living Apart } \\
\text { Treatment }\end{array}$ & 0.06 & $0.20 * *$ & $0.11 *$ & $-0.30 * *$ & 1 & & & \\
\hline $\begin{array}{l}\text { Condition } \\
\text { Prior }\end{array}$ & 0.02 & -0.05 & -0.01 & 0.06 & 0.04 & 1 & & \\
\hline $\begin{array}{l}\text { Placements } \\
\text { Changes } \\
\text { During }\end{array}$ & -0.05 & 0.11 & 0.05 & $-0.23 * *$ & $0.40 * *$ & -0.1 & 1 & \\
\hline Study & -0.11 & 0.72 & $0.16^{*}$ & $-0.25 * *$ & $0.24 * *$ & -0.09 & $0.32 * *$ & 1 \\
\hline
\end{tabular}

\begin{tabular}{|c|c|c|c|c|}
\hline \multicolumn{5}{|l|}{$\begin{array}{l}\text { Table } 12 \\
\text { Cross-Tabula }\end{array}$} \\
\hline & & \multicolumn{2}{|c|}{ Placement Change } & \multirow[t]{2}{*}{$\underline{\text { Total }}$} \\
\hline & & No & Yes & \\
\hline \multirow[t]{4}{*}{ Non-Relative } & Count & 66 & 133 & 199 \\
\hline & $\%$ within Kinship Status & $33.2 \%$ & $66.8 \%$ & $100.0 \%$ \\
\hline & $\%$ within Placement Change & $46.5 \%$ & $71.5 \%$ & $60.7 \%$ \\
\hline & $\%$ of Total & $20.1 \%$ & $40.5 \%$ & $60.7 \%$ \\
\hline \multirow[t]{4}{*}{ Kin } & Count & 76 & $53_{\mathrm{b}}$ & 129 \\
\hline & $\%$ within Kinship Status & $58.9 \%$ & $41.1 \%$ & $100.0 \%$ \\
\hline & $\%$ within Placement Change & $53.5 \%$ & $28.5 \%$ & $39.3 \%$ \\
\hline & $\%$ of Total & $23.2 \%$ & $16.2 \%$ & $39.3 \%$ \\
\hline \multirow[t]{4}{*}{ Total } & Count & 142 & 186 & 328 \\
\hline & $\%$ within Kinship Status & $43.3 \%$ & $56.7 \%$ & $100.0 \%$ \\
\hline & $\%$ within Placement Change & $100.0 \%$ & $100.0 \%$ & $100.0 \%$ \\
\hline & $\%$ of Total & $43.3 \%$ & $56.7 \%$ & $100.0 \%$ \\
\hline
\end{tabular}




\begin{tabular}{|c|c|c|c|c|c|}
\hline \multicolumn{6}{|l|}{ Chi-Square Tests } \\
\hline & $\begin{array}{l}\text { Chi- } \\
\text { Square }\end{array}$ & $\underline{\mathrm{DF}}$ & $\frac{\text { Sig. (2- }}{\underline{\text { sided) }}}$ & Exact Sig. (2-sided) & $\begin{array}{l}\text { Exact Sig. (1- } \\
\underline{\text { sided) }}\end{array}$ \\
\hline Chi-Square & 21.12 & 1 & .000 & & \\
\hline Continuity Correction & 20.10 & 1 & .000 & & \\
\hline Likelihood Ratio & 21.21 & 1 & .000 & & \\
\hline Fisher's Exact Test & & & & .000 & .000 \\
\hline $\begin{array}{l}\text { Linear-by-Linear } \\
\text { Association }\end{array}$ & 21.07 & 1 & .000 & & \\
\hline $\mathrm{N}$ of Valid Cases & 328 & & & & \\
\hline
\end{tabular}

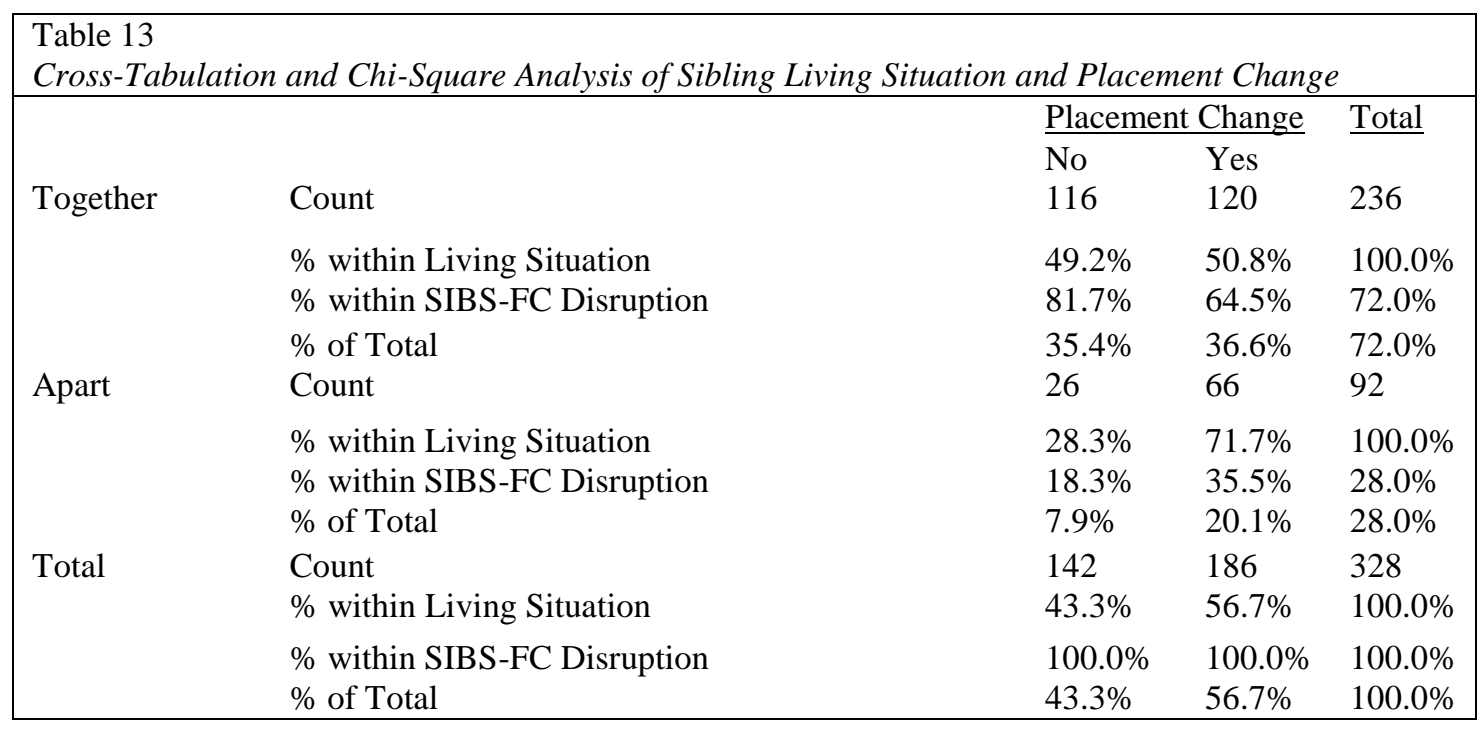

\begin{tabular}{|llllll|}
\hline Chi-Square Tests & & & & & \\
\hline & $\frac{\text { Chi- }}{\text { Square }}$ & $\underline{\text { DF }}$ & $\frac{\underline{\text { Sig. (2- }}}{\text { sided) }}$ & $\underline{\text { Exact Sig. (2-sided) }}$ & $\underline{\text { Exact Sig. (1- }}$ \\
Chi-Square & 11.77 & 1 & $\frac{\underline{.001}}{\text { sided) }}$ & & \\
Continuity Correction & 10.933 & 1 & .001 & & \\
Likelihood Ratio & 12.13 & 1 & .000 & & .000 \\
$\begin{array}{l}\text { Fisher's Exact Test } \\
\text { Linear-by-Linear }\end{array}$ & 11.73 & 1 & .001 & .001 & \\
Association & & & & & \\
N of Valid Cases & 328 & & & & \\
\hline
\end{tabular}




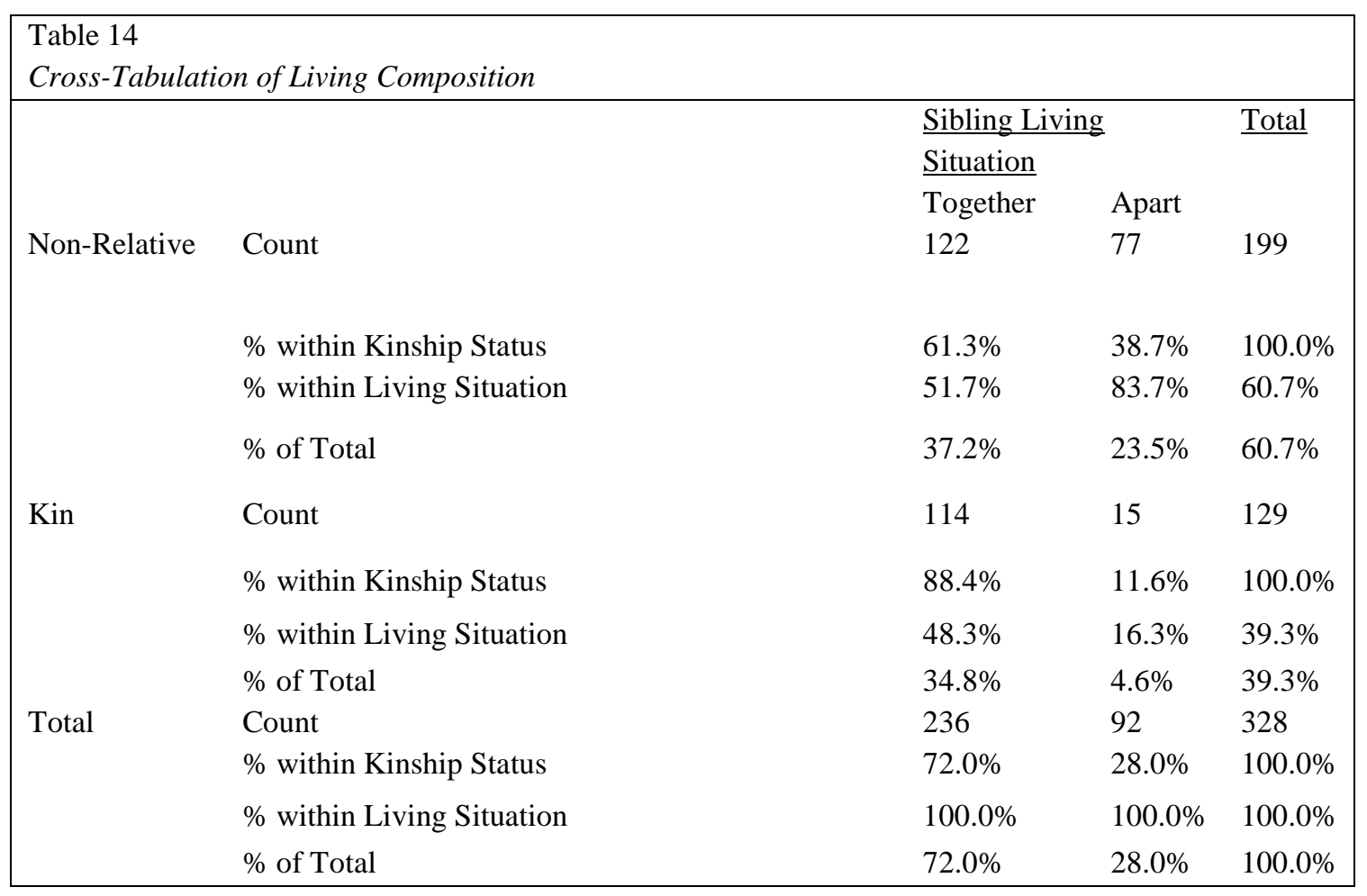

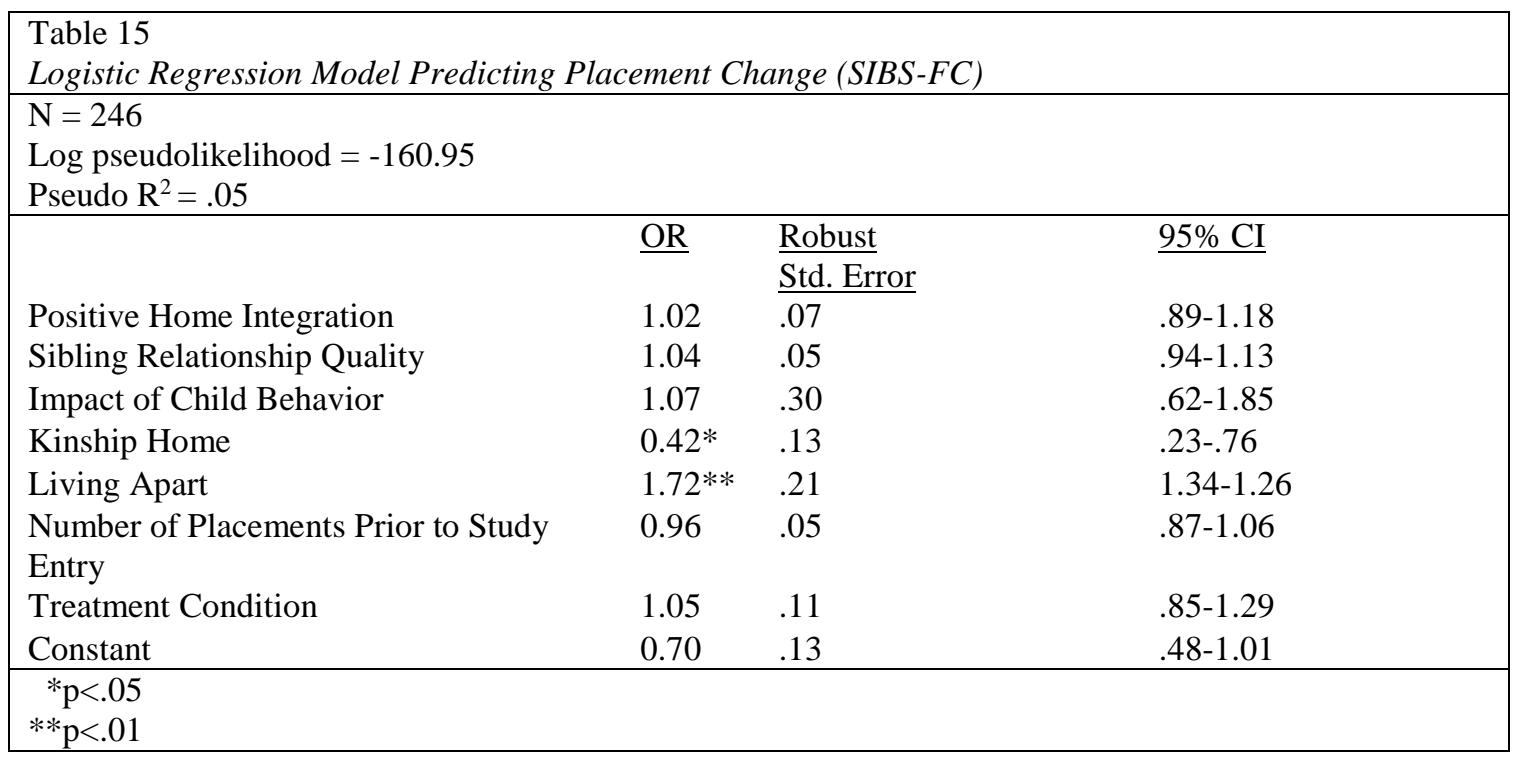




\begin{tabular}{|c|c|c|c|c|}
\hline \multicolumn{5}{|c|}{$\begin{array}{l}\text { Table } 16 \\
\text { Characteristics of Youth Living Apart from their Sibling in Kinship Care }\end{array}$} \\
\hline Dyad & $\begin{array}{l}\text { Sibling } \\
\text { Type }\end{array}$ & $\begin{array}{l}\text { Older Sibling } \\
\text { BL Placement }\end{array}$ & $\begin{array}{l}\text { Younger Sibling } \\
\text { BL Placement }\end{array}$ & Notes \\
\hline 1 & Full & $\begin{array}{l}\text { Biological } \\
\text { Grandmother }\end{array}$ & Biological Sister & \\
\hline 2 & Full & Biological Aunt & $\begin{array}{l}\text { Non-Relative } \\
\text { Foster Care }\end{array}$ & $\begin{array}{l}\text { Younger sibling has special needs (Autism } \\
\text { Spectrum Disorder). }\end{array}$ \\
\hline 3 & Full & Biological Aunt & Biological Aunt & $\begin{array}{l}\text { Children live in separate kinship homes with } \\
\text { different Biological Aunts. }\end{array}$ \\
\hline 4 & Half & $\begin{array}{l}\text { Biological } \\
\text { Grandmother }\end{array}$ & $\begin{array}{l}\text { Residential } \\
\text { Treatment } \\
\text { Facility }\end{array}$ & $\begin{array}{l}\text { Younger child experienced severe psychiatric } \\
\text { disturbances resulting in } 20 \text { separate } \\
\text { placements in a } 6 \text { week period of time. }\end{array}$ \\
\hline 5 & Full & $\begin{array}{l}\text { Biological } \\
\text { Mother }\end{array}$ & $\begin{array}{l}\text { Non-Relative } \\
\text { Foster Care }\end{array}$ & Mother was experiencing housing instability. \\
\hline 6 & Half & $\begin{array}{l}\text { Biological } \\
\text { Father }\end{array}$ & $\begin{array}{l}\text { Biological } \\
\text { Grandmother }\end{array}$ & $\begin{array}{l}\text { Older sibling was not in custody of child } \\
\text { welfare. }\end{array}$ \\
\hline 7 & Half & $\begin{array}{l}\text { Biological } \\
\text { Sister }\end{array}$ & $\begin{array}{l}\text { Non-Relative } \\
\text { Foster Care }\end{array}$ & \\
\hline 8 & Half & $\begin{array}{l}\text { Non-Relative } \\
\text { Foster Care }\end{array}$ & $\begin{array}{l}\text { Biological } \\
\text { Father }\end{array}$ & \\
\hline 9 & Full & $\begin{array}{l}\text { Biological } \\
\text { Mother }\end{array}$ & $\begin{array}{l}\text { Non-Relative } \\
\text { Foster Care }\end{array}$ & \\
\hline 10 & Half & $\begin{array}{l}\text { Biological } \\
\text { Grandmother }\end{array}$ & $\begin{array}{l}\text { Non-Relative } \\
\text { Foster Care }\end{array}$ & \\
\hline 11 & Half & $\begin{array}{l}\text { Non-Relative } \\
\text { Foster Care }\end{array}$ & $\begin{array}{l}\text { Biological } \\
\text { Mother }\end{array}$ & $\begin{array}{l}\text { Older sibling experienced } 5 \text { non-relative } \\
\text { foster care placements. }\end{array}$ \\
\hline 12 & Step & $\begin{array}{l}\text { Biological } \\
\text { Mother }\end{array}$ & Group Home & \\
\hline 13 & Half & $\begin{array}{l}\text { Biological } \\
\text { Mother }\end{array}$ & Biological Aunt & \\
\hline 14 & Half & $\begin{array}{l}\text { Non-Relative } \\
\text { Foster Care }\end{array}$ & $\begin{array}{l}\text { Biological } \\
\text { Mother }\end{array}$ & \\
\hline
\end{tabular}


Table 17

Analysis of Variance for Sibling Relationship Quality by Living Composition

Test of Homogeneity of Variances

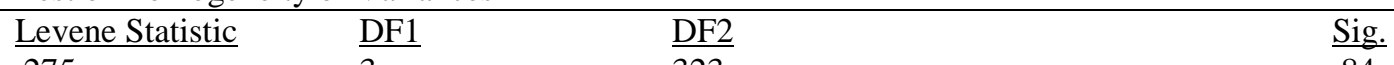

\begin{tabular}{llll}
\hline .275 & 323 & $\frac{\text { Sig }}{.84}$
\end{tabular}

\begin{tabular}{|llllll|}
\hline ANOVA & \multicolumn{1}{l|}{ Sum of Squares } & $\underline{\mathrm{DF}}$ & $\underline{\text { Mean Square }}$ & $\underline{\mathrm{F}}$ & $\underline{\text { Sig. }}$ \\
\hline Between Groups & 7.38 & 3 & 2.46 & 5.27 & .001 \\
Within Groups & 150.85 & 323 & .47 & & \\
Total & 158.23 & 326 & & \\
\hline
\end{tabular}

\begin{tabular}{|llllll|}
\hline Tukey's Multiple Comparisons & & & & \\
\hline Living Composition & & Mean Difference & Std. Error & Sig. & 95\% CI \\
\hline Non-Relative, Apart & Non-Relative, Together & .24 & .10 & .07 & $-.013-50$ \\
& Kin, Apart & -.31 & .19 & .38 & $-.81-.19$ \\
& Kin, Together & $.27^{*}$ & .10 & .04 & $.01-.53$ \\
Non-Relative, Together & Non-Relative, Apart & -.25 & .10 & .07 & $-.50-.01$ \\
& Kin, Apart & $-.55^{*}$ & .19 & .02 & $-1.04--.08$ \\
& Kin, Together & .02 & .09 & .10 & $-.21-.25$ \\
\multirow{5}{*}{ Kin, Apart } & Non-Relative, Apart & .31 & .19 & .38 & $-.19-.81$ \\
& Non-Relative, Together & $.55^{*}$ & .19 & .02 & $.07-1.03$ \\
Kin, Together & Kin, Together & $.58^{*}$ & .19 & .01 & $.09-1.06$ \\
& Non-Relative, Apart & $-.27^{*}$ & .10 & .04 & $-.53--.01$ \\
& Non-Relative, Together & -.02 & .09 & .96 & $-.25-.21$ \\
& Kin, Apart & $-.58^{*}$ & .19 & .013 & $-1.06--.09$ \\
\hline *p $<.05$ & & & & & \\
\hline
\end{tabular}

\begin{tabular}{|lllll|}
\hline \multicolumn{2}{ll}{ Living Composition } & $\underline{\mathrm{N}}$ & \multicolumn{2}{c|}{ Subset for alpha $=0.05$} \\
\hline Tukey HSD & Kin, Together & 114 & 3.56 & \\
& Non-Relative, Together & 122 & 3.57 & \\
& Non-Relative, Apart & 76 & 3.82 & 3.82 \\
& Kin, Apart & 15 & & 4.13 \\
& Sig. & & .29 & .17 \\
\hline
\end{tabular}




\begin{tabular}{|c|c|c|c|}
\hline $\begin{array}{l}\text { Table } 18 \\
\text { Analysis of Vari }\end{array}$ & Numbe & Prior & ositior \\
\hline Test of Homoge & Jarian & & \\
\hline Levene Statistic & $\underline{\text { DF1 }}$ & $\underline{\mathrm{DF} 2}$ & Sig. \\
\hline 6.675 & 3 & 267 & .00 \\
\hline
\end{tabular}

\begin{tabular}{|c|c|c|c|c|c|}
\hline \multicolumn{6}{|l|}{ ANOVA } \\
\hline & $\underline{\text { Sum of Squares }}$ & $\underline{\mathrm{DF}}$ & Mean Square & $\underline{F}$ & Sig. \\
\hline Between Groups & 472.86 & 3 & 157.62 & 18.44 & .00 \\
\hline Within Groups & 2282.51 & 267 & 8.55 & & \\
\hline Total & 2755.37 & 270 & & & \\
\hline
\end{tabular}

\begin{tabular}{|llllc|}
\hline \multicolumn{6}{l}{ Robust Tests of Equality of Means } \\
\hline & $\underline{\text { Statistic }}$ & $\underline{\text { DF1 }}$ & $\underline{\text { DF2 }}$ & $\underline{\text { Sig. }}$ \\
Welch & 11.30 & 3 & 36.11 & .00 \\
Brown-Forsythe & 16.10 & 3 & 69.34 & .00 \\
\hline
\end{tabular}

\begin{tabular}{|c|c|c|c|c|c|}
\hline \multicolumn{6}{|l|}{ Multiple Comparisons } \\
\hline Living Composition & & Mean Difference & Std. Error & Sig. & $95 \% \mathrm{CI}$ \\
\hline \multirow[t]{3}{*}{$\overline{\text { Non-Relative, Apart }}$} & Non-Relative, Together & $2.79^{*}$ & .47 & .00 & $1.57-4.01$ \\
\hline & Kin, Apart & 1.28 & 1.04 & .61 & $-1.42-3.97$ \\
\hline & Kin, Together & $3.36^{*}$ & .48 & .00 & $2.14-4.58$ \\
\hline \multirow{3}{*}{$\begin{array}{l}\text { Non-Relative, } \\
\text { Together }\end{array}$} & Non-Relative, Apart & $-2.79^{*}$ & .47 & .00 & $-4.01--1.57$ \\
\hline & Kin, Apart & -1.51 & 1.02 & .45 & $-4.14-1.12$ \\
\hline & Kin, Together & .57 & .41 & .50 & $-.50-1.64$ \\
\hline \multirow[t]{3}{*}{ Kin, Apart } & Non-Relative, Apart & -1.28 & 1.04 & .61 & $-3.97-1.42$ \\
\hline & Non-Relative, Together & 1.51 & 1.02 & .45 & $-1.12-4.14$ \\
\hline & Kin, Together & 2.08 & 1.02 & .17 & $-.55-4.71$ \\
\hline \multirow[t]{3}{*}{ Kin, Together } & Non-Relative, Apart & $-3.36^{*}$ & .47 & .00 & $-4.58--2.14$ \\
\hline & Non-Relative, Together & -.57 & .41 & .51 & $-1.64-.50$ \\
\hline & Kin, Apart & -2.08 & 1.02 & .17 & $-4.71-.55$ \\
\hline
\end{tabular}




\begin{tabular}{|l}
\begin{tabular}{|l} 
Table 19 \\
Analysis of Variance for Number of Placements Experienced During Study Enrollment According to \\
Living Composition
\end{tabular} \\
\hline \begin{tabular}{llll|}
\hline Test of Homogeneity of Variances \\
\hline Levene Statistic & $\underline{\text { DF1 }}$ & $\underline{\text { DF2 }}$ & $\underline{\text { Sig. }}$ \\
5.496 & 3 & 236 & .00 \\
\hline
\end{tabular}
\end{tabular}

\begin{tabular}{|c|c|c|c|c|c|}
\hline \multicolumn{6}{|l|}{ ANOVA } \\
\hline & $\underline{\text { Sum of Squares }}$ & $\underline{\mathrm{DF}}$ & Mean Square & $\underline{F}$ & Sig. \\
\hline Between Groups & 27.79 & 3 & 9.26 & 8.02 & .000 \\
\hline Within Groups & 272.61 & 236 & 1.16 & & \\
\hline Total & 300.40 & 239 & & & \\
\hline
\end{tabular}

\begin{tabular}{|c|c|c|c|c|}
\hline \multicolumn{5}{|c|}{ Robust Tests of Equality of Means } \\
\hline & $\underline{\text { Statistic }}$ & $\underline{\mathrm{DF} 1}$ & DF2 & $\underline{\text { Sig }}$ \\
\hline Welch & 6.014 & 3 & 28.85 & .00 \\
\hline Brown-Forsythe & 8.29 & 3 & 98.44 & .00 \\
\hline
\end{tabular}

\begin{tabular}{|c|c|c|c|c|c|}
\hline \multicolumn{6}{|l|}{ Multiple Comparisons } \\
\hline \multicolumn{6}{|c|}{ Dependent Variable: Number of Placement Changes During Study Enrollment } \\
\hline \multicolumn{2}{|l|}{ Living Composition } & Mean Difference & $\underline{\text { Std. Error }}$ & $\underline{\text { Sig. }}$ & $95 \% \mathrm{CI}$ \\
\hline \multirow[t]{3}{*}{ Non-Relative, Apart } & $\begin{array}{l}\text { Non-Relative, } \\
\text { Together }\end{array}$ & $.54^{*}$ & .18 & .02 & $.06-1.01$ \\
\hline & Kin, Apart & .97 & .43 & .11 & $-.15-2.08$ \\
\hline & Kin, Together & $.88^{*}$ & .18 & .00 & $.41-1.36$ \\
\hline \multirow{3}{*}{$\begin{array}{l}\text { Non-Relative, } \\
\text { Together }\end{array}$} & Non-Relative, Apart & $-.54^{*}$ & .18 & .02 & $-1.01--.06$ \\
\hline & Kin, Apart & .43 & .42 & .73 & $-.66-1.53$ \\
\hline & Kin, Together & .35 & .16 & .14 & $-.07-.77$ \\
\hline \multirow[t]{3}{*}{ Kin, Apart } & Non-Relative, Apart & -.97 & .43 & .11 & $-2.08-.15$ \\
\hline & $\begin{array}{l}\text { Non-Relative, } \\
\text { Together }\end{array}$ & -.43 & .42 & .73 & $-1.53-.66$ \\
\hline & Kin, Together & -.09 & .42 & 1.00 & $\begin{array}{l}-1.18- \\
1.01\end{array}$ \\
\hline \multirow[t]{3}{*}{ Kin, Together } & Non-Relative, Apart & $-.88^{*}$ & .18 & .00 & $-1.36--.41$ \\
\hline & $\begin{array}{l}\text { Non-Relative, } \\
\text { Together }\end{array}$ & -.35 & .16 & .14 & $-.77-.07$ \\
\hline & Kin, Apart & .09 & .42 & 1.00 & $\begin{array}{l}-1.01- \\
1.18\end{array}$ \\
\hline
\end{tabular}




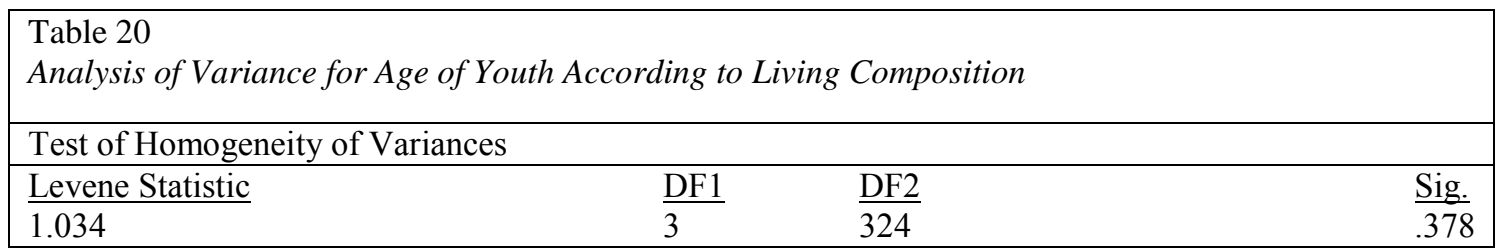

\begin{tabular}{|c|c|c|c|c|c|}
\hline ANOVA & & & & & \\
\hline & $\underline{\text { Sum of Squares }}$ & $\underline{\mathrm{DF}}$ & Mean Square & $\underline{F}$ & $\underline{\text { Sig }}$ \\
\hline Between Groups & 37.11 & 3 & 12.37 & 3.13 & .03 \\
\hline Within Groups & 1279.26 & 324 & 3.95 & & \\
\hline Total & 1316.37 & 327 & & & \\
\hline
\end{tabular}

\begin{tabular}{|lllll|}
\hline \multicolumn{2}{|l|}{ Robust Tests of Equality of Means } & & & $\underline{\text { Sig }}$ \\
\hline & $\underline{\text { Statistic }}$ & $\underline{\text { DF1 }}$ & $\underline{\text { DF2 }}$ & - \\
Welch & 3.07 & 3 & 60.98 & .03 \\
Brown-Forsythe & 2.67 & 3 & 69.60 & .05 \\
\hline
\end{tabular}

\begin{tabular}{|c|c|c|c|c|c|}
\hline \multicolumn{6}{|l|}{ Multiple Comparisons } \\
\hline Living Composition & & $\begin{array}{l}\text { Mean } \\
\text { Difference }\end{array}$ & $\underline{\text { Std. Error }}$ & Sig. & $95 \% \mathrm{CI}$ \\
\hline \multirow[t]{3}{*}{ Non-Relative, Apart } & $\begin{array}{l}\text { Non-Relative, } \\
\text { Together }\end{array}$ & $.76^{*}$ & .29 & .04 & $.02-1.51$ \\
\hline & Kin, Apart & .74 & .56 & .55 & $-.71-2.19$ \\
\hline & Kin, Together & $.83^{*}$ & .29 & .03 & $.07-1.58$ \\
\hline \multirow{3}{*}{$\begin{array}{l}\text { Non-Relative, } \\
\text { Together }\end{array}$} & Non-Relative, Apart & $-.76^{*}$ & .29 & .04 & $-1.51-.02$ \\
\hline & Kin, Apart & -.02 & .54 & 1.00 & $-1.43-1.38$ \\
\hline & Kin, Together & .06 & .26 & 1.00 & $-.61-.73$ \\
\hline \multirow[t]{3}{*}{ Kin, Apart } & Non-Relative, Apart & -.74 & .56 & .55 & $-2.19-.71$ \\
\hline & $\begin{array}{l}\text { Non-Relative, } \\
\text { Together }\end{array}$ & .02 & .54 & 1.00 & $-1.38-1.43$ \\
\hline & Kin, Together & .09 & .55 & 1.00 & $-1.32-1.50$ \\
\hline \multirow[t]{3}{*}{ Kin, Together } & Non-Relative, Apart & $-.83^{*}$ & .29 & .03 & $-1.58--.07$ \\
\hline & $\begin{array}{l}\text { Non-Relative, } \\
\text { Together }\end{array}$ & -.06 & .26 & 1.00 & $-.73-.61$ \\
\hline & Kin, Apart & -.09 & .55 & 1.00 & $-1.50-1.32$ \\
\hline
\end{tabular}




\begin{tabular}{|c|c|c|c|c|c|c|}
\hline $\begin{array}{l}\text { Table } \\
\text { Cross- }\end{array}$ & ulation and Chi & are Analysis $f$ & Gender $b$ & ing Comp & tion & \\
\hline & & $\begin{array}{l}\text { Non-Relative, } \\
\text { Apart }\end{array}$ & $\frac{\frac{\text { Non- }}{\text { Relative, }}}{\frac{\text { Together }}{\text { Toge }}}$ & $\frac{\text { Kin, }}{\text { Apart }}$ & Kin, Together & $\underline{\text { Total }}$ \\
\hline Femal & Count & 36 & 62 & 7 & 59 & 164 \\
\hline $\mathrm{e}$ & $\%$ within gender & $22.0 \%$ & $37.8 \%$ & $4.3 \%$ & $36.0 \%$ & $100.0 \%$ \\
\hline & $\begin{array}{l}\text { \% within Living } \\
\text { Composition }\end{array}$ & $46.8 \%$ & $50.8 \%$ & $46.7 \%$ & $51.8 \%$ & $50.0 \%$ \\
\hline & $\%$ of Total & $11.0 \%$ & $18.9 \%$ & $2.1 \%$ & $18.0 \%$ & $50.0 \%$ \\
\hline Male & Count & 41 & 60 & & 55 & 164 \\
\hline & $\begin{array}{l}\% \text { within Living } \\
\text { Composition }\end{array}$ & $53.2 \%$ & $49.2 \%$ & $53.3 \%$ & $48.2 \%$ & $50.0 \%$ \\
\hline & $\%$ of Total & $12.5 \%$ & $18.3 \%$ & $2.4 \%$ & $16.8 \%$ & $50.0 \%$ \\
\hline Total & Count & 77 & 122 & 15 & 114 & 328 \\
\hline & $\%$ within Gender & $23.5 \%$ & $37.2 \%$ & $4.6 \%$ & $34.8 \%$ & $100.0 \%$ \\
\hline & $\begin{array}{l}\% \text { within Living } \\
\text { Composition }\end{array}$ & $100.0 \%$ & $100.0 \%$ & $100.0 \%$ & $100.0 \%$ & $100.0 \%$ \\
\hline & $\%$ of Total & $23.5 \%$ & $37.2 \%$ & $4.6 \%$ & $34.8 \%$ & $100.0 \%$ \\
\hline
\end{tabular}

\begin{tabular}{|lllc|}
\hline Chi-Square Analysis & & & $\underline{\text { VF }}$ \\
\hline & $\underline{\text { Value }}$ & $\underline{.5}$ \\
Pearson Chi-Square & $.56^{\mathrm{a}}$ & 3 & .91 \\
Likelihood Ratio & .57 & 3 & .90 \\
Linear-by-Linear Association & .31 & 1 & .58 \\
N of Valid Cases & 328 & & \\
\hline
\end{tabular}




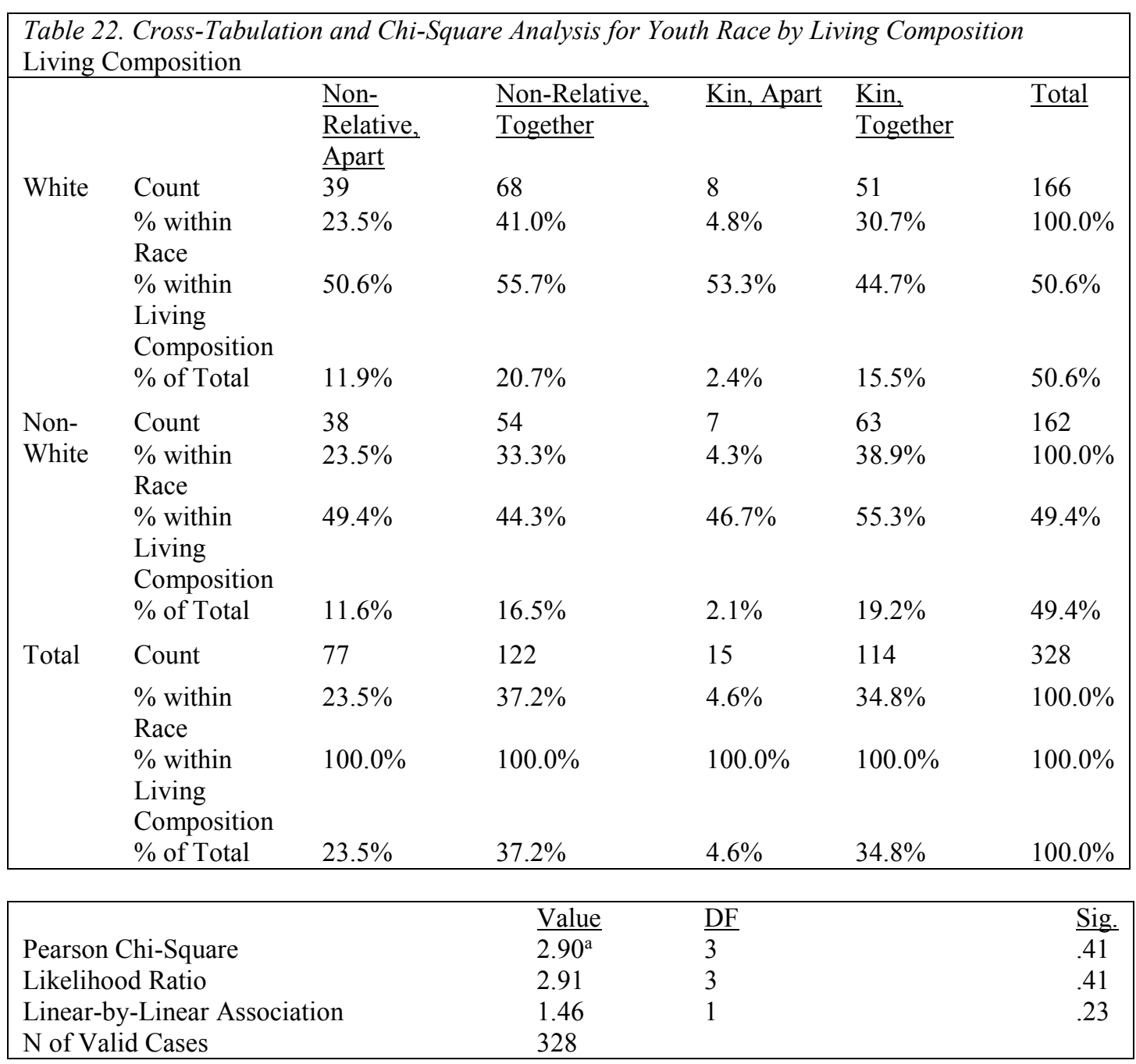




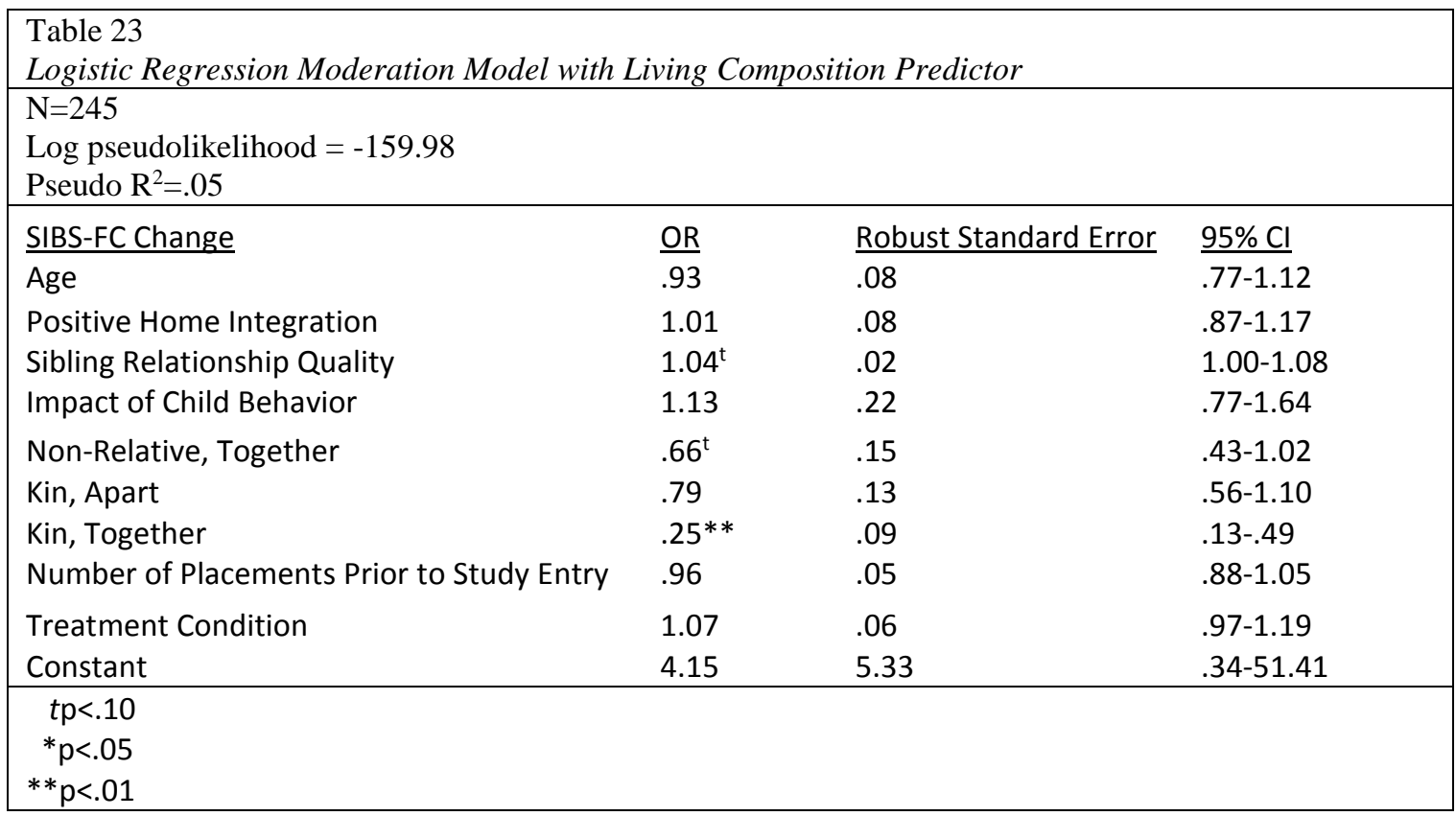




\begin{tabular}{|c|c|}
\hline $\begin{array}{l}\text { Table } 24 \\
\text { Major Study Findings }\end{array}$ & \\
\hline$\underline{\text { Variable }}$ & Major Descriptive Findings \\
\hline Sibling Living Situation & $72 \%$ of siblings in this sample lived together at study enrollment. \\
\hline Kinship Caregiver Status & $\begin{array}{l}\text { The majority }(60.7 \%) \text { of baseline caregivers were not related to the } \\
\text { child. The remaining } 39.3 \% \text { of the sample were comprised of kinship } \\
\text { caregivers. These kinship providers included Aunts }(12.5 \%) \text {, } \\
\text { grandmothers }(11 \%) \text {, mothers }(10.4 \%) \text {, uncles }(2.4 \%) \text {, fathers }(.9 \%) \text {, } \\
\text { and sisters }(.6 \%) \text {. }\end{array}$ \\
\hline Positive Home Integration & $\begin{array}{l}\text { Youth responses to the positive home integration construct were } \\
\text { skewed left, with an average rating of } 8.74(\mathrm{SD}=1.23) \text { on a } 10 \text { point } \\
\text { scale. }\end{array}$ \\
\hline Sibling Relationship Quality & $\begin{array}{l}\text { Youth responses to the sibling relationship questionnaire were } \\
\text { positive, with an average rating of } 3.65(\mathrm{SD}=.70) \text { on a } 5 \text { point scale. }\end{array}$ \\
\hline Impact of Child Behavior & $\begin{array}{l}\text { Caregivers reported low impact of child behavior, with an average } \mathrm{f} \\
1.87(\mathrm{SD}=.73) \text { on a } 5 \text { point scale. }\end{array}$ \\
\hline $\begin{array}{l}\text { Number of Placement Changes } \\
\text { During Study Enrollment }\end{array}$ & $\begin{array}{l}\text { Youth generally experienced few placement changes during study } \\
\text { participation, with an average of } .70(\mathrm{SD}=1.12) \text { and a range from } 0 \text { to } \\
7 \text { changes over } 18 \text { months of study enrollment. }\end{array}$ \\
\hline$\underline{\text { Variable }}$ & $\underline{\text { Major Bivariate Correlations }}$ \\
\hline Positive Home Integration & $\begin{array}{l}\text { Positive home integration with moderately positively associated with } \\
\text { sibling relationship quality }(\mathrm{r}=.18, \mathrm{p}<.01) \text { and living in a kinship home } \\
(\mathrm{r}=.11, \mathrm{p}<.05) \text {. }\end{array}$ \\
\hline Sibling Relationship Quality & $\begin{array}{l}\text { Sibling relationship quality was moderately positively associated with } \\
\text { living apart from ones sibling }(\mathrm{r}=.20, \mathrm{p}<.01) \text { and positive home } \\
\text { integration }(\mathrm{r}=.18, \mathrm{p}<.01) \text {. }\end{array}$ \\
\hline Impact of Child Behavior & $\begin{array}{l}\text { Impact of Child Behavior was positively moderately associated with } \\
\text { living apart from ones sibling }(\mathrm{r}=.11, \mathrm{p}<.05) \text { and number of placement } \\
\text { changes experienced during study enrollment }(\mathrm{r}=.16, \mathrm{p}<.05) \text {. }\end{array}$ \\
\hline Kinship Care & $\begin{array}{l}\text { Living in a kinship home was negatively associated with living apart } \\
\text { from one's sibling }(\mathrm{r}=-.30, \mathrm{p}<.01) \text {, number of placements experienced } \\
\text { prior to study entry }(\mathrm{r}=-.23, \mathrm{p}<.01) \text {, and number of placements } \\
\text { experienced during study enrollment }(\mathrm{r}=-.25, \mathrm{p}<.01) \text {. }\end{array}$ \\
\hline Sibling Living Situation & $\begin{array}{l}\text { Living apart from ones sibling was moderately positively associated } \\
\text { with number of placements experienced prior to study }(\mathrm{r}=.40, \mathrm{p}<.01) \\
\text { and number of placements experienced during the course of study } \\
\text { enrollment }(\mathrm{r}=.24, \mathrm{p}<.01) \text {. }\end{array}$ \\
\hline Number of Placement Changes & Number of placement changes prior to study enrollment was \\
\hline Prior to Study Enrollment & $\begin{array}{l}\text { moderately positively associated with the number of placement } \\
\text { changes experienced during study enrollment }(\mathrm{r}=.32, \mathrm{p}<.01)\end{array}$ \\
\hline$\underline{\text { Variable }}$ & $\underline{\text { Major Chi-Square Findings }}$ \\
\hline Kinship Status & $\begin{array}{l}\text { Children living in kinship care were less likely to experience a } \\
\text { placement change than were children in non-relative care }\left(X^{2}=21.12 \text {, }\right. \\
D F=1, p<.01)\end{array}$ \\
\hline
\end{tabular}


Sibling Living Situation

Variable

Kinship Care

Sibling Living Situation

Variable

Sibling Relationship Quality

Non Relative, Together

Kin, Together
Children living in care with their siblings were less likely to experience a placement change than children who were placed separately from their siblings $\left(X^{2}=11.77, D F=1, p<.01\right)$

Major Multivariate Findings

The odds of placement disruption for youth living in a kinship home was $57 \%$ less than children in non-relative care $(\mathrm{OR}=.42, \mathrm{RSE}=.13$, $\mathrm{p}<.05)$

The odds of placement disruption for youth living apart from their siblings was $72 \%$ than for those who were co-placed with their siblings $(\mathrm{OR}=1.72, \mathrm{RSE}=.21, \mathrm{p}<.01)$.

\section{Major Moderation Findings}

Sibling relationship quality trended towards significant, with a $4 \%$ increase in odds of disruption for every unit increase for sibling relationship questionnaire scores ( $\mathrm{OR}=1.04, \mathrm{RSE}=.02, \mathrm{p}<.10)$. Living together with ones sibling in non-relative care trended toward significant, with youth living in this category experiencing a $44 \%$ decrease in odds of placement disruption $(\mathrm{OR}=.66, \mathrm{RSE}=.15, \mathrm{p}<.10)$. Living together with ones sibling in kinship care decreased the odds of placement disruption by $75 \%$ (OR=.25, RSE=.09, p<.01). 
Figure 1. Conceptual Model
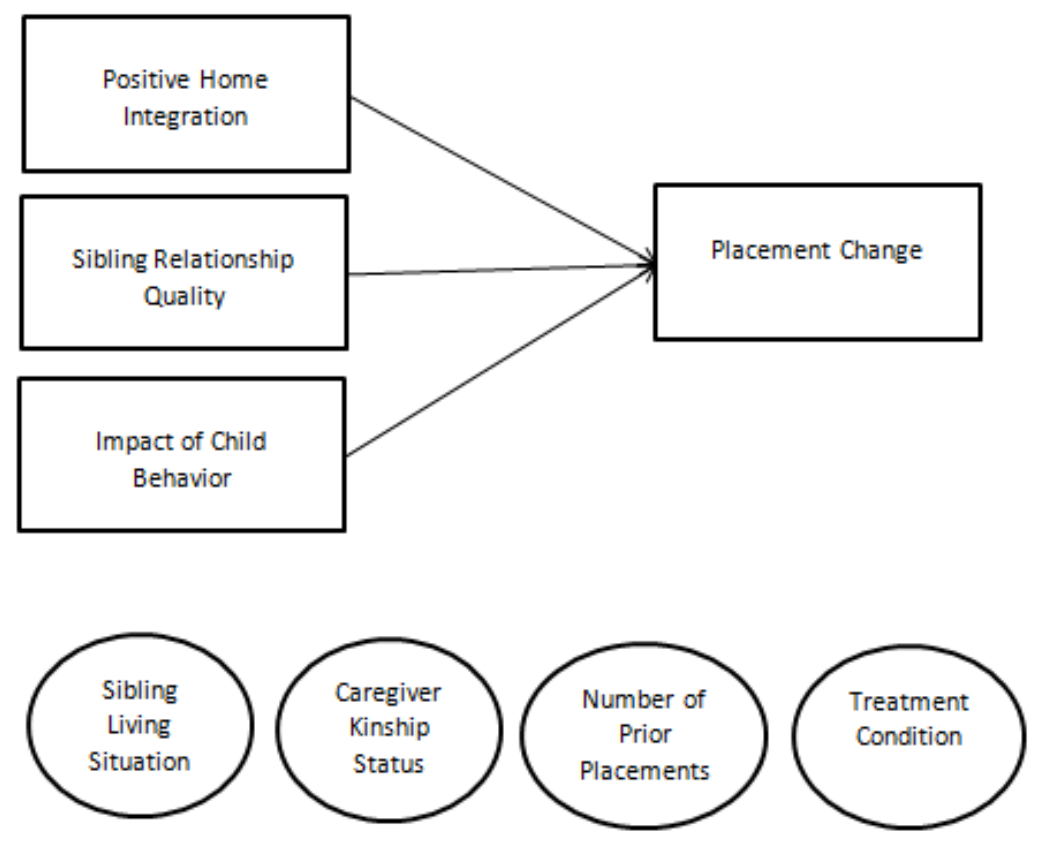

Figure 2. Moderation Model
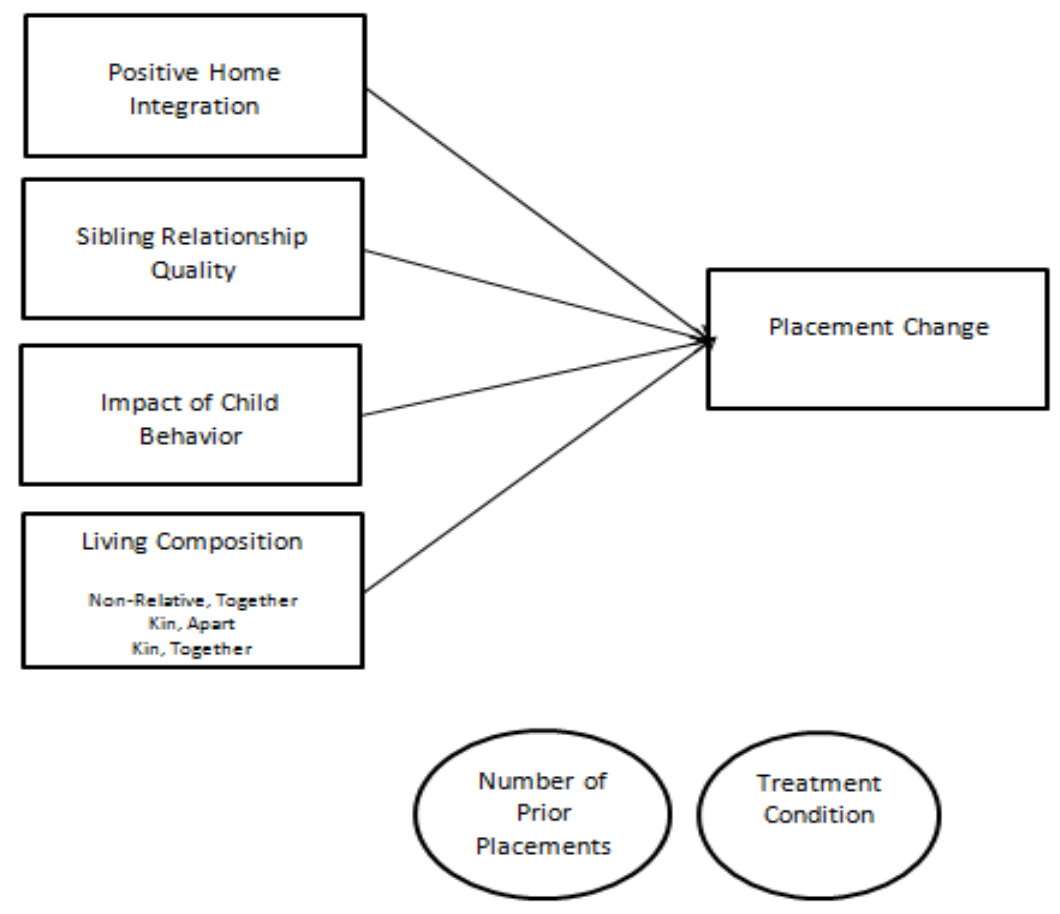
Figure 3. Theoretical Model

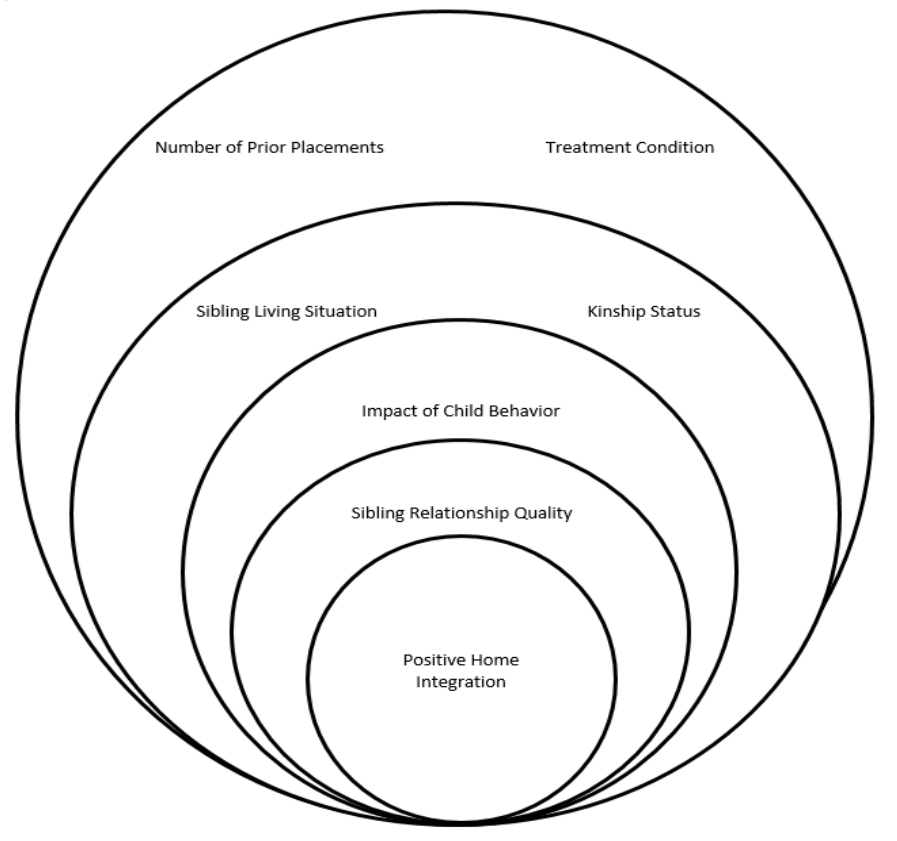

Figure 4. Measurement Schedule

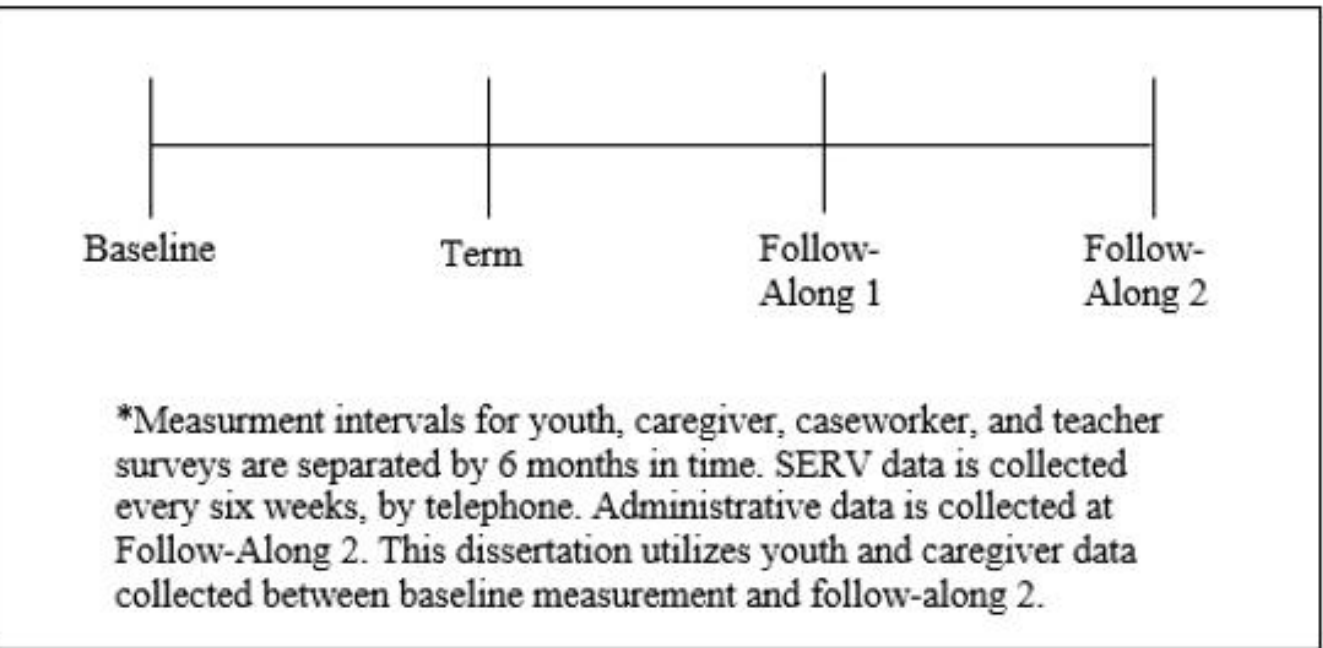


Figure 5. Histogram of Placement Changes Prior to Study Entry (ORKIDS)

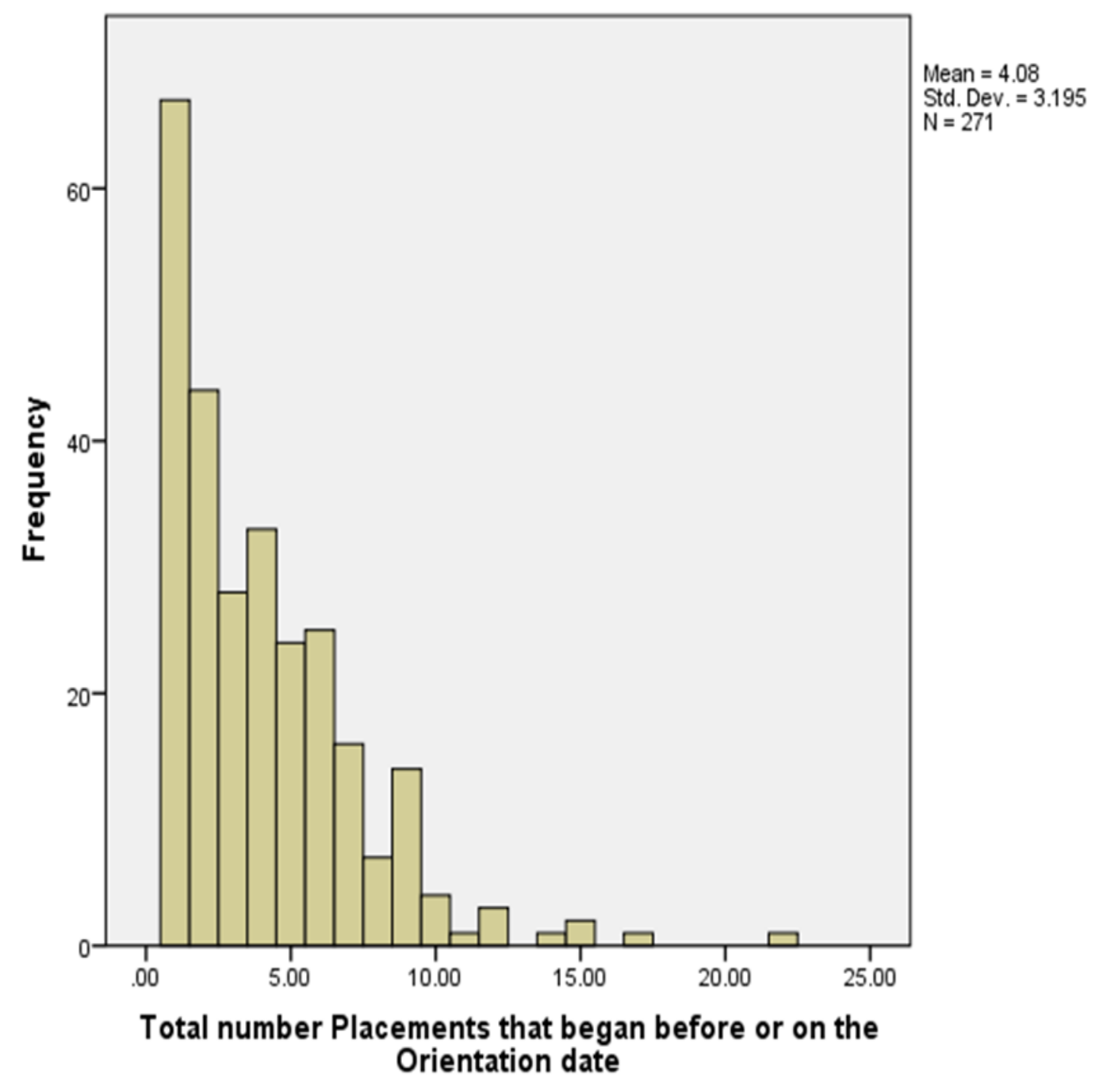


Figure 6. Histogram of Placement Changes (SIBS-FC)

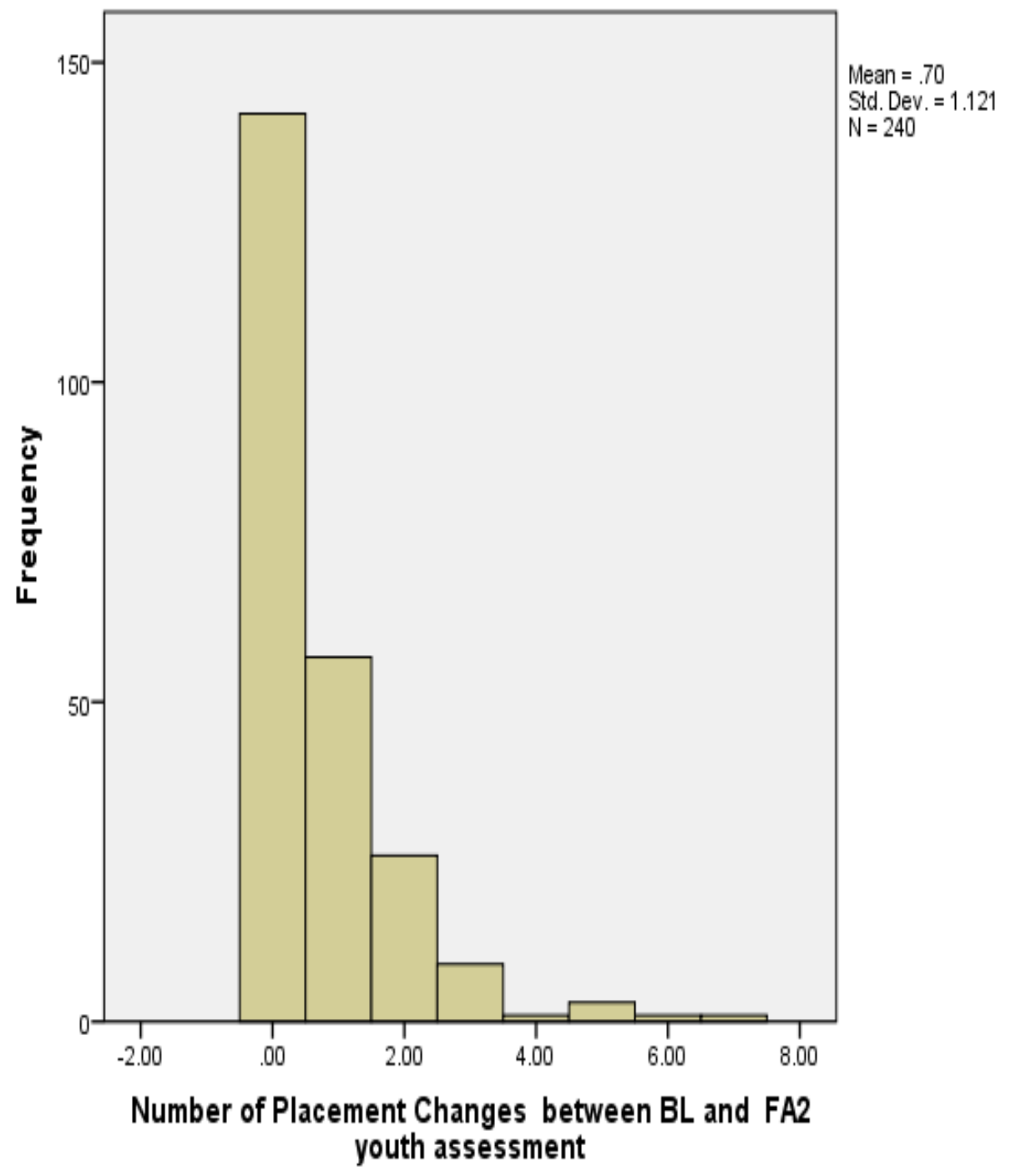


Figure 7. Histogram of placement changes (ORKIDS)

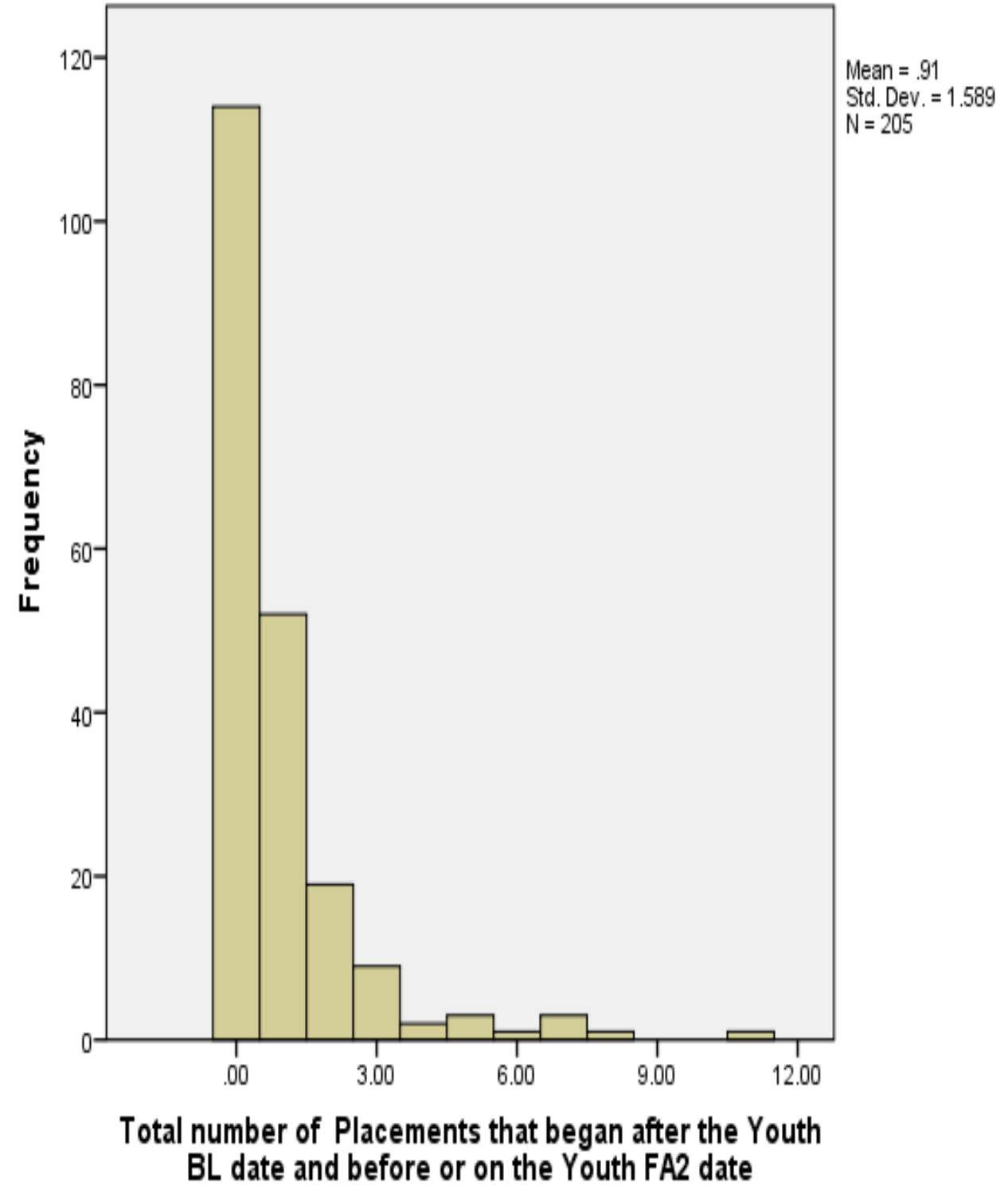


Figure 8. Histogram of Binary Placement Change Variable, $0=0$ Coding

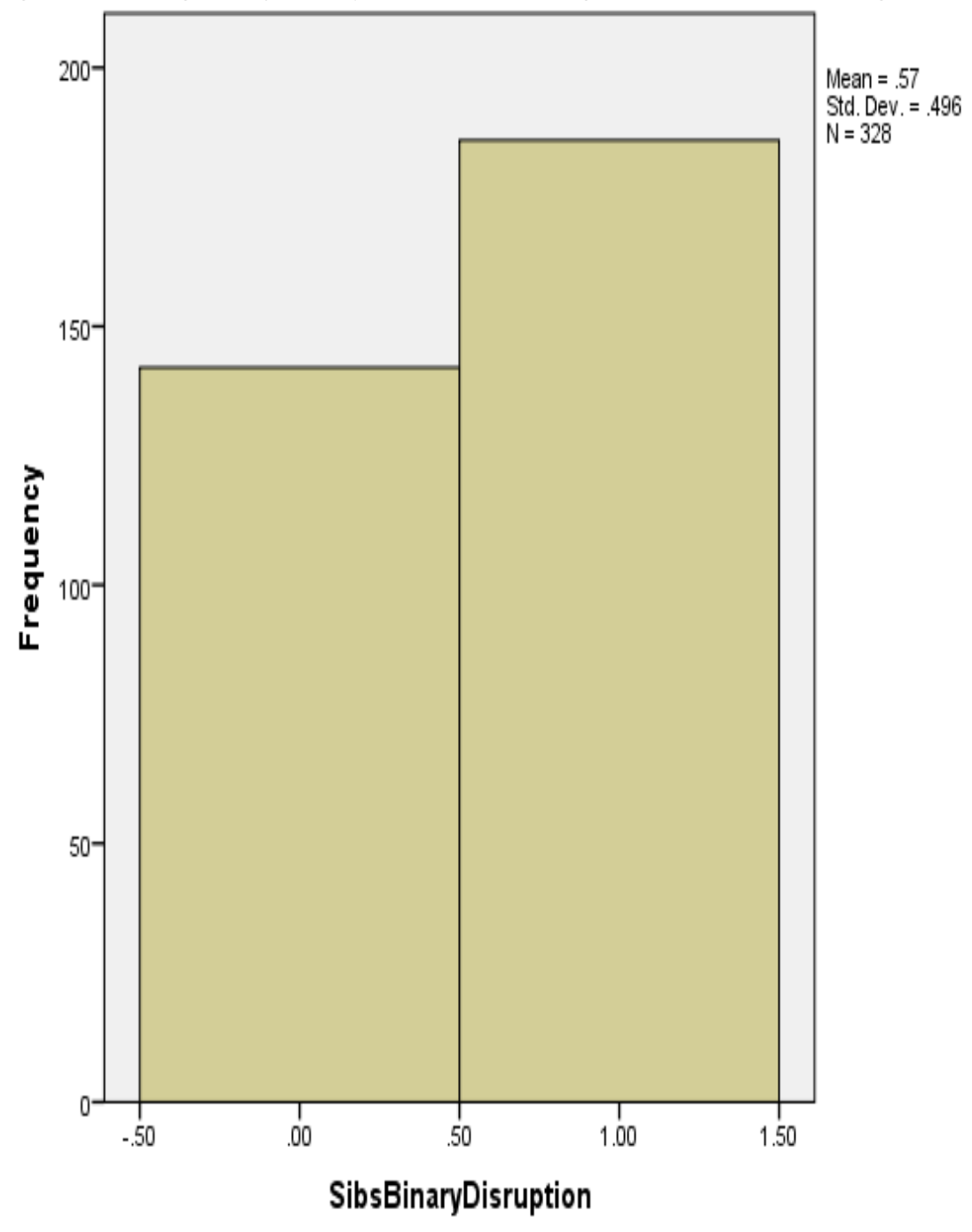


Figure 9. Histogram of Binary Placement Change Variable, $1=0$ Coding

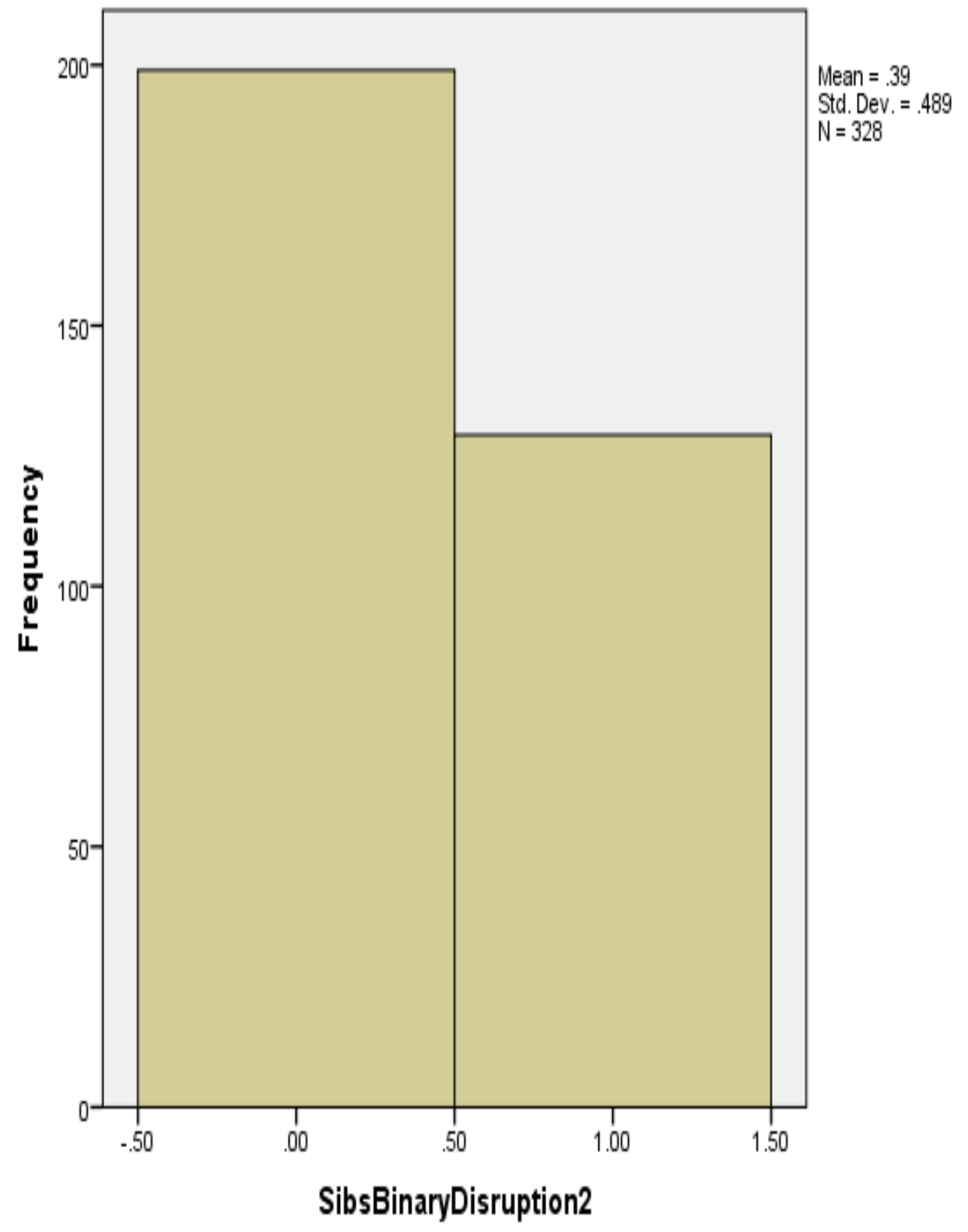




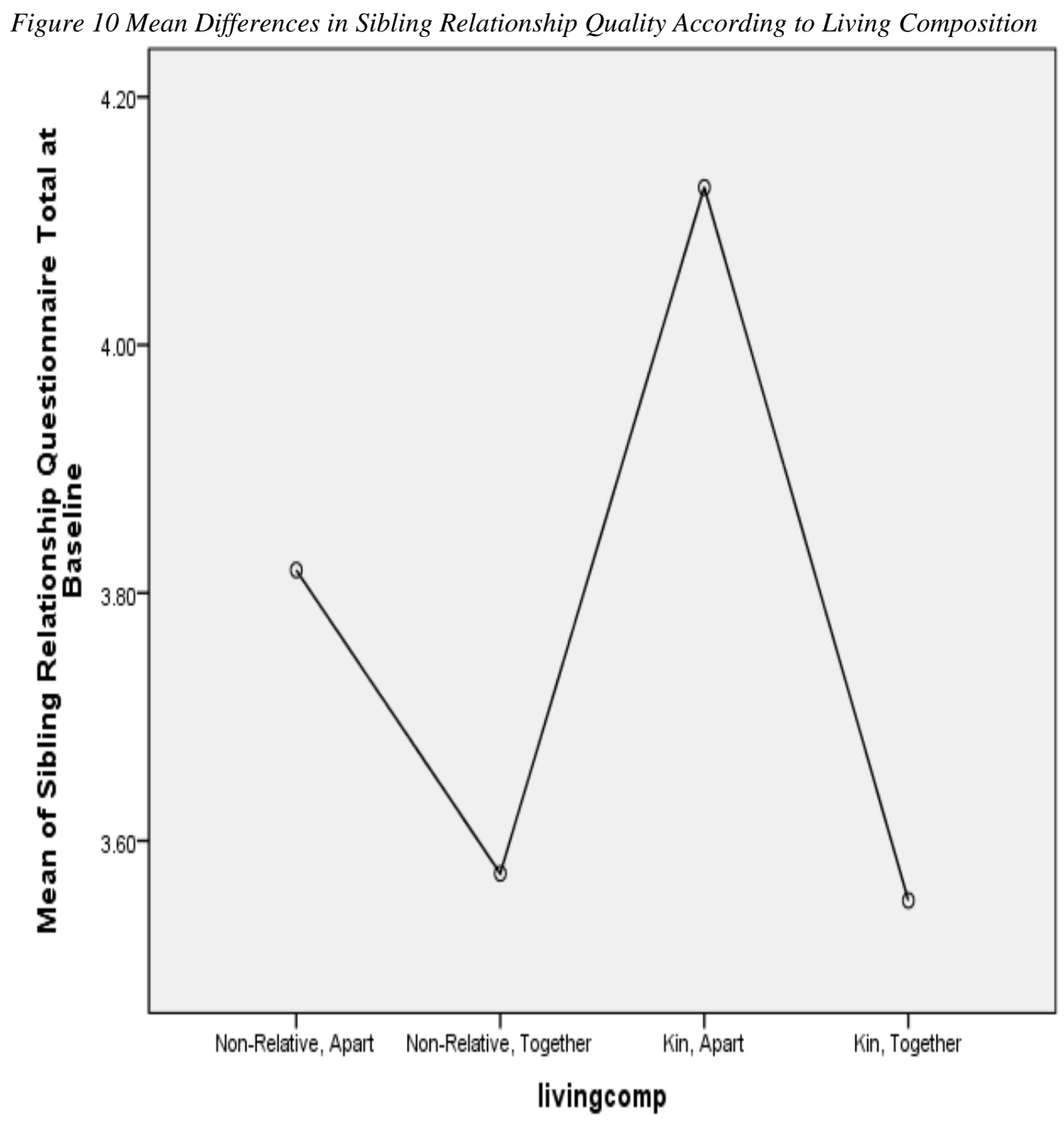


Figure 11. Mean Differences in Number of Placements Experienced Prior to Study Entry

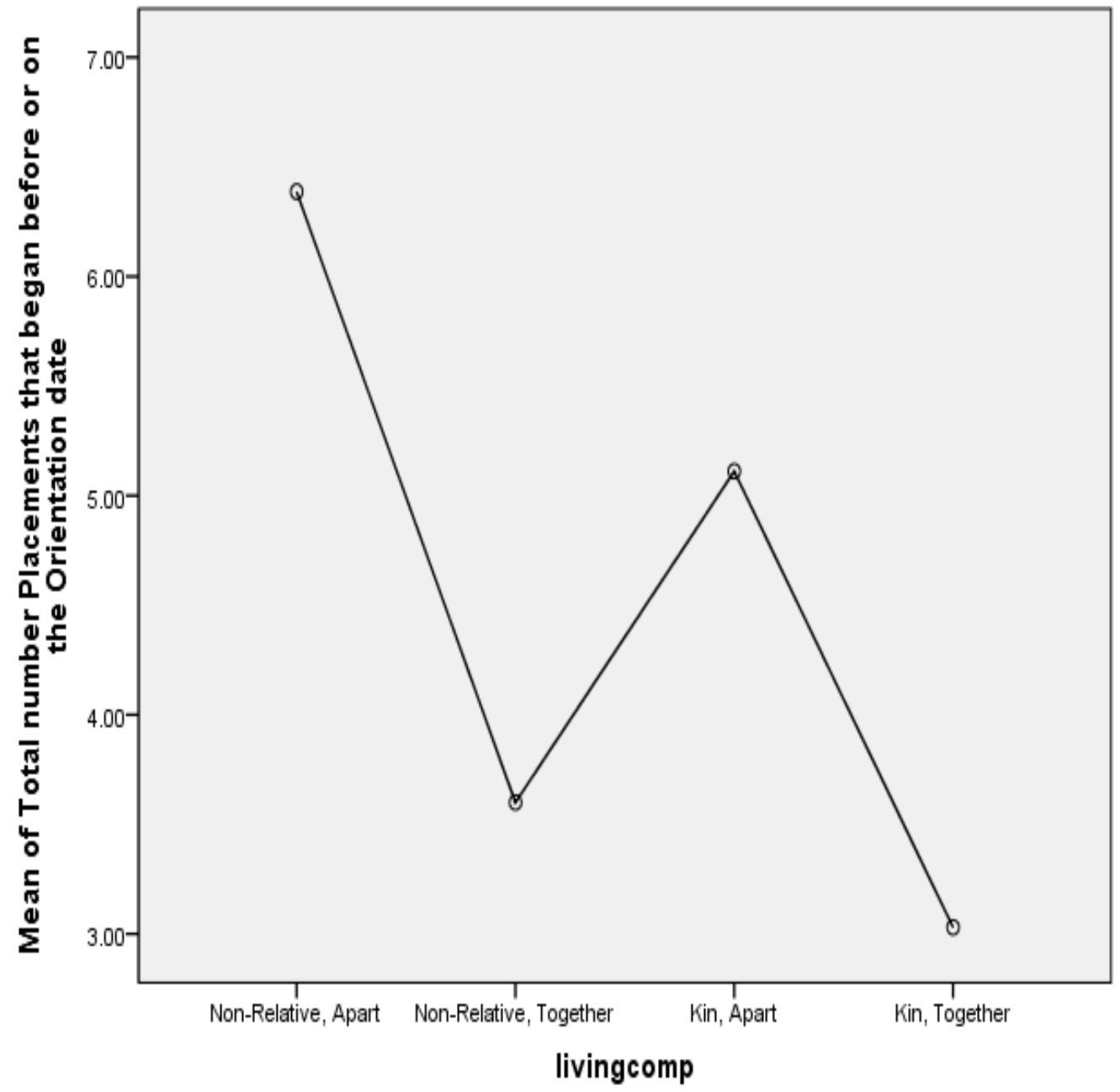


Figure 12. Mean Differences in Number of Placement Changes During the Course of Study Enrollment

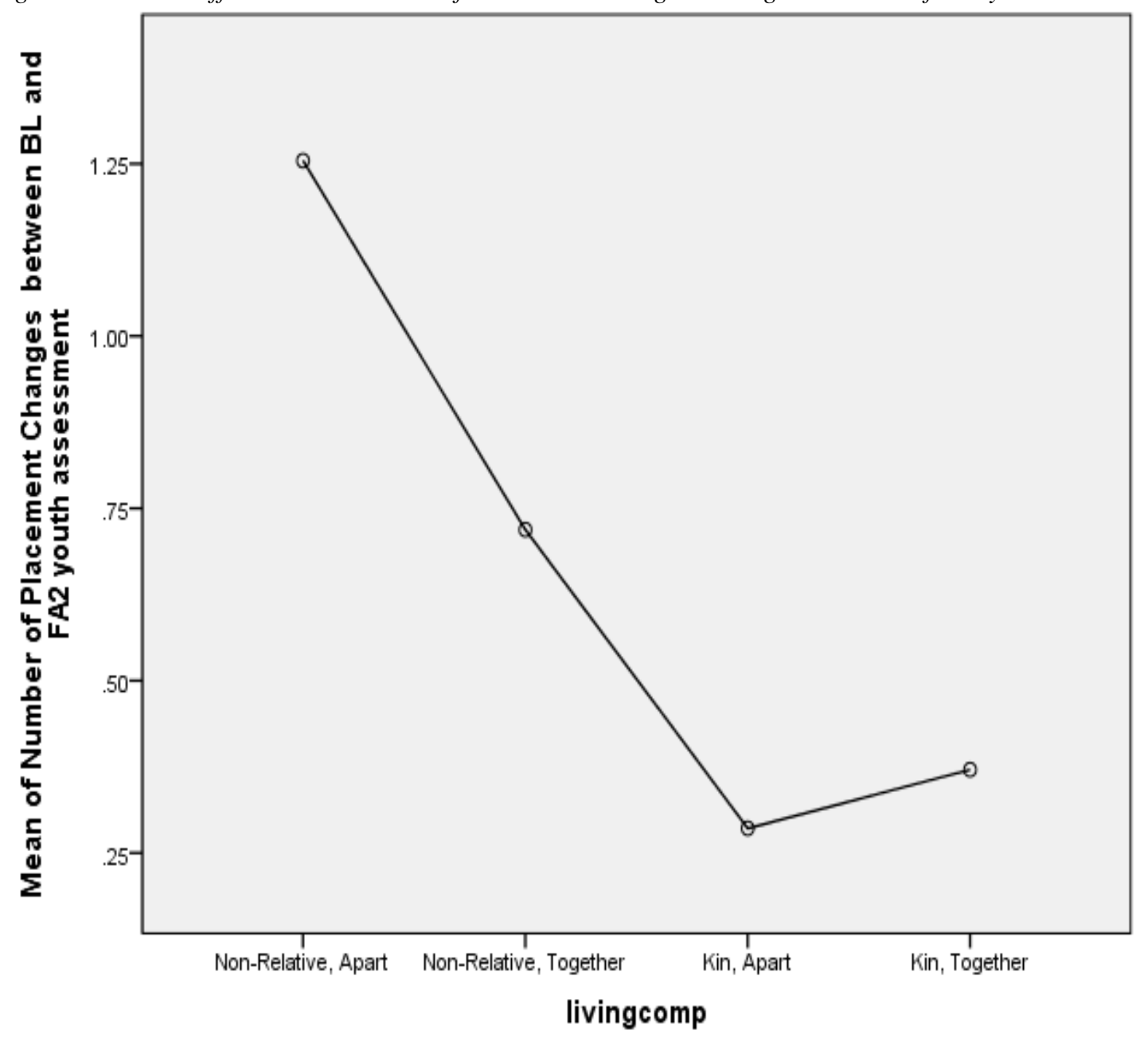


Figure 13. Mean Differences in Youth Age According to Living Composition

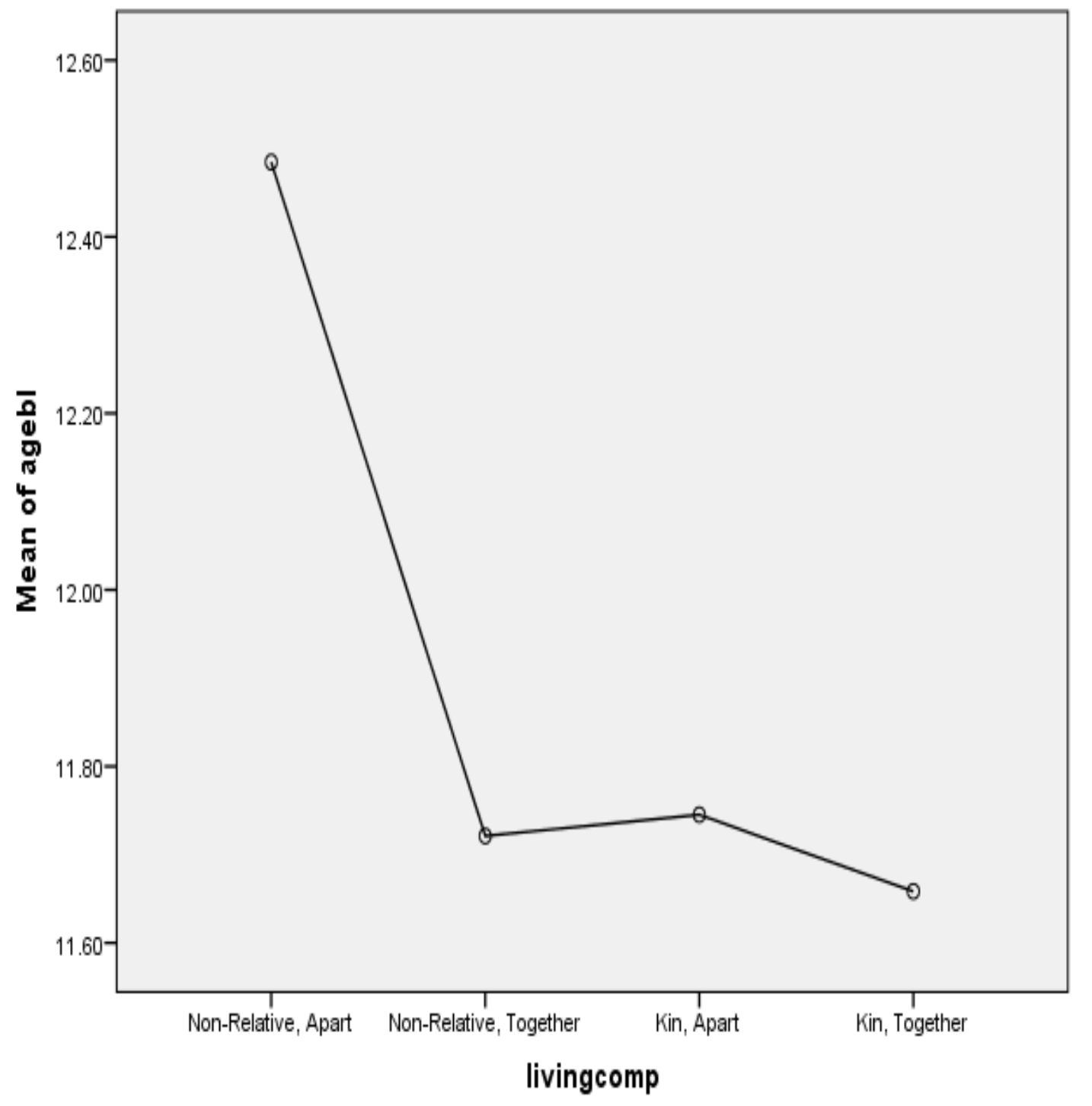


Figure 14. Causal Mechanisms within the conceptual model

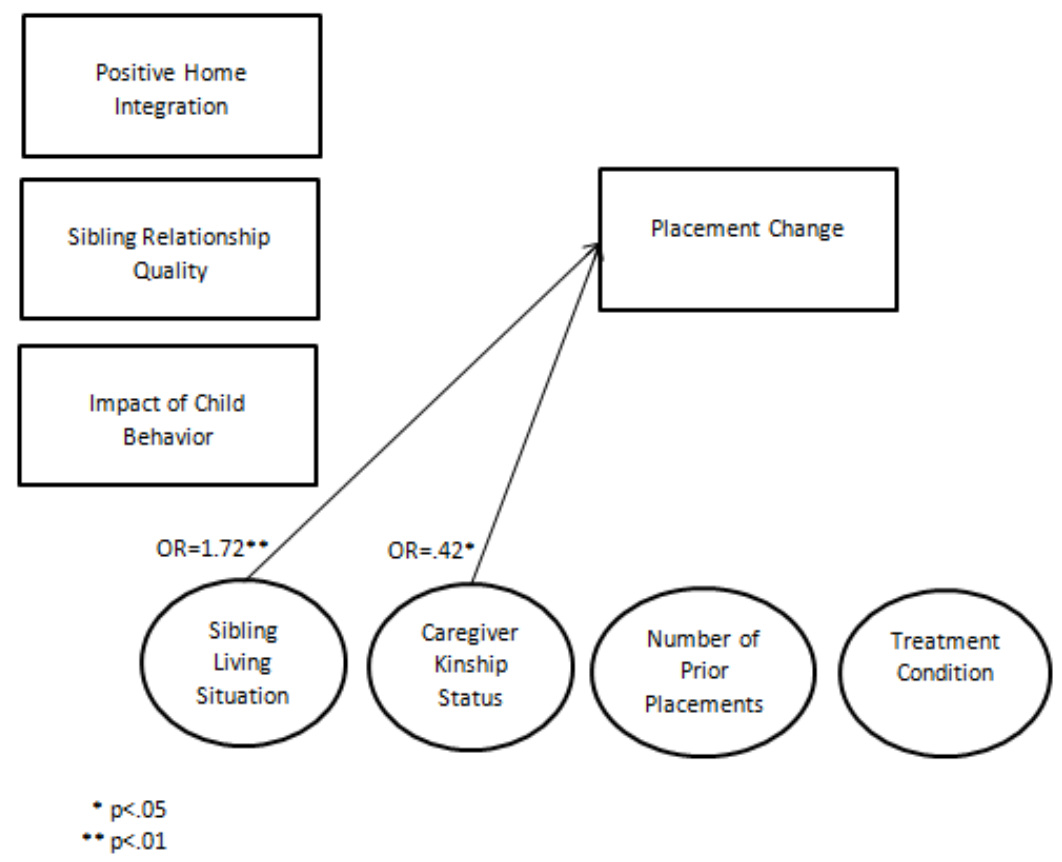

Figure 15. Causal Mechanisms within the moderation model

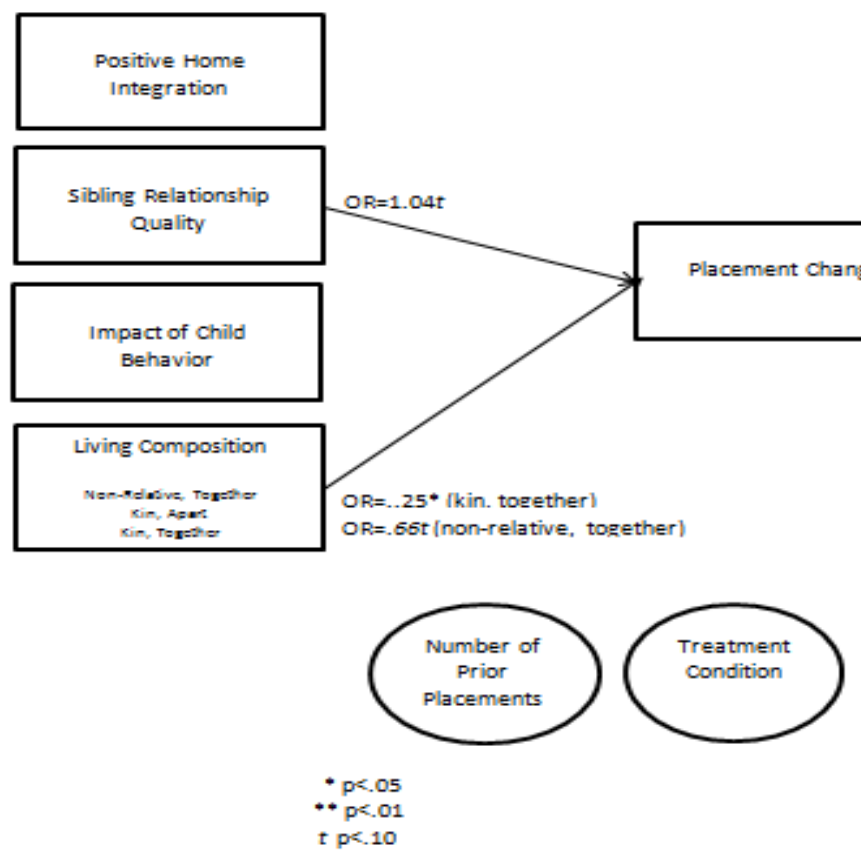




\section{References}

Adoption Assistance and Child Welfare Act of 1980 (P.L. 96-272)

Adoption and Safe Families Act of 1997 P.L. 105-89

Akin, B. A. (2011). Predictors of foster care exits to permanency: A competing risks analysis of reunification, guardianship, and adoption. Children and Youth Services Review, 33(6), 999-1011.

Albert, V. N., \& King, W. C. (2008). Survival analyses of the dynamics of sibling experiences in foster care. Families in Society, 89(4), 533-541.

Allen, B., \& Vacca, J. S. (2010). Frequent moving has a negative affect on the school achievement of foster children makes the case for reform. Children and Youth Services Review, 32(6), 829-832. doi:10.1016/j.childyouth.2010.02.001

Altshuler, S. J. (1998). Child well-being in kinship foster care: Similar to, or different from, non-related foster care? Children and Youth Services Review, 20(5), 369388. doi:10.1016/S0190-7409(98)00013-9

Bandura, A. (1977). Theoretical perspectives. In A. Bandura (Ed.), Social learning theory. Englewood Cliffs, NJ: Prentice-Hall, Inc.

Bank, L., Burraston, B., \& Snyder, J. (2004). Sibling Conflict and Ineffective Parenting as Predictors of Adolescent Boys' Antisocial Behavior and Peer Difficulties: Additive and Interactional Effects. Journal of Research on Adolescence, 14(1), 99-125.

Bank, L., Patterson, G.R., \& Reid, J.B. (1996). Negative sibling interaction patterns as predictors of later adjustment problems in adolescent and young adult males. In Brody, G.H. (Ed.), Sibling Relationships: their causes and consequences. Ablex, Norwood, NJ, pp. 197-229.

Barkan, S. E., Salazar, A. M., Estep, K., Mattos, L. M., Eichenlaub, C., \& Haggerty, K. P. (2014). Adapting an evidence-based parenting program for child welfare involved teens and their caregivers. Children and Youth Services Review, 41(0), 53-61. doi:10.1016/j.childyouth.2014.03.006

Barth, R. P., Lloyd, E. C., Green, R. L., James, S., Leslie, L. K., \& Landsverk, J. (2007). Predictors of placement moves among children with and without emotional and behavioral disorders. Journal of Emotional and Behavioral Disorders, 15(1), 4655. 
Bae, S., Famoye, F., Wulu, J. T., Bartolucci, A. A., \& Singh, K. P. (2005). A rich family of generalized Poisson regression models with applications. Second Special Issue: Selected Papers of the MSSANZ/IMACS 15th Biennial Conference on Modelling and Simulation MSSANZ/IMACS a5th Biennial Conference on Modelling and Simulation, 69(1-2), 4-11. doi:10.1016/j.matcom.2005.02.026

Beck, J.S. (1995) Cognitive therapy: Basics and beyond. The Guilford Press. London.

Bell, T., Romano, E., \& Flynn, R. J. (2013). Multilevel correlates of behavioral resilience among children in child welfare. Child Abuse \& Neglect, 37(11), 1007-1020. http://doi.org/10.1016/j.chiabu.2013.07.005

Ben-Arieh, A., \& Frones, I. (November 01, 2011). Taxonomy for Child Well-Being Indicators: A Framework for the Analysis of the Well-Being of Children. Childhood: a Global Journal of Child Research, 18, 4, 460-476.

Bruskas, D. (2008). Children in foster care: A vulnerable population at risk. Journal of Child and Adolescent Psychiatric Nursing, 21 (2), 70-77.

Bronfenbrenner, U. (1979). The ecology of human development: Experiments by nature and design. Harvard University Press, Cambridge, Massachusetts.

Bronfenbrenner, U. (1986). Ecology of the family as a context for development: Research perspectives. Developmental Psychology, 22, 723 - 742.

Brown, J. D., \& Bednar, L. M. (2006). Foster parent perceptions of placement breakdown. Children and Youth Services Review, 28(12), 1497-1511.

Brown, J. D., \& Campbell, M. (2007). Foster parent perceptions of placement success. Children and Youth Services Review, 29(8), 1010-1020.

Bruskas, D. (2008). Children in Foster Care: a Vulnerable Population at Risk. Journal of Child and Adolescent Psychiatric Nursing, 21(2), 70-77.

Buehler, C., Orme, J. G., Post, J., \& Patterson, D. A. (2000). The long-term correlates of family foster care. Children and Youth Services Review, 22(8), 595-625.

Chamberlain P. (2003). Treating chronic juvenile offenders: Advances made through the Oregon Multidimensional Treatment Foster Care model. Washington, DC: American Psychological Association.

Chamberlain, P., \& Bank, L. (1989). Toward an integration of macro and micro measurement systems for the researcher and the clinician. Journal of Family 
Psychology, 3(2), 199-205.

Chamberlain, P., Price, J. M., Reid, J. B., Landsverk, J., Fisher, P. A., \& Stoolmiller, M. (2006). Who disrupts from placement in foster and kinship care? Child Abuse \& Neglect, 30(4)-409-424.

Children's Bureau (n.d.). Concept and History of Permanency in U.S. Child Welfare. Retrieved June 9, 2014, from https://www.childwelfare.gov/permanency/overview/history.cfm

Cohen, J., Cohen, P., West, S.G., \& Aiken, L.S. (2003). Applied multiple regression/correlation analysis in the behavioral sciences (Third Edition). Mahwah, NJ: Erlbaum.

Cohen, J.A., Mannarino, A.P., \& Deblinger, E. (2006). Treating Trauma and Traumatic Grief in Children and Adolescents. The Guilford Press. London.

Conn, A.-M., Calais, C., Szilagyi, M., Baldwin, C., \& Jee, S. H. (n.d.). Youth in Out-ofHome Care: Relation of Engagement in Structured Group Activities with Social and Mental Health Measures. Children and Youth Services Review, (0). doi:10.1016/j.childyouth.2013.11.014

Crosswhite, J.M., \& Kerpelman, J.L. (2008). Coercion theory, self-control, and social information processing: Understanfing potential mediators for how parents influence deviant behaviors. Deviant Behavior, 30, 611-646.

Crum, W. (2010). Foster parent parenting characteristics that lead to increased placement stability or disruption. Children and Youth Services Review, 32(2), 185-190.

Cuddeback, G.S. (2004). Kinship family foster care: A methodological and substantive synthesis of research. Children and Youth Services Review, 26(7), 623-639.

DeGarmo, D. S., Chamberlain, P., Leve, L. D., \& Price, J. (2009). Foster parent intervention engagement moderating child behavior problems and placement disruption. Research on Social Work Practice, 19(4), 423-433.

Dorsey, S., Pullmann, M. D., Berliner, L., Koschmann, E., McKay, M., \& Deblinger, E. (2014). Engaging foster parents in treatment: A randomized trial of supplementing Trauma-focused Cognitive Behavioral Therapy with evidencebased engagement strategies. Child Abuse \& Neglect, (0). doi:10.1016/j.chiabu.2014.03.020

Dunn, J. (1983). Sibling relationships in early childhood. Child Development, 54, 787811. 
Dworsky, A., \& Courtney, M. E. (2010). The risk of teenage pregnancy among transitioning foster youth: Implications for extending state care beyond age 18 . Children and Youth Services Review, 32(10), 1351-1356. http://doi.org/10.1016/j.childyouth.2010.06.002

Eggertsein, L. (2008). Primary factors related to multiple placements for children in outof-home care. Child Welfare: Journal of Policy, Practice, and Program, 87(6), 71-90.

Fallesen, P. (2013). Time well spent: The duration of foster care and early adult labor market, educational, and health outcomes. Journal of Adolescence, 36(6), 10031011. doi:10.1016/j.adolescence.2013.08.010

Fanshel, D. (1982). On the road to permanency: An expanded database for service to children in foster care. New York: Child Welfare League of America \& Columbia University School of Social Work.

Feinberg, M. E., Sakuma, K.-L., Hostetler, M., \& McHale, S. M. (2013). Enhancing sibling relationships to prevent adolescent problem behaviors: Theory, design and feasibility of Siblings Are Special. Special Section: Rethinking Evaluation of Health Equity Initiatives, 36(1), 97-106. doi:10.1016/j.evalprogplan.2012.08.003

Felitti, V.J., Anda, R.F., Nordenberg, D., Williamson, D.F., Spitz, A.M., Edwards, V., Koss, M.P., \& Marks, J.S. (1998). Relationship of childhood abuse and household dysfuncton to many of the leading causes of death in adults. The adverse childhood experiences (ACE) study. American Journal of Preventive Medicine, 14 (4), 245-258.

Finkelhor, D., Turner, H., Ormrod, R., Hamby, S., \& Kracke, K. (2009). Children's exposure to violence: A comprehensive national survey. (NCJ227744). Juvenile Justice Bulletin. Retrieved August 12, 2012 from https://www.ncjrs.gov/pdffiles 1/ojjdp/227744.pdf

Fisher, P. A., Stoolmiller, M., Mannering, A. M., Takahashi, A., \& Chamberlain, P. (2011). Foster placement disruptions associated with problem behavior: Mitigating a threshold effect. Journal of Consulting and Clinical Psychology, 79(4), 481-487.

Fong, R., Schwab, J., \& Armour, M. (2006). Continuity of activities and child well-being for foster care youth. Children and Youth Services Review, 28(11), 1359-1374. doi:10.1016/j.childyouth.2006.02.005

Fostering Connections to Success and Increasing Adoptions Act of 2008 (P.L. 110-351) 
Furman, $W$., \& Buhrmester, D. (1985). Children's perceptions of the personal relationships in their social networks. Developmental Psychology , 21, 10161024.

Gamble, W.C., Jeong, J.Y., \& Keuhn, E.D. (2011). Adolescent sibling relationship quality and adjustment; Sibling trustworthiness and modeling, as factors directly and indirectly influencing these associations. Social Development, 20(3), 605-623.

Gass, K., Jenkins, J., \& Dunn, J. (2007). Are sibling relationships protective? A longitudinal study. Journal of Child Psychology and Psychiatry, 48(2), 167-175.

Heck, R.H., \& Thomas, S.L. (2009). An introduction to multilevel modeling techniques ( $2^{\text {nd }}$ Edition). Routelege, NY.

Hegar, R. L. (2005). Sibling placement in foster care and adoption: An overview of international research. Special Issue: Siblings in Foster Care and Adoption. Children and Youth Services Review, 27(7), 717-739.

Hegar, R. L., \& Rosenthal, J. A. (2009). Kinship care and sibling placement: Child behavior, family relationships, and school outcomes. Children and Youth Services Review, 31(6), 670-679.

Hegar, R. L., \& Rosenthal, J. A. (2011). Foster children placed with or separated from siblings: Outcomes based on a national sample. Children and Youth Services Review, 33(7), 1245-1253.

Herrick, M. A., \& Piccus, W. (2005). Sibling connections: The importance of nurturing sibling bonds in the foster care system. Special Issue: Siblings in Foster Care and Adoption. Children and Youth Services Review, 27(7), 845-861.

Holtan, A., Handegard, B.H., Thornblad, R., \& Vis, S.A. (2013). Placement disruption in long term kinship and nonkinship foster care. Children and Youth Services Review, 35(7), 1087-1094.

Isquith, P., Maerlender, A., Racusin, R., Sengupta, A., \& Straus, M. (2005). Psychosocial treatment of children in foster care: A review. Community Mental Health Journal 41(2), 199-221.

James, S., Landsverk, J., \& Slymen, D. J. (2004). Placement movement in out-of-home care: Patterns and predictors. Children and Youth Services Review, 26(2), 185206.

James, S., Monn, A. R., Palinkas, L. A., \& Leslie, L. K. (2008). Maintaining sibling 
relationships for children in foster and adoptive placements. Children and Youth Services Review, 30(1), 90-106.

Kazdin, A.E. (1997). Parent management training: evidence, outcomes, and issues. Journal of the American Academy of Child \& Adolescent Psychiatry, 36(10), 1349-1356. doi:10.1097/00004583-199710000-00016

Kazdin, A.E.., Esveldt-Dawson, K., French, N. H., \& Unis, A. S. (1987). Effects of parent management training and problem-solving skills training combined in the treatment of antisocial child behavior. Journal of the American Academy of Child \& Adolescent Psychiatry, 26(3), 416-424. doi:10.1097/00004583-198705000-00024

Kim, J., McHale, S.M., Crouter, A.C., \& Osgood, D.W. (2007). Longitudinal linkages between sibling relationships and adjustment from middle childhood through adolescence. Developmental Psychology, 43(4), 960-973.

Kjøbli, J., Hukkelberg, S., \& Ogden, T. (2013). A randomized trial of group parent training: Reducing child conduct problems in real-world settings. Behaviour Research and Therapy, 51(3), 113-121. doi:10.1016/j.brat.2012.11.006

Kling, Å., Forster, M., Sundell, K., \& Melin, L. (2010). A Randomized Controlled Effectiveness Trial of Parent Management Training With Varying Degrees of Therapist Support. Behavior Therapy, 41(4), 530-542. doi:10.1016/j.beth.2010.02.004

Koh, E. (2010). Permanency outcomes of children in kinship and non-kinship foster care: Testing the external validity of kinship effects. Children and Youth Services Review, 32(3), 389-398.

Kolko, D. J., Iselin, A.-M. R., \& Gully, K. J. (2011). Evaluation of the sustainability and clinical outcome of Alternatives for Families: A Cognitive-Behavioral Therapy (AF-CBT) in a child protection center. Child Abuse \& Neglect, 35(2), 105-116. doi:10.1016/j.chiabu.2010.09.004

Kothari, B., McBeath, B., Sorenson, P., Waid, J., \& Bank, L. (Under Review). Test of an intervention for improving sibling relationship quality among youth in foster care. Prevention Science.

Kothari, B., McBeath, B., Lamson-Siu, E., Webb, S.J., Sorenson, P., Bowen, H., Waid, J., Bank, L. (2014). Development and feasibility of a sibling intervention for youth in foster care. Evaluation and Program Planning, 47, 91-99.

Kuncel, N. R., Ones, D. S., \& Sackett, P. R. (2010). Individual differences as predictors 
of work, educational, and broad life outcomes. Collected Works from the Festschrift for Tom Bouchard, June 2009: A Tribute to a Vibrant Scientific Career, 49(4), 331-336. doi:10.1016/j.paid.2010.03.042

Lawrence, C.R., Carlson, E.A., \& Egeland, B. (2006). The impact of foster care on development. Development and Psychopathology, 18, 57-76.

Leathers, S.J. (2002). Foster children's behavioral disturbance and detachment from caregivers and community institutions. Children and Youth Services Review, 24(4) 239-268.

Leathers, S. J. (2005). Separation from siblings: Associations with placement adaptation and outcomes among adolescents in long-term foster care. Special Issue: Siblings in Foster Care and Adoption. Children and Youth Services Review, 27(7), 793819.

Leathers, S.J. (2012). Behavior problems, foster home integration, and evidence based behavioral interventions: What predicts adoption of foster children? Children and Youth Services Review, 34(5) 891-899.

Lee, P., Niew, W., Yang, H., Chen, V. C., \& Lin, K. (2012). A meta-analysis of behavioral parent training for children with attention deficit hyperactivity disorder. Research in Developmental Disabilities, 33(6), 2040-2049. doi:10.1016/j.ridd.2012.05.011

Lery, B., Shaw, T. V., \& Magruder, J. (2005). Using administrative child welfare data to identify sibling groups. Special Issue: Siblings in Foster Care and Adoption. Children and Youth Services Review, 27(7), 783-791.

Linares, L. O., Li, M., Shrout, P. E., Brody, G. H., \& Pettit, G. S. (2007). Placement shift, sibling relationship quality, and child outcomes in foster care: A controlled study. Journal of Family Psychology, 21(4), 736-743.

Lundstrom, T., \& Sallnas, M. (2012). Sibling contact among Swedish children in foster and residential care-Out of home care in a family service system. Children and Youth Services Review, 34(2), 396-402.

Maruyama, G.M. (1998). Basics of structural equation modeling. Thousand Oaks, CA: Sage.

McBeath, B., Kothari, B. H., Blakeslee, J., Lamson-Siu, E., Bank, L., Linares, L. O., ... Shlonsky, A. (2014). Intervening to improve outcomes for siblings in foster care: Conceptual, substantive, and methodological dimensions of a prevention science framework. Children and Youth Services Review, 39(0), 1-10. 
http://doi.org/10.1016/j.childyouth.2013.12.004

McHale, S. M., Kim, J., \& Whiteman, S. D. (2006).Sibling relationships in childhood and adolescence. In P. Noller \& J. A. Feeney (Eds.), Close relationships:

Functions, forms and processes (pp. 127 - 150). New York: Psychology Press.

McCue Horwitz, S., Hurlburt, M. S., Heneghan, A., Zhang, J., Rolls-Reutz, J., Fisher, E., ... Stein, R. E. K. (2012). Mental Health Problems in Young Children Investigated by U.S. Child Welfare Agencies. Journal of the American Academy of Child \& Adolescent Psychiatry, 51(6), 572-581. doi:10.1016/j.jaac.2012.03.006

Matta Oshima, K. M., Narendorf, S. C., \& McMillen, J. C. (2013). Pregnancy risk among older youth transitioning out of foster care. Children and Youth Services Review, 35(10), 1760-1765. doi:10.1016/j.childyouth.2013.08.001

Mersky, J. P., \& Janczewski, C. (2013). Adult well-being of foster care alumni:

Comparisons to other child welfare recipients and a non-child welfare sample in a high-risk, urban setting. Children and Youth Services Review, 35(3), 367-376. doi:10.1016/j.childyouth.2012.11.016

Mulvey, E. P., Arthur, M. W., \& Reppucci, N. D. (1993). The prevention and treatment of juvenile delinquency: A review of the research. Clinical Psychology Review, 13(2), 133-167. doi:10.1016/0272-7358(93)90038-N

Newton, R. R., Litrownik, A. J., \& Landsverk, J. A. (2000). Children and youth in foster care: Disentangling the relationship between problem behaviors and number of placements. Child Abuse \& Neglect, 24(10), 1363-1374.

Oosterman, M., Schuengel, C., Slot, N. W., Bullens, R. A. R., \& Doreleijers, T. A. H. (2007). Disruptions in foster care: A review and meta-analysis. Children and Youth Services Review, 29(1), 53-76.

Pecora, P. J. (2012). Maximizing educational achievement of youth in foster care and alumni: Factors associated with success. Educational Interventions, Practices, and Policies to Improve Educational Outcomes Among Children and Youth in Out-of-Home Care, 34(6), 1121-1129. doi:10.1016/j.childyouth.2012.01.044

Pecora, P. J., Kessler, R. C., O’Brien, K., White, C. R., Williams, J., Hiripi, E., ... Herrick, M. A. (2006). Educational and employment outcomes of adults formerly placed in foster care: Results from the Northwest Foster Care Alumni Study. Children and Youth Services Review, 28(12), 1459-1481. doi:10.1016/j.childyouth.2006.04.003 
Postlethwait, A. W., Barth, R. P., \& Guo, S. (2010). Gender variation in delinquent behavior changes of child welfare-involved youth. Children and Youth Services Review, 32(3), 318-324. doi:10.1016/j.childyouth.2009.09.012

Poulin, J.E (1985). Long term foster care, natural family attachment, and loyalty conflict. Journal of Social Service Research, 9(1), 17-29.

Price, J. M., Chamberlain, P., Landsverk, J., Reid, J. B., Leve, L. D., \& Laurent, H. (2008). Effects of a foster parent training intervention on placement changes of children in foster care. Journal of Developmental and Behavioral Pediatrics, 29(4), 328.

Ryan, J. P., Marshall, J. M., Herz, D., \& Hernandez, P. M. (2008). Juvenile delinquency in child welfare: Investigating group home effects. Children and Youth Services Review, 30(9), 1088-1099. doi:10.1016/j.childyouth.2008.02.004

Ryan, J. P., \& Testa, M. F. (2005). Child maltreatment and juvenile delinquency: Investigating the role of placement and placement instability. Children and Youth Services Review, 27(3), 227-249. doi:10.1016/j.childyouth.2004.05.007

Rubin, D.M. (2008). Impact of kinship care on behavioral well-being for children in outof-home care. Archives of Pediatric Medicine, 162 (6), 550-556.

Sackett, D. L. (1997). Evidence-based medicine. Fatal and Neonatal Hematology for the 21st Century, 21(1), 3-5. doi:10.1016/S0146-0005(97)80013-4

Samuels, B. (Director) (2011, June 21). A frame for child welfare's future: Promoting social and emotional well-being to facilitate healing and recovery. SLO/CGA Grantees Meeting. Lecture conducted from Administration for Children and Families, Retrieved from http://nrccps.org/wp-content/uploads/Bryan-SammuelspresentationSLO-CJA-62011.pdf

Sander, J. B., Patall, E. A., Amoscato, L. A., Fisher, A. L., \& Funk, C. (2012). A metaanalysis of the effect of juvenile delinquency interventions on academic outcomes. Children and Youth Services Review, 34(9), 1695-1708. doi:10.1016/j.childyouth.2012.04.005

Semanchin Jones, A., \& LaLiberte, T. (2013). Measuring youth connections: A component of relational permanence for foster youth. Children and Youth Services Review, 35(3), 509-517. http://doi.org/10.1016/j.childyouth.2012.12.006

Seneca Center. (n.d.). Definition of Permanency|Seneca Center. Retrieved June 9, 2014, from http://www.senecacenter.org/perm_permanency_def 
Shlonsky, A. \& Berrick, J. (2001). Assessing and promoting quality in kin and nonkin foster care. Social Services Review, 60-83

Shlonsky, A., Bellamy, J., Elkins, J., \& Ashare, C. J. (2005). The other kin: Setting the course for research, policy, and practice with siblings in foster care. Special Issue: Siblings in Foster Care and Adoption. Children and Youth Services Review, 27(7), 697-716.

Shlonsky, A., Webster, D., \& Needell, B. (2003). The ties that bind: A cross-sectional analysis of siblings in foster care. Journal of Social Service Research, 29(3), 2752.

Smith, D. K., Stormshak, E., Chamberlain, P., \& Bridges Whaley, R. (2001). Placement disruption in treatment foster care. Journal of Emotional and Behavioral Disorders, 9(3), 200-205.

Snijders, T.A.B., \& Bosker, R.J. (2012). Multilevel analysis: An introduction to basic and advanced multilevel modeling (2nd Edition). London: Sage.

Staff, I \& Fein, E. (1992). Together or Separate: A study of Siblings in Foster Care. Child Welfare, 71, 257-70.

Semanchin Jones, A., \& LaLiberte, T. (2013). Measuring youth connections: A component of relational permanence for foster youth. Children and Youth Services Review, 35(3), 509-517. doi:10.1016/j.childyouth.2012.12.006

Stevenson Wojciak, A., McWey, L.M., \& Helfrich, C.M. (2013). Sibling relationships and internalizing symptoms of youth in foster care. Children and Youth Services Review, 35(7), 1071-1077.

Stewart, C. J., Kum, H.-C., Barth, R. P., \& Duncan, D. F. (2014). Former Foster Youth: Employment Outcomes up to Age 30. Children and Youth Services Review, 36, 223-229. doi:10.1016/j.childyouth.2013.11.024

Sullivan, D. J., \& van Zyl, M. A. (2008). The well-being of children in foster care: Exploring physical and mental health needs. Children and Youth Services Review, 30(7), 774-786. doi:10.1016/j.childyouth.2007.12.005

Tabachnick, B.G. \& Fidell, L.S. (2007). Using multivariate statistics. Boston, MA: Pearson Publishing.

Tolan, P. H., \& Guerra, N. G. (1994). Prevention of delinquency: Current status and issues. Applied and Preventive Psychology, 3(4), 251-273. doi:10.1016/S0962- 
1849(05)80098-8

Tarren-Sweeney, M., \& Hazell, P. (2005). The mental health and socialization of siblings in care. Special Issue: Siblings in Foster Care and Adoption. Children and Youth Services Review, 27(7), 821-843.

U.S. Department of Health and Human Services, Administration for Children and Families, Children's Bureau (2013a). About AFCARS Retrieved from http://www.acf.hhs.gov/programs/cb/resource/about-afcars

U.S. Department of Health and Human Services, Administration for Children and Families, Children's Bureau (2013a1). The AFCARS report. Retrieved from http://www.acf.hhs.gov/sites/default/files/cb/afcarsreport19.pdf

U.S. Department of Health and Human Services, Administration for Children and Families, Administration on Children, Youth and Families, Children's Bureau. (2013). Child maltreatment 2012.Available from http://www.acf.hhs.gov/programs/cb/research-data-technology/statisticsresearch/child-maltreatment.

U.S. Department of Health and Human Services, Administration for Children and Families, Children's Bureau (2013b). National Survey of Child and Adolescent Well-Being. Retrieved from http://www.acf.hhs.gov/programs/opre/research/project/national-survey-of-childand-adolescent-well-being-nscaw-1

U.S. Department of Health and Human Services, Administration for Children and Families, Children's Bureau (2012). Oregon context data. Retrieved from http://cwoutcomes.acf.hhs.gov/data/downloads/pdfs/oregon.pdf

U.S. Department of Health and Human Services, Administration for Children and Families, Children's Bureau (2013d). Technical bulletin \#1:

Data Elements REVISED: February 2012. Retrieved from http://www.acf.hhs.gov/sites/default/files/cb/afcars_tb1.pdf

U.S. Department of Health and Human Services, Administration for Children and Families, Children's Bureau (2013e). About the measures. Retrieved from http://www.acf.hhs.gov/sites/default/files/opre/nscaw_measures.pdf

U.S. Department of Health and Human Services, Administration for Children and Families, Children's Bureau (2013f). Child, family, and caseworker constructs, their rationale and source in NSCAW data collection. Retrieved from http://www.acf.hhs.gov/sites/default/files/opre/nscaw_data_collection.pdf 
U.S. Department of Health and Human Services, Administration for Children and Families, Children's Bureau (2013g). Child welfare outcomes 2008-2011: Report to Congress. Retrieved from https://www.acf.hhs.gov/sites/default/files/cb/cwo08_11.pdf\#page=25

U.S. Department of Health and Human Services, Administration for Children and Families, Children's Bureau (2015). Child welfare policy manual. Retrieved from http://www.acf.hhs.gov/cwpm/programs/cb/laws_policies/laws/cwpm/policy_dsp. jsp?citID $=122$

U.S. Department of Health and Human Services, Administration for Children and Families, Children's Bureau (2013h). NSCAW II Wave 2 Report: Child Permanency. Retrieved from http://www.acf.hhs.gov/sites/default/files/opre/nscaw_wave_ii_permanency_repo rt_2012_clean.pdf

Van Horn, M. L., Fagan, A. A., Hawkins, J. D., \& Oesterle, S. (2014). Effects of the Communities That Care System on Cross-Sectional Profiles of Adolescent Substance Use and Delinquency. American Journal of Preventive Medicine, 47(2), 188-197. doi:10.1016/j.amepre.2014.04.004

Waid, J. (2014) Sibling foster care, placement stability, and well-being: A theoretical and conceptual framework. Journal of Family Social Work, 17, 283-297.

Washington, K. (2007). Research review: Sibling placement in foster care: A review of the evidence. Child and Family Social Work, 12(4), 426-433.

Whiteman, S. D., McHale, S. M., \& Soli, A. (2011). Theoretical perspectives on sibling relationships. Journal of Family Theory \& Review, 3(2), 124-139.

Winokur, M., Holtan, A., \& Batchelder, K.E. (2009). Kinship care for the safety, permanency, and well-being of children removed from the home for maltreatment. Cochrane Database of Systematic Reviews, 21(3).

Wulczyn, F., \& Zimmerman, E. (2005). Sibling placements in longitudinal perspective. Special Issue: Siblings in Foster Care and Adoption. Children and Youth Services Review, 27(7), 741-763.

Zill, N., \& Bramlett, M. D. (2014). Health and well-being of children adopted from foster care. Children and Youth Services Review, 40(0), 29-40. doi:10.1016/j.childyouth.2014.02.008

Zorc, C. S., O'Reilly, A. L. R., Matone, M., Long, J., Watts, C. L., \& Rubin, D. (2013). The relationship of placement experience to school absenteeism and changing 
schools in young, school-aged children in foster care. Children and Youth Services Review, 35(5), 826-833. doi:10.1016/j.childyouth.2013.02.006

Zorn, C. (2006). Comparing GEE and Robust Standard Errors for Conditionally Dependent Data. Political Research Quarterly, 59(3), 329-341. http://doi.org/10.1177/106591290605900301 